\title{
WestVirginiaUniversity
}

THE RESEARCH REPOSITORY @ WVU

Graduate Theses, Dissertations, and Problem Reports

2004

\section{What is the impact of parental support on early literacy?}

Deborah K. Bush

West Virginia University

Follow this and additional works at: https://researchrepository.wvu.edu/etd

\section{Recommended Citation}

Bush, Deborah K., "What is the impact of parental support on early literacy?" (2004). Graduate Theses, Dissertations, and Problem Reports. 2624.

https://researchrepository.wvu.edu/etd/2624

This Dissertation is protected by copyright and/or related rights. It has been brought to you by the The Research Repository @ WVU with permission from the rights-holder(s). You are free to use this Dissertation in any way that is permitted by the copyright and related rights legislation that applies to your use. For other uses you must obtain permission from the rights-holder(s) directly, unless additional rights are indicated by a Creative Commons license in the record and/ or on the work itself. This Dissertation has been accepted for inclusion in WVU Graduate Theses, Dissertations, and Problem Reports collection by an authorized administrator of The Research Repository @ WVU.

For more information, please contact researchrepository@mail.wvu.edu. 
What is the Impact of Parental Support on Early Literacy?

Deborah K. Bush

\begin{abstract}
Dissertation submitted to the College of Human Resources and Education at West Virginia University in partial fulfillment of the requirements for the degree of
\end{abstract}

\author{
Doctor of Education \\ in \\ Curriculum and Instruction \\ Joy Faini Saab, Ed.D., Chair \\ Patricia Obenauf, Ed.D. \\ Lynn Rupp, Ed.D. \\ James A. Rye, Ph.D. \\ Jaci Webb-Dempsey, Ph.D. \\ Department of Curriculum and Instruction
}

Morgantown, West Virginia

2004

Keywords: Literacy, Emergent literacy, Preschool, Scaffolding, Parental involvement Copyright 2004 Deborah K. Bush 


\author{
ABSTRACT \\ What is the Impact of Parental Support on \\ Emergent Literacy in Preschoolers? \\ Deborah K. Bush \\ Joy Faini Saab, adviser
}

Today, more than 75 percent of women ages 25-34 and 75 percent of women with a child under six years of age participate in the labor force. When both parents work outside the home, they often want to send their child to preschool, but preschool classes aren't always available, and often those that are available are the government programs that are open only to those of lower socio-economic status.

In addition, parents often want to support the emergent literacy of their children and help prepare them for kindergarten but aren't sure of how to provide the type of assistance that might maximize their efforts. In order to meet this need, a ten-week parent involvement program was implemented with two preschool classes. Students attended the evening sessions with their parents and participated in dialogic reading, journaling, and literacy activities. Take-home packets were provided with activities focused on skill development in the areas of concepts of print and words, letter identification, and sound classification. Parents were asked to spend ten minutes daily for five days working with their children on these packet activities and also to keep records of progress.

Data was gathered using pre and post tests, interviews, observations, journal analysis, and parental records from the weekly packets. Results were examined qualitatively with these four research questions in mind:

1. How will participating preschoolers' concepts of print and words change during the course of the family support literacy program?

2. How will the participating preschoolers' ability to identify sound-letter relationships change during the course of the family support literacy program?

3. How will participating preschoolers' acquisition of letter names change during the course of the family support literacy program?

4. In what ways do family literacy training sessions impact the ability of parents to support their preschooler's emergent literacy skills?

Findings showed that the preschoolers' skills did improve in the areas of concepts of print and words, letter identification, and sound classification; the parents felt more confident in their ability to work with their children on literacy skills and were eager to continue using the packets after the program ended. 


\section{Acknowledgements}

I wish to express sincere appreciation to everyone who has contributed in any way to the production of this document. Dr. Joy Saab, my committee chairman and adviser, has been an excellent mentor, and her expertise in the field of Early Childhood Education has been an invaluable asset to me. Without the tireless guidance, time, and expertise of committee members, Dr. Pat Obenauf, Dr. Jim Rye, Dr. Lynn Rupp, and Dr. Jaci Webb-Dempsey, this document would have never come to fruition. An extra measure of gratitude goes to my colleague, Dr. Lynn Rupp, who supported me through the process and accompanied me to Morgantown when the committee met. Special recognition goes to Dr. Karen Petitto who counseled this technologically-handicapped grandmother through her bumbling attempts to launch this document electronically. The encouragement of colleagues and students at West Virginia Wesleyan College sustained me through the times when I doubted that completing this degree was a possibility, and the enthusiasm with which they greeted my success was both overwhelming and humbling.

Setting goals and achieving the goals you've set can be very rewarding. Some goals are life goals that must be put on the back burner until a more convenient time. This document is the culmination of my efforts to reach a life goal. It represents the support of a husband of 34 years and the encouragement of my family and friends. I dedicate it to all those who don't give up in their quest for reaching goals and to those who support and encourage others along their journey. 
Table of Contents

Table of Contents ................................................................................................. iv

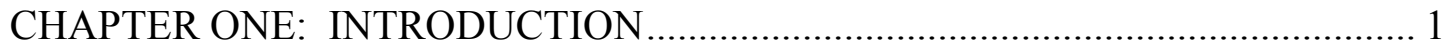

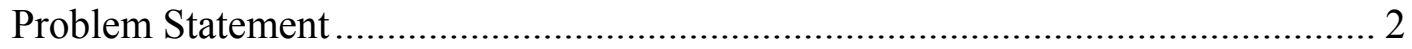

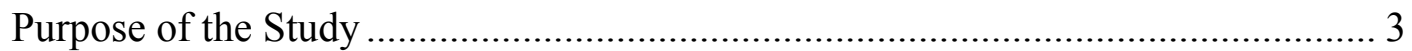

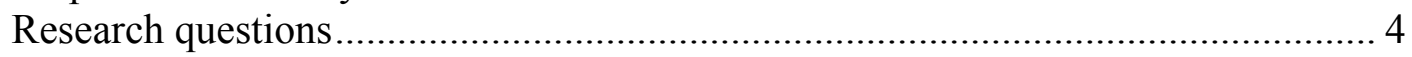

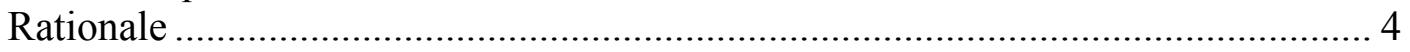

The Focus of the Preschool Curriculum .............................................................. 12

The Role of Parents........................................................................................ 19

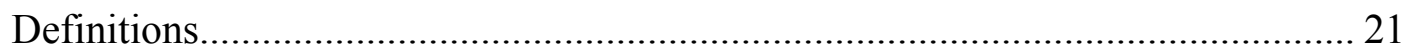

CHAPTER TWO: REVIEW OF LITERATURE ................................................ 22

Models for Learning in Preschools ............................................................... 24

A Theoretical Model for Preschools .................................................................... 35

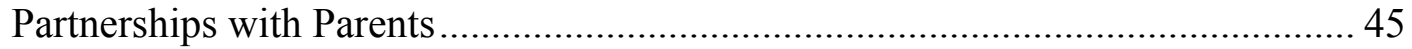

Research Summary ............................................................................................. 54

CHAPTER THREE: RESEARCH DESIGN AND METHOD .................................. 57

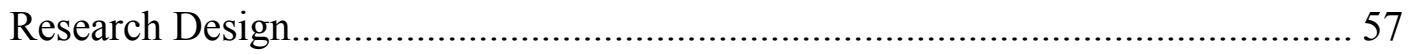

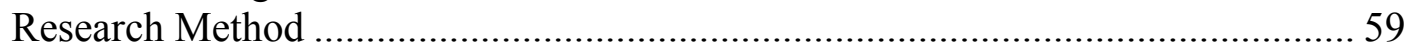

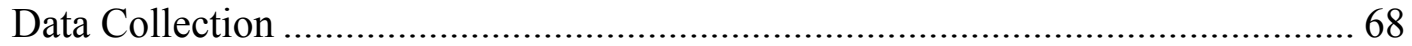

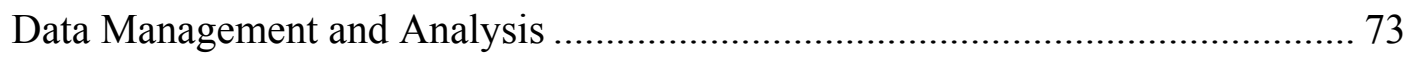

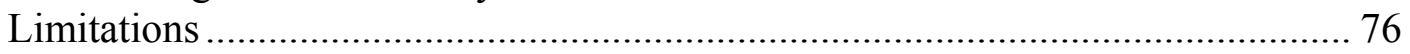

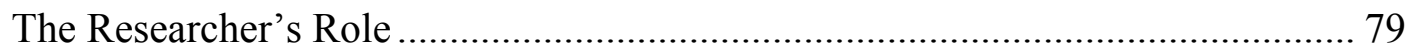

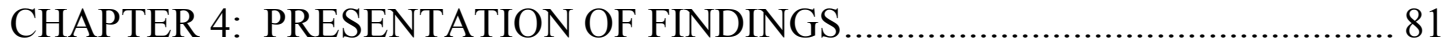

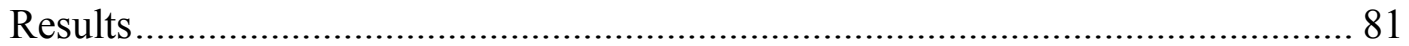

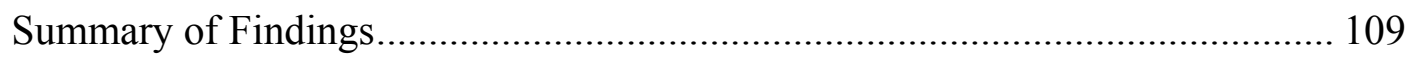

CHAPTER 5: CONCLUSIONS, IMPLICATIONS AND RECOMMENDATIONS

Recommendations for Research …......................................................... 119

Implications for Practice ......................................................................... 121

Recommendations for Research ................................................................... 124

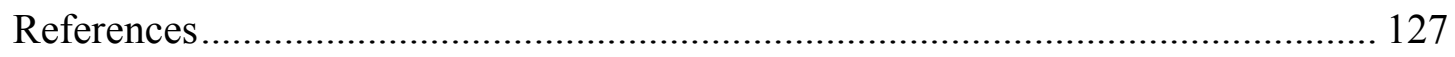

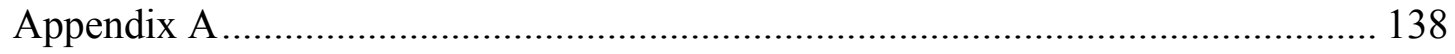

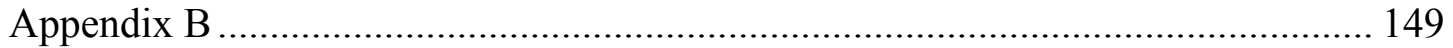

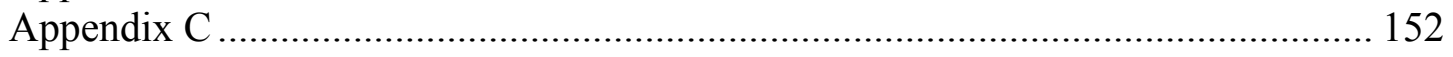

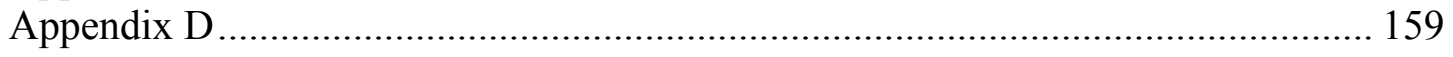

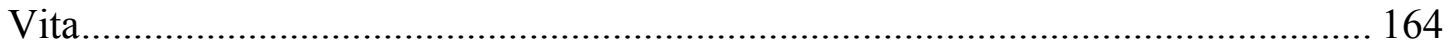

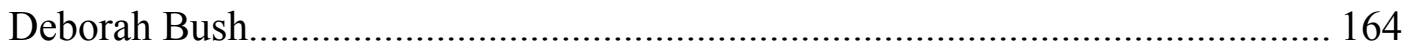




\section{CHAPTER ONE: INTRODUCTION}

A look of concern was on his face. The handsome thirty-something man shook his head in disbelief as he explained his predicament to me.

Karen [his wife] and I spent several days visiting the kindergarten programs available to Ashley [his five-year-old daughter]. When we finally found the one whose program we thought best fit our needs and expectations, Ashley was put on a waiting list. The teacher assured us that circumstances often allowed them to include some of the students from the waiting list when school actually started. All summer, we expected to get word that Ashley had been accepted, knowing that if she didn't get in, we would have to enroll her in the public kindergarten in our district. One week before the beginning of school, we received the call we'd been waiting for. They actually had room for Ashley! Then came the bad news. One of the requirements for entry to their program was that the children must be able to recognize all the letters of the alphabet. We had one week to teach Ashley 26 letters! If we'd known, we could have been working on this daily at home, but we were reluctant to push academics because we'd been cautioned that it would cause Ashley to "burn out" before actually getting to school. Now, don't get me wrong, we read daily with Ashley; in fact, we probably pick up more children's books off the living-room floor than the public library has on its shelf. Our refrigerator is covered with magnetic letters; we do alphabet books and alphabet puzzles, we even sing that letter song with Ashley, but we've never formally tried to teach her 
to recognize each letter. She can write her name and can identify most of the letters in it, but that's as far as it goes.

Karen and I thought we were doing the right thing. Since we both work, my mom has taken care of Ashley until now. We wanted to put her in some kind of preschool program, but nothing affordable is available in our community except Head Start. We don't qualify for that. Ashley has been involved with Sunday School, Bible School, and all the programs our church offers for young children, and she enjoys being with other children her age. It's just this letter thing ... I really wish Karen and I had known how to help prepare Ashley for school. Her success is so important to us.

The dilemma of this young couple has been replicated time and again over the past few years. Forty-five years ago, the school day went from 8:00 to 3:30, and after school a majority of the children returned home to their mothers. Today, the school day has not changed, but the needs of the average family have. What happens to the young child who returns home from school two hours before her parents' work day ends? How do the schools meet the needs of working parents whose child wants to go to school and is ready to be in school but isn't old enough for kindergarten? Isn't it time for the schools to adapt to the needs of our changing society?

\section{Problem Statement}

Ashley's parents are just one example of parents who want to prepare their children for school, but don't know how; many parents in today's society are in the same predicament. Parents who want to support the emergent literacy of their 
preschool children often aren't sure of how to provide the type of assistance that might maximize their efforts. In order to meet this need, a parent program should be implemented and studied to see if by providing appropriate resources and training for parents, the program might enhance the parents' ability to help their children develop skills necessary for emergent literacy.

\section{Purpose of the Study}

The purpose of this study was to describe the impact of parental support on emergent literacy in preschoolers. Within the ranks of early childhood education, interested parties are wrestling with the implications of brain research and misunderstandings about the adult's role in providing for literacy as part of developmentally appropriate practices. Many are confused by controversies such as nature vs. nurture, teacher-directed vs. child initiated learning, maturation vs. critical period, and how these issues relate to best practice. An additional problem is the vast difference in the developmental levels of preschool children and how to provide experiences that are appropriate for all. Some of this discrepancy is caused by the difference in early experiences and home environments of young children, so our government has intervened to provide services for at-risk children. But this issue goes beyond environmental concerns to practical needs caused by societal changes. With an increasing number of working mothers, even middle- and high-income families feel the need for quality child care for their preschool-age children. Is it fair that some quality programs that depend on governmental support might not be 
available to their children because they don't qualify financially? If a child is in a preschool program, how much impact will the parents have on supporting the child's literacy development?

\section{Research questions}

1. How will participating preschoolers' concepts of print and words change during the course of the family support literacy program?

2. How will the participating preschoolers' ability to identify sound-letter relationships change during the course of the family support literacy program?

3. How will participating preschoolers' acquisition of letter names change during the course of the family support literacy program?

4. In what ways do family literacy training sessions impact the ability of parents to support their preschooler's emergent literacy skills?

\section{Rationale}

Ashley's family is a paradigm of today's working-class family. Although both parents work outside the home, they want the best preschool setting for their child, but that isn't always available to them. A number of factors integrate to cause this scenario, and this project grows from a study of these factors: the need for public preschools, the focus of the preschool curriculum, and the role that parents play in the development of early literacy.

Data from the United States Census Bureau (2001) indicate that childcare most often occurs outside the family unit. In 2000, more than 75 percent of women ages 
25-34 and 75 percent of women with a child under six years of age participated in the labor force. Corresponding with the decrease in the number of mothers staying at home is an increase in the number of preschool children with caretakers other than parents, in child care settings or in preschool day care- 62.2 percent of three-yearolds, 74.1 percent of four year olds, and 75.7 percent of five year olds. With this increased need, shouldn't the focus be on providing quality, affordable (or free) preschool programs for all who want their children to participate rather than focusing on low socio-economic groups or at-risk children?

Because a significant number of young children are cared for outside the home by people other than their parents, Federal and State governments provide resources for low-income families, to purchase non-parental care. Programs administered through the Department of Health and Human Services include: Head Start, Early Head Start, the Child Care Development Fund, Temporary Assistance for Needy Families, and the Social Services Block Grant. Programs administered through the Department of Education include: Title I-supported Preschool Programs, Early Reading First, Even Start, Special Education Preschool Grants and State Grants, Special Education Grants for Infants and Families, The Early Childhood Educator Professional Development Program. All of the programs listed previously focus on either high-poverty communities, children with disabilities, or low-income families.

Between Federal and State funding for early childhood care, most low-income families are able to provide care for their young children before they start school. Over the past decade, Federal funds specifically appropriated for childcare have 
tripled. Funding from the Child Care Development Fund, the Temporary Assistance for Needy Families, and the Social Services Block Grant alone will provide child care assistance to an estimated 2.7 million children per month, the majority of whom are under the age of six. This funding is expected to provide care for 72 percent of children between the ages of three and five whose parents are low income and work at least 20 hours a week. In addition, Head Start provides care to 915,000 children (Bush, 2002).

Most of the support for early literacy has focused on low socio-economic families because of the assumption that this group cannot provide a literacy-rich environment for their children. As a public school teacher, I can attest to the success of programs such as Title 1 and Head Start. However, these programs are available because of the perception that children from upper- and middle-class families need no additional academic help since they come from literacy-rich environments. It appears as if our government has supported the "nurture" side of the nature vs. nurture controversy. Twenty-eight years of teaching experience at the early childhood and primary level in the public schools has revealed to me that having books, magazines, and newspapers in a home might provide optimal resources to promote literacy, but availability doesn't necessarily mean usage. The element of lack of time has ingratiated itself into the life of families today initiated by the necessity for both parents to work. Parents who arrive home after 5:00 are pressed to prepare a meal and complete daily chores at home and often miss the opportunity to take advantage of the resources available to them. 
A focus on providing educational opportunities for preschool children has been requested for at least fifteen years. In a report entitled "Early Childhood Education and the Public Schools," the position statement of the National Education Association (1990) was "The Association believes that the public schools should be a primary provider of high quality early childhood education programs designed to serve students ages three to eight." (p.9) States were urged to mandate the availability of programs for three- and four- year-old youngsters in public schools.

At the 1989 Education Summit of the President and the nation's governors, the first of several goals set for American education was that "by the year 2000, all children in America will start school ready to learn." Achieving this goal, in turn, depended on reaching the following objectives:

- Children will receive the nutrition, physical activity experiences and health care needed to arrive at school with healthy minds and bodies, and to maintain the mental alertness necessary to be prepared to learn, and the number of low-birth-weight babies will be significantly reduced through enhanced prenatal systems.

- Every parent in the United States will be a child's first teacher and devote time each day to helping such parent's preschool child learn, and parents will have access to the training and support parents need.

- All children will have access to high-quality and developmentally appropriate preschool programs that help prepare children for school. 
The American Federation of Teachers (AFT, 2002) reports that while every state provides kindergarten, only twenty-eight states provide preschool programs to threeand four-year-olds; twenty-one of these states give enrollment priority to low-income children and children with other risk factors. Nationwide, states only provide statefunded programs to approximately 12 percent of all three- and four-year-olds. In his documentary, "The Promise of Preschool" which aired on PBS's Frontline, John Merrow (2002) concludes by saying "and in the country that was the first to provide public elementary and high school for all its children — the question remains: Why are we one of the last to provide public preschool?" He also compares the number of U. S. preschools to that of preschools available across Europe: almost all four-yearolds in England, Luxembourg and the Netherlands go to public school; as do more than 70 percent of Greek children of preschool age, more than 80 percent of Spanish children and more than 90 percent of those in Germany, Denmark and Italy.

In his State of the Union Address delivered January 2002, President Bush outlined the next critical step in education reform - the need to prepare children to read and succeed in school with improved Head Start and early childhood development programs (Bush, 2002). According to Bush, early childhood is a critical time for children to develop the physical, emotional, social, and cognitive skills they will need for the rest of their lives. These young children receive care in a wide variety of settings. While 38 percent receive care solely from their parents, the remaining 62 percent receive care through a variety of arrangements, including care by nonparental relatives, non-relatives, and center-based programs including Head Start. 
President Bush has made the education of every child in America among his top domestic priorities. To that end, he signed the No Child Left Behind Act, which proposed reforms expressing his confidence in our public schools and their mission to build the mind and character of every child, from every background, in every part of America. The No Child Left Behind Act is important because it ensures that public schools are teaching students what they need to know to be successful in life. It also draws attention to the need to prepare children before they start school. What children learn before coming to school is vital to their success.

The first five years of a child's life are a time of tremendous physical, emotional, social, and cognitive growth. Children enter the world with many needs in order to grow: love, nutrition, health, social and emotional security, and stimulation in the important skills that prepare them for school success. Children also enter the world with a great capacity to learn. It should be our goal as a Nation to ensure that all children are given the opportunity to learn the fundamental skills needed to be successful in school (Bush, 2002). President Bush believes that all children must begin school with an equal chance at achievement so that no child is left behind. The Bush Administration has proposed a new early childhood initiative_-Good Start, Grow Smart — to help states and local communities strengthen early learning for young children. The goal is to ensure that young children are equipped with the skills they will need to start school ready to learn. 
Emma Bass (1998) reports that there seems to be agreement that early childhood education is both critically needed and wanted by parents in today's society. She shares that with the steady increase in the number of working mothers, there have appeared in the literature more and more references not only for the need to examine early childhood education but a need to determine how providers would work with young children during extended absences of mothers, rather than just for intermittent periods of time as in the past.

The Committee for Economic Development (2002) concurs, but goes a step beyond a need to "examine" and "determine" to a demand for action:

For too long the United States has paid lip service to the importance of preschool opportunities that prepare children for school without undertaking the level of investment needed to turn promise into reality. For the sake of both the children and of our society, it is time to make good on the commitment to provide early learning opportunities for all. (p. 1)

It is time for the United Stated to recognize, as do many other countries, that the public interest in assuring educational opportunity for all should include younger children and not just those who have reached their fifth or sixth birthdays. In the past, society's responsibility for providing educational opportunity for children started with their entry into schools. But a new understanding of how children learn makes it clear that the nation can no longer afford to wait that long. Just as we have long seen elementary and secondary education for all as a societal 
responsibility, we must now undertake to extend educational opportunity to all children age 3 and up. (p. 3)

The Committee also acknowledges societal changes saying,

Since most mothers of young children now work, parents need early education programs that meet their child care needs as well; but public policies still too often treat education and care separately. Policies must encompass simultaneously the goals of school readiness for children and support of working parents. (p.3)

Craig Ramey (1999), preschool specialist at Georgetown University, agrees, but he goes a step further and says, "Child care is early childhood education."

Why stress the need for more preschool programs? Brain research shows that children whose neural circuits are not stimulated before kindergarten are never going to be what they could have been. "You want to say that it is never too late," says Joseph Sparling, who designed the Abecedarian curriculum. "But there seems to be something very special about the early years" (Begley, 1995, p. 62). Craig Ramey (1999) suspected that Head Start had fallen short of the high hopes invested in it (children's IQ gains fade after about three years) because of timing. He took children from 120 poor families and assigned them to one of four groups: intensive early education in a day-care center using the Abecedarian curriculum from about 4 months to age 8 , from 4 months to age 5 , from 5 to 8 years, or none at all. Ramey reports that children enrolled as preschoolers still scored higher in math and reading at the age of 15 than untreated children. The children still retained an average IQ edge of 4.6 points. The earlier the children were enrolled, the more enduring the gain. And 
intervention after age 5 conferred no IQ or academic benefit. Much has been said about the critical window of opportunity for learning during the ages of 3 to 10 . If these years are the time for optimal learning according to research, shouldn't we offer preschool programs for all four-year-olds? In spite of the research of neuroscientists and others, affordable preschool programs are not available to all four-year-olds.

Neither brain science nor education research has been able to free the majority of America's schools from their $19^{\text {th }}$ century roots. If more administrators were tuned into brain research, scientists argue, not only would schedules change, but subjects such as foreign language and geometry would be offered to much younger children. "We do more education research than anyone else in the world." says Frank Vellutino, a professor of educational psychology at State University of New York at Albany, "and we ignore more as well" (Begley, 1995, p.58). "Our school system was invented in the late 1800s, and little has changed," says Linda Darling-Hammond, professor of education at Columbia University's Teachers College. "Can you imagine if the medical profession ran this way?" (Hancock, 1995, p.59).

The Focus of the Preschool Curriculum

There has been a controversy in the field of early childhood education as to whether it is appropriate to teach specific skills to students during the preschool years. Part of the controversy regarding teaching the alphabet to young children lies in what is meant by teach. The National Association for the Education of young Children (NAEYC) has been instrumental in defining appropriate practices for teaching young children. The NAEYC 1987 guidelines defining developmentally appropriate 
practices for four- and five-year-olds state that "stressing isolated skill development such as recognizing single letters [or] reciting the alphabet song” (Bredekamp,1987, p. 55) is inappropriate early childhood instruction. Unfortunately, this advice was misinterpreted to mean that any teaching of the alphabet to young children is not developmentally appropriate. In the revised NAEYC guidelines (Bredekamp \& Copple 1997), the approach to teaching the alphabet is presented differently. The guidelines state that practices following a "rigid sequence of prerequisites" and taking a "single approach" (p. 31) for all children, regardless of what the children can already do, are developmentally inappropriate for young children. When "letters are introduced one at a time and with insufficient context in words," the guidelines point out, "some children are bored because they already know the letters, and other children are confused because they cannot make sense of isolated bits of information.” (p. 131) The NAEYC guidelines do not recommend against teaching the alphabet; they address only the teaching methods for doing so. Furthermore, the recent position statement Learning to Read and Write”: Developmentally Appropriate Practices for Young Children (1998), co-published by NAEYC and the International Reading Association, clearly states that learning the alphabet plays an important role in the development of literacy skills.

Are all four-year-olds ready to pursue pre-reading techniques? Rather than answering this specific question, Johnson and Louis (1987) pose an even broader dilemma: "The problem is that in most classrooms children vary greatly in intelligence, aptitude, self-confidence, the desire to please, temperament, language 
ability, the capacity to listen and a host of other ways. They also differ in the manner and rate at which they develop. In an ideal world, this diversity would be matched by a diversity in teaching methods: 'Each according to her or his need." (p.5)

What causes this diversity of needs? According to Roberts and Burchinal (2001), the multiple determinants of children's success in reading and writing have been of considerable interest in the research literature for the past 25 years. Children's early literacy skills build on their cognitive and linguistic capabilities. Emergence of these skills results from a sound, functioning biological system, a supportive environment, and the interplay between them. Study of disruption of any of these systems can help shed light on factors that support children's normal development, just as the study of the impact of interventions can help reveal the capacity of supportive environments to counteract the negative effects of some environments. Home environmental factors important to children's emergent literacy acquisition include the interactions of caregivers during joint book reading, exposure to literacy-related activities, and the responsiveness of caregivers in the environment. Shared book reading is the most widely studied and believed to be the most important activity for supporting children's emergent literacy skills.

Shirley Brice Heath (1982) would probably say that cultural factors and patterns of language use also have a striking effect on the diversity of needs among preschool children. She studied three communities and found substantial differences in the ways the children approached literacy events because of the model that adults in the community provided. She also found radical differences between the communities in 
the ways in which children and adults interact in the preschool years. Heath explains that close analyses of how mainstream school-oriented children come to learn from books at home suggest that such children learn not only how to take meaning from books, but also how to talk about it. Her findings support the theory that environment is a strong determinant of children's academic success.

Genetic determinism seemed to have the strongest support from scientists in the late twentieth century until the effects of childhood environment—specifically, the “environment" supplied by parenting — came under renewed scrutiny. Neurological studies revealed that the structure of a child's brain remains surprisingly malleable months and even years after birth. The number of connections between nerve cells in an infant's brain grows more than 20 -fold in the first few months of life; for example, a two-year-old's brain contains twice as many of these connections, called synapses, as an adult's brain. Throughout early childhood, synapses multiply and are pruned away at a furious pace. Something directs this dynamic rewiring, and researchers have concluded that that something is experience (Wright, 1997).

Deprived of a stimulating environment, a child's brain suffers. Researchers at Baylor College of Medicine, for example, have found that children who don't play much or are rarely touched develop brains $20 \%$ to $30 \%$ smaller than normal for their age. Laboratory animals provide another provocative parallel. Not only do young rats reared in toy-strewn cages exhibit more complex behavior than rats confined to sterile, uninteresting boxes, researchers at the University of Illinois at UrbanaChampaign have found, but the brains of these rats contain as many as $25 \%$ more 
synapses per neuron. Rich experiences, in other words, really do produce rich brains Nash, 1997).

Further proof of the impact of the environment on brain development came out in a study by Betty Hart, Ph.D., professor emeritus of human development at the University of Kansas at Lawrence, and Todd R. Risley, Ph.D., professor of psychology at the University of Alaska at Anchorage. They observed 42 babies of various economic backgrounds from the time the children were 7 to 12 months until they turned 3, spending one hour per month recording their interactions with their parents. The researchers determined the average number of words directed at each child per hour, then compared those numbers with how well each performed on intelligence tests at age 3 and age 9 (Phillips, 1997).

"The relationship between the number of words spoken to the children when they were babies and their latter test scores was remarkable," says Hart. "Those testing at the highest levels had been exposed to more than three times the amount of spoken language than had the youngsters who scored the lowest $-2,100$ words versus 600 words an hour."

As they grew older, the children whose parents talked to them the most continued to have a significant advantage over their peers. "Since children are constantly building upon their prior experience," says Hart, "attempting to catch up is almost like running after a speeding train" (Phillips, 1997, p.107). The importance of enriching environments on the development of young brains was confirmed in the work of Ron Kotulak (1996), an esteemed science writer who 
wrote a series of Pulitzer-Prize winning articles on brain science. According to Kotulak, "By the age of three, the brains of children are two and a half times more active than the brains of adults - and they stay that way throughout the first decade of life." This suggests that young children—particularly infants and toddlers—are biologically primed for learning and that these early years provide a unique window of opportunity or prime time for learning (Kotulak, 1996).

The findings of Dr. Harry Chugani, M.D., at Wayne State University support the idea of a "window of opportunity or prime time for learning. His imaging studies of children's brains revealed that children's brains learned fastest and easiest between the ages of 4 and 10. In a review of his work, Chugani writes:

The notion of an extended period during childhood when activity-dependent [synapse] stabilization occurs has recently received considerable attention by those individuals and organizations dealing with early intervention to provide "environmental enrichment" and with the optimal design of educational curricula. Thus, it is now believed by many (including this author) that the biological "window of opportunity" when learning is efficient and easily retained is perhaps not fully exploited by our educational system (Chugani, 1998, p.186).

David Sousa also claimed that there is a critical or sensitive period in brain development which occurs between the ages of 2 and 11. Sousa says that during this time children learn faster, easier, and with more meaning than at any other time in their lives. 
As the child grows, the brain selectively strengthens and prunes connections based on experience. Although this process continues throughout our lives, it seems to be most pronounced between the ages of 2 and 11, as different development areas emerge and taper off. ... These so-called "windows of opportunity" represent critical periods when the brain demands certain types of input to create or consolidate neural networks, especially for acquiring language, emotional control, and learning to play music. Certainly, one can learn new information and skills at any age. But what the child learns during that window period will strongly influence what is learned after the window closes (Sousa, 1998, p.35).

Psychiatrists and educators have long recognized the value of early experience. But their observations have until now been largely qualitative. What's so exciting says Matthew Melmed, executive director of Zero to Three, a nonprofit organization devoted to highlighting the importance of the first three years of life, is that modern neuroscience is providing the hard, quantifiable evidence that was missing earlier. "Because you can see the results under a microscope or in a PET scan," he observes, "it's become that much more convincing" (Nash, 1997, p.7).

Recent findings of the neuroscientists suggest that the brain's greatest growth spurt, or the critical years for learning go from the age of 3 to around the age of 10 or 11, when the balance between synapse creation and atrophy shifts. Wouldn't it be wise to take advantage of this "window of opportunity for learning" by providing educational experiences for all four-year-olds? 
According to William Glasser, (1969) dispositions are broadly defined as relatively enduring "habits of mind," or characteristic ways of responding to experience across types of situations (including persistence at a task, curiosity, generosity, meanness, the tendency to read or to solve problems.) Unlike an item of knowledge or a skill, a disposition is not an end state to be mastered once and for all. It is a "trend or consistent pattern of behavior and its possession is established only if its manifestation is observed repeatedly." Thus a person's disposition to be a reader, for example, can only be ascertained if he or she is observed to read spontaneously, frequently, and without external coercion. Working in partnership with parents, keeping them current with practices occurring at school, and being open to the ideas and information that parents share about their child will provide the optimum environment to foster the knowledge, skills, and disposition to read.

\section{The Role of Parents}

A recurring theme that has permeated the entire issue of early childhood education and exactly what that should mean is the importance of the family in the early education of the child. Whether parent involvement is formal or informal does not seem to be the question but rather whether the parent is actively involved. It is paramount that we as educators do whatever is necessary to provide school settings that not only encourage parents to get involved but demand their involvement. This can only be accomplished through concerted efforts of entire communities. Schools cannot alone take on the challenges facing our nation in meeting the national goal on readiness. 
In a paper entitled "Increasing Parental Involvement as a Means of Improving our Nation's Schools," Moore (1990) stressed the importance of parent involvement being considered a "partnership." She went on to emphasize the fact that "Parents' abilities to reinforce what is taught in school is one of the most significant determinants of children's abilities to master new material and develop new skills." (p. 19) Studies show that the most important predictor of academic success is whether parents read to their children consistently through the preschool years (Renkl, 1999). Children who are read to three times per week or more do much better in later development than children who are read to less than three times per week.

Beginning in 2005, to achieve NAEYC Accreditation, early childhood programs will have to demonstrate compliance with each of the NAEYC's ten program standards. Program Standard 9 focuses on family and community partnerships. Programs will be required to establish and maintain collaborative relationships with families. According to the standard's rationale, all communication between programs and families must "be two-way and based on the concept that parents are and should be the principal influence in their children's lives" (Goffin, 2003). This highlights the vital role of partnerships with parents in preschool programs.

Considering the need for public preschools and the opportunity of partnering with parents to reinforce the curricular goals, I used inductive reasoning to formulate this guiding question: What is the impact of parent support on promoting emergent 
literacy? This study explored the answer to this question as it related to two preschool programs.

\section{Definitions}

Academic - those parts of the early childhood curriculum intended to help children master the basic skills involved in literacy and numeracy. Sometimes called direct instruction.

Childcare programs - designed to care for children in the absence of parents.

Dialogic reading - reading that includes structured conversations about the text being read.

Emergent literacy — the reading and writing behaviors that evolve from children's earliest experiences with reading and writing and that gradually grow into conventional literacy.

Preschool programs_-Developmentally appropriate programs for children under age five

Primary school-Grades K-2

Scaffolding the learning environment-- setting up instructional situations that allow learners to succeed as they advance toward higher levels of understanding. Zone of proximal development-- the distance between the actual developmental level as determined by independent problem solving and the level of potential development as determined through problem solving under adult guidance or in collaboration with more capable peers. 


\section{CHAPTER TWO: REVIEW OF LITERATURE}

What lessons can be drawn from the findings in Chapter One? Among other things, it is clear that good, affordable day care is not a luxury or a fringe benefit for welfare mothers and working parents but essential brain food for the next generation. While new synapses continue to form throughout life, and even adults continually refurbish their minds through reading and learning, never again will the brain be able to master new skills so readily or rebound from setbacks as easily as it does during the years from age three through ten. Shouldn't literacy experiences be available to all children beginning at age three or when this window of opportunity opens? And if these experiences are offered, how should they be provided?

The National Association for the Education of Young Children (NAEYC, 1990) and the International Reading Association (IRA) held differing views regarding the answer to this question. According to Sue Bredekamp, one of NAEYC's specialists in developmentally appropriate practices:

All early childhood programs will not have identical goals; priorities may vary in some respects because programs serve a diversity of children and families.

Such differences notwithstanding, NAEYC believes that all high quality, developmentally appropriate programs will have certain attributes in common. A high quality early childhood program is one that provides a safe and nurturing environment that promotes the physical, social, emotional, aesthetic, intellectual, and language development of each child while being sensitive to the needs and preferences of families (Bredekamp \& Copple, 1997, p. 3). 
In reaction, IRA President John Pikulski (1997) noted that his work with kindergarten teachers led to his concern that there are many missed opportunities for learning in the name of developmentally appropriate practice. His fear was that "developmentally appropriate practice" is often misrepresented as meaning no teaching about literacy to young children. These two groups collaborated in an attempt to answer the question of how literacy experiences should be provided. Their joint position statement appears in The Reading Teacher (1998) and outlines these critical issues:

- It is essential and urgent to teach children to read and write competently, enabling them to achieve today's high standards of literacy

- With the increasing variation among young children in our programs and schools, teaching today has become more challenging.

- Among many early childhood teachers, a maturationist view of young children's development persists despite much evidence to the contrary.

- Recognizing the early beginnings of literacy acquisition too often has resulted in use of inappropriate teaching practices suited to older children or adults perhaps but ineffective with children in preschool, kindergarten, and the early grades.

- Current policies and resources are inadequate in ensuring that preschool and primary teachers are qualified to support the literacy development of all children, a task requiring strong preservice preparation and ongoing professional development. 
Models for Learning in Preschools

Some specialists say that children should learn through play until they are mature enough to initiate their own learning experiences. Others agree with Chugani that preschoolers should learn through direct instruction from the teacher while they are in the "window of opportunity" and learning is efficient and easily retained. Many specialists agree with one of these positions, while others are on the continuum between these two schools of thought.

Turner and Hamner (1994) are proponents of the maturation point of view with an emphasis on language. They say that language development activities include those that promote speaking and listening, and they lay the groundwork for later reading and writing. Formalized reading and writing skills are not appropriate for the preschool years, because reading and writing skills involve a complex combination of mental, physical, and emotional skills that develop over a long period of time. Instead, emphasis should be placed on developing readiness for these complex skills. Considerable eye-hand coordination and fine muscle development are required for writing. These and other activities that develop visual discrimination, understanding of likenesses and differences, and an appreciation for books and the printed word are appropriate for developing readiness for reading and writing.

According to Lisa Klein (2002), vice president of early education at the Kauffman Foundation, “To insure children's success in school, we must go beyond a single focus and target programs and policies that connect strong cognitive and literacy development with positive social and emotional development." This qualitative 
connection is difficult to measure, and states are getting pressure from educators to develop school-readiness indicators that they can use to screen young children before they enter kindergarten. More and more preschools are feeling the pressure to develop cognitively based formal curriculum because such an approach produces skills that can be easily measured (such as mastering color names, letters and numbers, etc.) The American Federation of Teachers (AFT) (AFT, 2002) study found that fourteen states already have school readiness standards and require programs to use them. The shift toward accountability will prompt more states to develop standards that will guide the preschool curriculum and swing the focus more toward skill development.

It is readily accepted that practice — and lots of it — is an important part of the learning process, particularly in acquiring skills. But it is also important that every teaching encounter should have some element of guidance. It is not sufficient simply to assign an activity and wander about giving vague moral support. Whole language advocates say, "Children learn to read by reading; they learn to write by writing." Perhaps such statements would become clearer if they asserted that children learn to read and write by trying to read and write. Reading and writing are skills, not subjects, and skills are acquired through the predominance of practice over instruction.

Children will not benefit from being told about language. What they do need is help in getting started, gentle feedback on their attempts to do so, and kind tolerance of their errors. Johnson and Louis (1987) use the analogy of learning to walk in an 
effort to clarify the process of learning language. Very young children clutch at furniture for support, tire easily and fall down a lot. When all else fails, they regress to crawling. The role of the expert walkers around them is instructive. They act as if there is no doubt the children will eventually learn. Praise is given for effort, and support is rushed forward to eliminate the consequences of error. No one sneers at the first fumbling attempts. Perfection is never expected. No one imagines that explaining to a child how one walks will help her or him to do so. Success, given adequate physical equipment, is essentially universal. Few children are sent to remedial walking schools!

Brian Cambourne (1987) suggests that there are seven conditions for learning and provides this model of learning as it applies to any skill including walking and talking. Figure 1 shows how these conditions relate to literacy acquisition.

\begin{tabular}{|l|l|}
\hline Conditions & How manifested in the emergent literacy classroom \\
\hline Immersion & $\begin{array}{l}\text { Print displays around the room: labels, charts, books, dictated } \\
\text { stories }\end{array}$ \\
\hline Demonstration & $\begin{array}{l}\text { Reading print displays, choral reading, discussion of print and } \\
\text { graphophonic conventions in context. Teacher demonstrations of } \\
\text { how reading and writing are done. Regular opportunities to use } \\
\text { print and see it being used. }\end{array}$ \\
\hline Expectations & $\begin{array}{l}\text { Positive/negative expectations which teachers hold and } \\
\text { communicate (both implicitly and explicitly) to children and } \\
\text { which affect their learning. }\end{array}$ \\
\hline Responsibility & $\begin{array}{l}\text { The degree to which the child is permitted to decide what will be } \\
\text { written, when it will be written, what will be learned (from the } \\
\text { demonstrations) and what will be ignored }\end{array}$ \\
\hline Approximation & $\begin{array}{l}\text { The degree to which the child is allowed to approximate the adult } \\
\text { model; degree to which the emphasis is on error avoidance or } \\
\text { error reduction. }\end{array}$ \\
\hline Practice & $\begin{array}{l}\text { Degree to which opportunities to engage in writing-learning are } \\
\text { made available. }\end{array}$ \\
\hline Engagement & Degree to which the learner engages with print and the \\
\hline
\end{tabular}




\begin{tabular}{|l|l|}
\hline & demonstrations being offered about how print works. \\
\hline Response & $\begin{array}{l}\text { The type of response and the degree to which it is meaning- } \\
\text { centered, non-threatening, functional, and relevant to the child's } \\
\text { needs }\end{array}$ \\
\hline
\end{tabular}

Figure 1. Brian Cambourne's conditions for learning (1987).

Mason and Shobha say that the acquisition of reading ability has been misunderstood for most of this century and give examples of the theories of Elkind and Clay who hold two extreme positions regarding educational support for literacy (Mason \& Shobha, 1993). Elkind believes that children might be pressed by adults to learn at too early an age (Elkind, 1981) and has led some educators to reject all support for literacy before the first grade. Unfortunately, this belief builds on the erroneous assumption that children cannot develop reading concepts until a certain maturational level is reached. This belief was given credence by an influential physician, Arnold Gesell, (1940) who wrote the following:

Reading is a complex achievement, which came late in the cultural history of the race. Why should it not come with difficulty and delay for countless children who for reasons of maturity and inheritance have insufficient command of basic coordination of eyes, hands, speech perception, and comprehension at the age of 6 years? ... It is most significant that many of the early reading difficulties would vanish if the natural processes of maturation were given a chance to assert themselves. (pp. 312-313)

When reading readiness was first introduced in the 1900 s, it was generally agreed that maturation was the precondition of reading readiness. Gesell advocated a naturalist position and believed that development was the result of maturation. The 
direct outcome of this kind of position was the philosophy of "wait and see" until the child was ready for instruction. Applied to reading instructions, this theory translated into the reading readiness approach. Accordingly, educators delayed reading instruction until a child was "ready" to read, that is, until the child possessed some prerequisite skills.

Gesell's conclusion was directly countered by Marie Clay (1979) who devised Reading Recovery, a successful program developed in New Zealand that provides intensive tutoring for first grade children who would otherwise become poor readers. Clay asked the following:

Do we have any evidence of accelerated progress in late starters? There may be isolated examples which support this hope, but correlations from a follow-up study of 100 children two and three years after school entry lead me to state rather dogmatically that where a child stood in relation to his age-mates at the end of his first year at school was roughly where one could expect to find him at 7:0 or 8:0. This is what one would expect if learning to read is dependent on the acquisition and practice of a complex set of learned behaviors, and not the product of sudden insights. (p. 13)

Educators who agreed with Clay saw several instructional problems with a reading readiness theory. If one believes that readiness can be influenced by instruction, then the maturational concept must be rejected. On the other hand, if instruction does influence reading readiness, then prereading instruction will help a child to read, and research has shown that prereading instruction for children who are lagging behind 
their classmates helps. Another problem with the readiness theory is its assumption that the age when formal reading instruction begins should matter. In some countries instruction begins at age 5 , in others at age 6 , and in still others at age 7 . If the maturational viewpoint were correct, then the countries that began instruction at 5 would have numerous cases of reading failure, and those that began at 7 would have few failures. This prediction has not been borne out.

Research and writings in the 1950s and 1960s by cognitive psychologists such as Bruner (1960) provided evidence that early childhood was crucial in the cognitive development of an individual. This conclusion called into question the notion of waiting for children to mature. Readiness programs now began to include activities to develop auditory discrimination and memory and visual discrimination and memory. Later, letter names and sounds, word recognition, and some general skills were added.

Gaye Gronlund (2001) of Pacific Oaks College describes the debate as one of "pablum preschools and kindergartens versus academically rigorous ones." She says that much of the misunderstanding in the debate between pablum preschools and academically rigorous ones stems from the definition of what it means to teach young children. Many people see a teacher only as an instructor, imparting concepts and skills to patiently listening young children. That instruction is teacher-directed; the children are passive receivers of the information that the teacher dispenses. The children demonstrate their understanding through paper-and-pencil tasks (usually 
workbooks or ditto sheets), and their progress is evaluated through on-demand assessments or tests.

Good early childhood practices acknowledge that three, four, and five-year-olds are wigglers and doers. To help children stay with tasks and learn important concepts and skills, teachers work with, instead of against, their individual developmental styles. The teacher's role then becomes one of observer as the child goes about exploring materials. She asks open-ended questions that stimulate the child's thinking" "What do you think would happen if you tried ...?" She helps promote vocabulary development by describing what the child is doing.

Most teachers recognize that we must have expectations and standards for our early childhood programs. But they also know the nature of learning at this age, and they carefully define how academics are most appropriately and effectively incorporated into preschool and kindergarten programs. Because a program uses playful ways to build children's success does not mean the curriculum is not rigorous or academic. It means that it is just right for what's best for three, four, and fiveyear-old children (Gronlund, 2001).

The debate continues today as proponents of a standards-based, "academic" curriculum say that children must learn such skills as recognizing their ABC's, colors, shapes, sound-letter relationships, and numbers as they prepare for the expectations of formal schooling. Other professionals disagree saying that this is a time for free play and exploration as children move toward a greater degree of independent functioning and actively construct their own knowledge. Ron Banks 
(2001) says that both approaches have pros and cons, but that Goals 2000 emphasizes accountability and improved academic achievement. Stating that the goal is that all children should enter school "ready to learn" mandates that academic learning occur in preschool in specific areas.

Lilian Katz (1999) reminds her readers that today most preschool classrooms offer a blend of child-centered and teacher-directed instruction. She says that one of the major problems resulting from the historical squabbling over goals and methods is that both sides in the struggle may overlook curriculum and teaching methods beyond the traditional dichotomy. Both sides underemphasize and undervalue the idea of addressing children's intellectual development as distinct from the direct instruction emphasis on academic learning and the child-initiated learning emphasis on children's play and self-initiated learning.

As with other skills, reading is an outcome that results from the continual interplay of development and learning. Given exposure to appropriate literacy experiences and good teaching in early childhood experiences, most children learn to read at age 6 or 7, a few learn at 4, some learn at 5, and some need intensive individualized support to learn to read at 8 or 9 . Some children who do not explore books and other print during their early years are likely to need more focused support for literacy development when they begin preschool or kindergarten. Early childhood teachers are compelled to use well-researched teaching practices that support children's intellectual development while also enhancing their social, emotional, and physical development (such as project work, play, small-group learning experiences, 
engagement in real-life tasks such as cooking or woodworking, and other appropriate practices).

Usually discussions of curriculum and pedagogical practices use the concept of development to refer to what is known about the typical characteristics of children at each age. Many curriculum guides, for instance, include sections describing typical characteristics of four-year-olds, five-year-olds, six-year-olds, and on and on. However, characteristics of children at particular ages are only one aspect of their development - the normative one. The concept of development can be seen as having two distinctive but related dimensions: the normative and the dynamic (Katz, 1995), each of which should be taken into account when deciding what and how children should learn. The normative dimension deals with what most children can or can't do at a given age or stage, and the dynamic dimension deals with within-individual growth through time.

One point of controversy dealing with what children should be able to do before entering kindergarten is whether it is appropriate to teach the alphabet (Wasik, 2001). Some opponents of teaching the alphabet interpret teaching letters as only one step removed from teaching reading and do not believe it is developmentally appropriate to teach such skills to young children. Others object to the teaching methods that typically employ skill and drill rather than developmentally appropriate practices for teaching the alphabet. Early work examining the relationship between alphabet knowledge and learning to read demonstrated overwhelming evidence that suggested alphabet knowledge is one of the best predictors of success in early reading--that is, 
children who learn to read well and most easily in the first grade are those children who have prior knowledge of the alphabet (Adams 1990).

Venezky (1975) explained that children's home experiences are directly related to their knowledge of letters and a wide range of literacy skills. Venezky argued that alphabet knowledge is just a byproduct of the effects of enriched home literacy experience, which in turn has a positive effect on first-grade reading. This theory brings one back to the predicament of primary teachers which results from the fact that a large number of children entering school do not have the luxury of an "enriched home literacy experience." Are preschool teachers responsible for providing these experiences to those who don't receive them at home?

Walsh, Price, and Gillingam (1988) attempted to answer this question when they examined the effects of alphabet knowledge on learning to read. Their results showed that first-graders from similar middle-class backgrounds who knew the alphabet before they started first grade learned to read earlier and better than children who did not have the same skill. Although they acknowledge the fact that learning to read involves focusing on letter sounds rather than on letter names, they argue that children need to learn the letter names as a bridge to decoding and learning to read. Learning letters sets the foundation to learn other skills.

Research on phonemic awareness - the ability to recognize and manipulate sounds in words - also contributes to our understanding of the importance of learning the alphabet. Research indicates that along with alphabet knowledge, phonemic awareness is a significant predictor in children's learning to read (Stanovich 1994). 
Children who learn to read with little difficulty have been found to have welldeveloped phonemic awareness skills, and children who have difficulty learning to read do not have well-developed phonemic awareness skill. Training studies also show that when children are trained in phonemic awareness strategies, their ability to learn to read improves.

The reason that learning the alphabet is important is that many studies investigating phonemic awareness have also found that children with well-developed phonemic awareness skills have a solid knowledge of the alphabet (Stahl \& Murray 1997). This suggests some relationship between alphabet knowledge and phonemic awareness, which makes sense because many of the phonemic awareness tasks, such as understanding rhyming words and alliteration, focus on children's understanding letters and sounds.

It is important to note that children learn the alphabet at their own rates. Preschool teachers should not expect that teaching the alphabet will enable all of the children to master this concept. The teacher should give every young child opportunities to learn the alphabet, ensuring that those who do not have literacy-rich home environments can acquire critical prerequisite skills. For children who do have numerous literacy experiences, alphabet activities reinforce letter learning in playful, developmentally appropriate ways. Direct teaching of letters, when done in the context of meaningful experiences, can help young children learn the alphabet. Over the years, practices in early childhood education have evolved, moving from an avoidance of alphabet teaching to an excessive focus on didactic teaching. Research and experience point to 
a middle way--a playful approach grounded in children's background knowledge and interest, one that enables children to build and apply alphabet knowledge in meaningful contexts.

\section{A Theoretical Model for Preschools}

Mason and Shobha (1993) suggest that a way out of this conflict about whether to introduce skills for literacy to preschool children is for educators to learn about and apply a Vygotskian model to literacy development. In 1929 Vygotsky proposed a model of development that matched the basic principles of early childhood education (children are active constructors of their language and literacy; they do not develop in a vacuum) and suggested an appropriate way for teachers to guide and support children's learning and development. He distinguished two kinds of development, natural and cultural. Natural development "is closely bound up with the processes of general organic growth and the maturation of the child." Cultural development allows mastery not only of "the items of cultural experience, but the habits and forms of cultural behavior, the cultural methods of reasoning" (Vygotsky, 1929, p. 415). Cultural development, under which literacy learning and development are explained, arises from the use of symbols to solve problems, that is, through the use of speech and actions involving more abstract representations. Vygotsky considered this concept analogous to the invention and use of tools.

Vygotsky (1929) proposed 4 stages in cultural development. These can be applied to the process of reading and writing as well as to other aspects of reasoning: 
Stage 1- The child creates "associative or conditional reflexive connections between the stimuli and reactions." This is the natural developmental level.

Stage 2-The child makes use of symbols. The adult operates within the child's range of understanding, providing connecting links or concrete representations of concepts, maintaining the child's interest, and easing memory demands.

Stage 3-The child figures out how to make effective use of symbols or tools and then practices that discovery.

Stage 4---The child is freed from external signs or symbols; the process becomes internalized. (p.427)

Mason and Shobha (1993) applied Vygotsky's model to 3 major constructs of literacy acquisition: concepts about texts, concepts about words, and concepts about letters. By interweaving Vygotsky's developmental model with researchers' descriptions of children's acquisition of emergent literacy constructs, they explain how children's first concepts about literacy can be interpreted and then extended to early childhood instruction.

\section{Concepts about Text}

The first stage of development is seen in children's spontaneous use of text. At the second stage, adults often encourage children to view their language play in new ways. As children become more knowledgeable about the meaning of stories, adults provide fewer explanations and interpretations of story events. At the third stage of development, a child independently uses props to reconstruct aspects of the text. In the fourth stage, children are released from the use of props and pictured 
representations of story information. Through book reading, they gradually replace picture-directed understandings with text-directed understandings, thus acquiring more abstract representations of story ideas so that in the end it becomes an independent endeavor (Mason \& Shobha, 1993).

\section{Concepts about words}

In the first stage of word concept development, children usually treat print no differently than objects. Print is meaningful within the context that children see it, and each printed word is connected uniquely with something that is meaningful. Children's writing begins as a part of their drawings, continuing the symbolic function of representing things. In the second stage, when guided by parents and teachers to notice and make use of printed labels, children memorize words, and whole texts in books, on signs, and on labels. They hear and separate out the beginning (alliterative) and ending (rhyming) patterns of words in print and begin to separate the stream of speech into word units. They also hear connections made between letters and words in alphabet books, they learn to recognize their own name, and they ask to have names of signs and labels identified. In the third stage, children begin building words and phrases from consonant sounds to words using sounds and words they know, extending concepts they understand, and moving toward the use of new print concepts. During the fourth stage of word concept development, conventional word writing is established (Mason \& Shobha, 1993).

Ferreiro and Teberosky have done extensive studies to gain an understanding of how children come to know the written language system - its form, its uses and 
purposes, and its relationship to the objects within the culture. Teberosky (1990) says that teachers, psychologists, and researchers involved with innovative approaches to the teaching or learning of reading and writing tend to succumb to the temptation of wondering how to get children to advance to the next level. She goes on to say, "The initial curricula we developed in the area of written language had this orientation, although we always believed that the activities should be functional, considering the issue of what writing is for. A few years of practice helped us to let go of that initial orientation and to develop some ideas that would be useful in considering how to propose a new approach to the teaching/learning of reading and writing." (p.56) Their more recent work suggests that children draw their conclusions not only from the written texts but also from the contexts, in their experience, in which the texts occur. Children's responses to print in their environment show not only development in awareness of the forms of the print but also an awareness of the different messages of the print and development of the ability to express those messages in their responses.

When Ferrerio (1990) refers to the stages of literacy, he calls attention to the need for scaffolding and intervention through the schools.

Knowing the psychogenesis of literacy does not imply, therefore, remaining static, waiting for the next level to appear. Particularly in developing countries, where a large part of the population is still outside the literacy community, the school has the enormous responsibility of providing children with literacy experiences that parents cannot provide. . In my opinion, it is necessary to think 
about school settings in terms of literacy environments and not just in terms of teaching methods (as has traditionally been the case). It is essential to reflect on the kinds of practices through which children are introduced into literacy and the way written language is presented through these practices. (p. 24)

However, he strongly suggests that the schools allow children to experiment with the written language system in order to make it meaningful and practical.

More often than not, school practices present the writing system as an object of contemplation. Children can look at it and reproduce it, but they are not allowed to experiment with it or transform it. When the writing system is presented as an object of contemplation, the hidden message that is transmitted is that this object is the property of others and cannot be under the ownership of children. It is an object that has a permanent and immutable condition that cannot be transformed, altered, or recreated through social exchanges. (p.25)

\section{Concepts about Letters and Letter Sounds}

The first stage of letter concept development could begin when babies spontaneously make sounds. The second stage of letter and letter sound development overlaps with the first because parents often begin assisting their child's letter learning at a very young age. Because letters and letter sounds are often directly taught in preschool and kindergarten, there is much research evaluating the effectiveness of letter and letter-sound instruction. At the third stage of letter development, children read and write, but they use props and receive some help. Letter concept understanding at this stage is best seen in children's writing, which 
they usually carry out in order to form words. Their attempts begin as preconventional forms - scribbling, drawing, writing random letters, phonetic spelling and copying — before they are able to write conventionally. The third stage of letter development occurs when children's constructions are directed to goals of producing meaningful and communicative messages. The fourth stage of letter construction is completely encompassed by word and text concept development. Letter knowledge alone has no separate, conscious function, except perhaps for spelling (Mason \& Shobha, 1993).

Vygotsky (1978) focuses on the fact that school learning introduces something fundamentally new into the child's development. In order to elaborate on this new dimension of school learning, Vygotsky describes the concept of the zone of proximal development. Vygotsky based his theory on the idea that learning should be matched in some manner with the child's developmental level. He says that the teaching of reading, writing, and arithmetic are initiated at a specific age level, but that this limits the discovery of the relationship between the developmental process and learning capabilities. Therefore, he suggests that one must determine at least two developmental levels.

The first level can be called the actual developmental level, that is, the level of development of a child's mental functions that has been established as a result of certain already completed developmental cycles. When we determine a child's mental age by using tests, we are almost always dealing with the actual developmental level. In studies of children's mental development it is generally 
assumed that only those things that children can do on their own are indicative of mental abilities. This assumption disregards the idea that what children can do with the assistance of others (scaffolding) might be in some sense even more indicative of their mental development than what they can do alone.

When it was first shown that the capability of children with equal levels of mental development to learn under a teacher's guidance varied to a high degree, it became apparent that those children were not mentally the same age and that the subsequent course of their learning would obviously be different. This difference is what we call the zone of proximal development. It is the distance between the actual developmental level as determined by independent problem solving and the level of potential development as determined through problem solving under adult guidance or in collaboration with more capable peers. Vygotsky's theory requires social constructs of development and provides an explanation of how changing social interactions between learner and tutor — where the tutor could be a parent, teacher, or more knowledgeable child - lead the learner toward proficiency (Mason \& Shobha, 1993).

One of the central tenets of Vygotsky's theory is that children practice skills unconsciously and spontaneously before they have conscious control over a concept. At first, that idea seems impossible. As Bruner (1985) phrased it, "How could 'good learning' be that which is in advance of development and, as it were, bound initially to be unconscious since unmastered?" (p. 4) Bruner answers his own question saying: 
The teacher or other tutor serves the learner as a vicarious form of consciousness until such a time as the learner is able to master his own action through his own consciousness and control. When the child achieves that conscious control over a new function or conceptual system, it is then that he is able to use it as a tool. Up to that point, the tutor in effect performs the critical function of "scaffolding" the learning task to make it possible for the child, in Vygotsky's words, to internalize external knowledge and convert it into a tool for conscious control. (pp.24-25)

The American researcher Dorothea McCarthy studied scaffolding in children between the ages of three and five. She studied two groups of functions: those the children already possess, and those they can perform under guidance, in groups, and in collaboration with one another but which they have not mastered independently. McCarthy's study demonstrated that this second group of functions is at the actual developmental level of five-to-seven-year-olds. What her subjects could do only under guidance, in collaboration, and in groups at the age of three-to-five years they could do independently when they reached the age of five-to-seven years. (McCarthy, 1930).

Vygotsky (1983) argues that the "psychic functions: required for learning the basic school subjects are not mature at the beginning of schooling. As a result, teachers cannot expect children to draw exclusively on what they already know in order to progress. Reading instruction need not be delayed, but it does need to be supported; that is, because of its complexity, reading cannot be expected to develop without 
assistance from others. However, the nature of assistance does not follow a reading readiness or direct instruction model. As suggested in the earlier quote from Bruner (1985), we can say that the tutor/teacher provides "vicarious forms of consciousness" until children have experienced various aspects of the concepts. That is, the tutor organizes (scaffolds) learning tasks, making it possible for children to try them out and, in applying concepts to practical and increasingly more complex tasks, learn to understand how to use them for their own purposes.

The work of Vygotsky (1978) emphasizes the role of language development and social interaction in cognitive development. According to Vygotsky, young children often use private speech when they are trying to perform a task in their "zone of proximal development" - that is, just beyond their current level of functioning but achievable with another person's assistance or supportive scaffolding. Cues, questions, and other forms of assistance are given by adults and other children. For example, as a child struggles with a puzzle piece, instead of directly showing the child how to place the piece, an adult may say, "What color is it? Where do you see that color on the puzzle?" or "Try turning it around another way." Vygotsky demonstrated that much of children's understanding first occurs in communication with other people, then appears in private speech, and eventually is internalized as thought. Vygotsky (1983) described the role of the adult in assisting development: [It is not true that] imitation is a mechanical activity and that anyone can imitate almost anything if shown how. To imitate, it is necessary to possess the means of stepping from something one knows to something new. With assistance, 
every child can do more than he can by himself - though only within the limitations of his development ... [Imitation and instruction] bring out the specifically human qualities of the mind and lead the child to new developmental levels.... What the child can do in cooperation today he can do alone tomorrow. Therefore the only good kind of instruction is that which marches ahead of development and leads it; it must be aimed not so much at the ripe as at the ripening functions. . . . For a time our schools favored the "complex" system of instruction, which was believed to be adapted to the child's way of thinking. In offering the child problems he was able to handle without help, this method failed to utilize the zone of proximal development and to lead the child to what he could not yet do. Instruction was oriented to the child's weakness rather than his strength, thus encouraging him to remain at the preschool stage of development. (p. 268)

Children do not construct their own understanding of a concept in isolation but in the course of interaction with others. In developing the notion of "school," for instance, the child uses what she hears people say about schools, glimpses of buildings identified by others as school and stories about school that she has had read to her. Her initial ideas may be challenged, confirmed, elaborated on, or altered by later interactions with peers, older children, or adults. This process is known as the social construction of knowledge (Vygotsky 1978). As children's memory and other aspects of cognition improve and change, their relationships with other people are affected. From their experiences and interactions, children discover that other people 
have different points of view, which challenges and begins to break down their egocentrism. As children overcome their egocentric perspectives, they become more successful in interacting with other people, although not always consistent in applying this knowledge. Once again, the highly integrated nature of development and learning is evident. Children's cognition affects their social interaction and their social interaction affects their cognition.

In the preschool and kindergarten years, children acquire literacy principally through exploration and adult support, which, using a Vygotskian model of learning and development, does not preclude adults from fostering children's interest but also does not lead to direct instruction. Using Vygotsky's theory, teaching reading and writing to preschool children is attractive given today's requirements for entering some schools. But the teaching should be organized in such a way that reading and writing are necessary for something. If they are not relevant to the child's needs, then the process will be purely mechanical and may soon bore the child: his activity will not be manifest in his writing and his budding personality will not grow. Finally, effective communication patterns should be developed and maintained between teachers and parents so that key caregivers at school and home have a coordinated program for each child.

\section{Partnerships with Parents}

The significance of a partnership with parents was affirmed by the Association for Childhood Education International (ACEI). In their Global Guidelines for Early Childhood Education and Care in the $21^{\text {st }}$ Century, (2000-2002), ACEI includes a 
section dealing with "Partnership with Families and Communities." Their opening statement is:

The care and education of the child is a shared responsibility among the family, educators and caregivers, and the community. Within the family and community, all participants share an ethical/moral responsibility to promote the optimum conditions for the well-being of children. The program policies should achieve the following:

- Promote partnership and positive constructive relationship with families and community

- Provide opportunities for families to participate at different levels, based on their strengths and life experiences

- Support the development of positive, constructive relationships between educators/caregivers and children, between children, and between educators/caregivers and families

- Provide support for families, either directly or through links with other community resources.

Research on Parent Participation in Early Literacy Programs According to Grover Whitehurst, Director of the Stony Brook Reading and Language Project (1992), it is important to begin reading to your child at an early age. By nine months of age, infants can appreciate books that are interesting to touch or that make sounds. But, how we read to preschoolers is as important as how frequently we read to them. The Stony Brook Reading and Language Project 
developed a method of reading to preschoolers called dialogic reading. When most adults share a book with a preschooler, they read and the child listens. In dialogic reading, the adult helps that child become the teller of the story. The adult becomes the listener, the questioner, the audience for the child. No one can learn to play the piano just by listening to someone else play. Likewise, no one can learn to read just by listening to someone else read. Children learn most from books when they are actively involved.

The fundamental reading technique in dialogic reading is the PEER sequence. This is a short interaction between a child and the adult. The adult prompts the child to say something about the book, evaluates the child's response, expands the child's response by rephrasing and adding information to it, and repeats the prompt to make sure that the child has learned from the expansion. (p.2)

Parents can be trained to use the PEER sequence with their preschooler and increase their child's comprehension.

Parents also need to understand the importance of creating a positive disposition toward reading in their child. A child with a positive disposition toward reading will choose to read often. The consequence of a positive disposition will be more opportunities to practice the skill of reading. One easy thing parents of preschoolers can do to create this disposition is to make the reading experience comforting. Joanne Roberts, senior researcher at the Frank Porter Graham Child Development Center at the University of North Carolina suggests that parents create a special 
space for a child that's relaxing and encourages him to bond and interact with Mom or Dad while he's being read to (Fears, 1999).

Stevens, Hough, and Nurss, (1993) report that there are some tentative trends that can be drawn from a small group of studies, primarily measuring high-quality research-and-demonstration parent-education programs. Results of these studies suggest that programs to help parents teach their own children may have small but potentially important positive effects. Positive short-term effects for target children have been found by a number of investigators on measures of IQ and on measures of social competence, such as appropriate infant responsiveness to parent behavior, increased verbalization during play, and positive social-emotional functioning in early education settings. Although these positive results are the apparent result of parent participation in supportive programs, most of the programs studied trained parents to teach their children within a broader parent-child support system. Therefore, it is not possible to say absolutely whether these improvements are due to differences in parent-child interactions or some other aspect of the support program.

Although most studies have reported short-term effects, a few investigators have measured effects of longer duration. A 5-year evaluation of the Parent Child Development Centers (PCDCs) found some evidence that children's enhanced cognitive, language, conceptual, and abstraction skills were still present one year after they completed the program. Although there is no current evidence of IQ increases being sustained more than 1 year beyond the interventions, there are some data to support other enduring effects of parent-education programs, such as reduced 
placement in special-education classes and less negative school behavior and juvenile delinquency (Stevens et al., 1993).

The success of school-based family-support programs has been measured by scores on achievement tests, but also on other outcomes likely to show more rapid improvement, such as attendance, discipline, grades, and level of parent involvement. Studies of schools including parent involvement as part of their program demonstrated that (1) parents increase home interactions with their children, feel more positive about their abilities to help their children, and perceive the school more positively; and (2) students improve their attendance, attitudes, and achievement (Stevens et al., 1993).

Patricia Edwards (1999) stresses the need for an equal partnership with parents. Often schools and teachers take a "father-knows-best" approach; essentially parenting the parent. Schools must realize that while they may have expertise on pedagogy, curriculum, and child development, they are not experts on individual families or children. The parents know their child and what occurs in their family better than any outsider and schools/teachers need to respect and learn from their clientele. (p. xx)

She later adds that in her experience teachers return again and again to the homeschool connection, especially in their remarks about children's language abilities, social skills, emotional needs, and learning styles. Edwards emphasizes that although parents do interact with a variety of school personnel, "the home-school connection is best understood in the context of the teacher-parent relationship." (p. 5) She conveys 
stories that parents have shared with teachers about their educational background and parallels the influence these parent experiences have on the literacy development of their children.

Parents of young children are constantly encouraged to read to their young children; the benefits that may be expected include enjoyment, language, and literacy acquisition, and cognitive development. Training parents to select and read appropriate storybooks has been shown to have a positive effect on young children's development. In Missouri, parent education was begun at the child's birth by providing parents with services such as information on development, home visits by parent educators, group meetings, periodic screening of the children, and a referral network. Parent-child activities included showing parents the kinds of books their child would enjoy and modeling how to use the books with their child. At age 3 years, children in the program were significantly more advanced than comparison group children in language, social development, problem solving, and other cognitive abilities (Winter \& Rouse, 1990).

In a U.S. replication of British research, Nurss, Huss, and Hannon focused on the effects of children reading to their parents on the children's literacy attainment in first- and second-grade children. Findings demonstrated improved attitudes toward reading, increased motivation to read, increased interest in reading, and improved progress through the school's series of reading books (Winter and Rouse, 1990). Without engaging in a specific instructional program, parents positively affected their children's reading through daily interactions around books. 
Edwards (1989) coached 5 mothers of Head Start children in reading stories to their children over a period of 8 weeks. Only 1 of the mothers acquired successful book-reading strategies (e.g., use of scaffolding). She was the best reader in the group and the one most willing to change. Edwards concludes that urging parents to read to their children is not sufficient; they must also be shown how to read effectively and be supported in their attempts.

Stevens, Hough, and Nurss (1993) report the findings of another study in which Head Start children were given stories to share with their parents. Children in the book recitation group heard their teacher read short stories emphasizing the print, and they reread (recited) the stories several times. One of these books was mailed home each week for the children to read to the parents. Children in the story discussion (control) group had stories told to them and copies of the illustrations mailed to them. During kindergarten the book recitation group continued to receive storybooks at home, whereas the story discussion group was sent worksheets. At the end of kindergarten, the book recitation group scored significantly higher on story-reading tasks and on reading, letter sounds, and parental assessment of literacy knowledge. At the end of first grade more of the treatment group were in the middle or high reading groups than were the control group, and none in the treatment group was retained or placed in special (transition or learning disabilities) programs, as were children in the control group. By listening to their children read aloud, parents had a beneficial effect on the children's acquisition of literacy. 
A longitudinal study by Gottfried and colleagues (1998) again illustrates the difference that parental involvement can make. Gottfried tracked the development of 130 children (from widely diverse racial and socio-economic backgrounds) beginning in 1979. He found that parents who placed more emphasis on reading to their children and exposed them more to learning opportunities and activities had children who were more academically motivated.

Another study by Senechal and Lefevre (2002) focused on 168 middle- and upper middle-class children and the correlations among early home literacy experiences, subsequent receptive language, and emergent literacy skills, and reading achievement. Results showed that children's exposure to books was related to the development of vocabulary and listening comprehension skills, and that language skills were directly related to children's reading in grade 3 . In contrast, parent involvement in teaching children about reading and writing words was related to the development of early literacy skills. Early literacy skills directly predicted word reading at the end of grade 1 and indirectly predicted reading in grade 3 . Word reading at the end of grade 1 predicted reading comprehension in grade 3 . Thus, the various pathways that lead to fluent reading have their roots in different aspects of children's early experiences.

Understanding how different aspects of parental involvement might influence or enhance children's academic development is of potentially great importance. Researchers have studied this concept in a variety of research contexts. For example, Lonigan and Whitehurst (1998) conducted an intervention study designed to increase the vocabulary skills of 3- and 4-year-old children. Teachers and parents were trained 
to read to the children using dialogic reading in which they were encouraged to pose questions to the children. Lonigan and Whitehurst found that the intervention was most effective when parents as well as teachers were trained. Similarly, Leslie and Allen (1999) found that the degree of parent involvement in a reading intervention of children in grades 1 through 4 who were nonreaders or were behind by one or two grade levels predicted children's reading growth.

Many parents are eager to help build a foundation for reading for their children, but are not sure what strategies to use to make the most of their reading time. An intervention called Project EASE (Jordan et al., 2000) was designed to provide parents both with a theoretical understanding of how to help their children and with scaffolded interactive practices to facilitate their children's early literacy development. This program provided support for parents' involvement in their children's oral language development, focusing on vocabulary, narratives, and exposition. The Project focused on families that were not necessarily limited in their literacy support having children attending schools with generally good achievement results. This was a moderate- to-low risk sample of English-speaking European American families with median family incomes above the poverty level and access to good schools for their children. The impact of participation in Project EASE on children's language scores is striking:

- language skills showed the largest effect

- the amount of participation as indexed by completing book-related activities at home relates to the size of the effect observed 
- receiving this intervention had a particularly powerful impact on the children who scored low at the pretest

In other words, even in this moderate-to-low risk sample of English-speaking European American families, with median family incomes above the poverty level and access to good schools for their children, there is room for parental involvement to improve children's school performance.

For parenting education, it is assumed that having structured time for parents and children in an instructional setting is important for promoting parent-child interactions focused on literacy activities as well as for promoting positive parentchild relationship (Wasik et al., 2001). Another assumption is that children who are participating in early-childhood education and whose parents are participating in adult education will have more academic gain than those in programs providing direct services only to the children. This assumption was challenged in Purcell-Gates' review of programs offering a variety of services: programs offering direct services to both children and parents (i.e., Even Start), programs offering parenting education, and programs provided directly to children, including home-school programs. From her review she drew positive conclusions, stating that the documentation from the literature shows "clear benefits to children of family literacy programs of all types (Purcell-Gates, 2000).

\section{Research Summary}

Overall, research suggests that home environmental factors important to children's emergent literacy acquisition include the interactions of caregivers during 
joint book reading, exposure to literacy-related activities, and the responsiveness of caregivers in the environment. Shared book reading is the most widely studied and believed to be the most important activity for supporting children's emergent literacy skills. Shared book reading advances a child's language_-increasing understanding and use of vocabulary and concepts, structure of story narratives, and decontextualized language, as well as the conventions of print, letter-sound correspondences, and linguistic awareness. During book reading, the adult scaffolds and supports the child's interactions, allowing him or her to acquire higher level of skills. Certain styles of interactions (describing, labeling, and focusing on meanings and inferences) during book reading may be particularly facilitative of literacy skills, and this may depend on the child's level of literacy skills (Roberts \& Burchinal, 2001).

Studies show that the most significant predictor of academic success is whether parents read to their children consistently through the preschool years says David Yaden, $\mathrm{PhD}$., associate professor of curriculum and teaching at the University of Southern California. Children who are read to from the age of about four months more easily master reading in first grade according to Debbie Rowe, PhD., associate professor of early-childhood education at Vanderbilt University. And it's the ability to read fluently and independently that leads to achievement in the higher grades as well. In addition, storybook reading encourages children to ask questions about the pictures, plot lines, and characters. Yaden's studies have shown that a child who is read to regularly over the course of the preschool years can ask his parents as many as 
10,000 to 15,000 questions about printed language, and get that many answers in return (Renkl, 1999).

Partnering with parents is more than assigning homework, asking parents to read with their children, and conferencing about the child's progress. Partnering implies that interested parties will contribute equally toward a common goal. Most parents want to help their child to succeed but need to be taught how. This project will offer parent training sessions to guide parents to extend the learning process that is started during the school day, and then measure the impact these parents have on the early literacy acquisition of their children. 


\section{CHAPTER THREE: RESEARCH DESIGN AND METHOD}

\section{Research Design}

Because the purpose of this study is to describe the impact of parental support on early literacy, a descriptive research design was preferred. Specifically, a qualitative approach was used to portray the child's disposition for literacy activities and the parents' perception of the effect their support had on the literacy development of their children and the amount of support that they were able to give their children after being involved with training. In addition, a qualitative approach was used to illustrate the children's academic gain in the areas of the three constructs for early literacy acquisition: concepts about texts, concepts about words, concepts about letters. Using this design, these questions were used to drive the study:

1. How will participating preschoolers' concepts of print and words change during the course of the family support literacy program?

2. How will participating preschoolers' acquisition of letter names change during the course of the family support literacy program?

3. How will the participating preschoolers' ability to identify sound-letter relationships change during the course of the family support literacy program?

4. In what ways do family literacy training sessions impact the ability of parents to support their preschooler's emergent literacy skills? 


\section{Qualitative Research Design}

Michael Patton (2002) explains that qualitative findings grow out of three kinds of qualitative data. This data typically come from fieldwork; according to Patton, "The themes, patterns, understandings, and insights that emerge from fieldwork and subsequent analysis are the fruit of qualitative inquiry.” (2002, p. 5)

1. Interviews-yield direct quotations from people about their experiences, opinions, feelings, and knowledge.

2. Observations - yield detailed descriptions of people's activities, behaviors, actions, and the full range of interpersonal interactions and organizational processes that are part of observable human experiences

3. Documents - yield information from organizational, clinical, or program records; memoranda and correspondence; official publications and records; personal diaries; and open-ended written responses to questionnaires and survey.

"Fieldwork," Patton (2002, p. 306) reveals, "is more than a single method or technique." Patton goes on to say that multiple sources of information are used because no single source of information can be trusted to provide a comprehensive perspective on the program. By using a combination of observations, interviewing, and document analysis, the fieldworker is able to use different data sources to validate and cross-check findings. Each type and source of data has strengths and weaknesses. Using a combination of data types - triangulation - increases validity as the strengths of one approach can compensate for the weaknesses of another approach. Observations provide a check on what is reported in interviews; interviews 
permit the observer to go beyond external behavior to explore feelings and thoughts. Document analysis provides a behind-the-scenes look at a component of the study that may not be directly observable and about which the interviewer might not ask appropriate questions without the leads provided through the documents. By using a variety of sources and resources, I was able to build on the strengths of each type of data collection while minimizing the weaknesses of any single approach.

Sociologist John Lofland (1971) has suggested the following four people-oriented mandates in collecting qualitative data:

1. The qualitative methodologist must get close enough to the people and situation being studied to personally understand in depth the details of what goes on.

2. The qualitative methodologist must aim at capturing what actually takes place and what people actually say: the perceived facts.

3. Qualitative data must include a great deal of pure description of people, activities, interactions, and settings.

4. Qualitative data must include direct quotations from people, both what they speak and what they write down.

\section{Research Method}

This section will describe and justify the logistical processes for this study including site selection and sampling procedures, techniques for data collection, and strategies for data management and analysis. The section concludes with a description of the procedures that were employed to ensure quality of the data. 


\section{Site Selection}

The site selection method was a convenience sample because an entire group of individuals, a preschool classroom, was available to participate in the study.

Specifically, the preschool class of 15 students, ages four and five, at Rockville Elementary School which is under the administration of the Title I director of the Downey County school system was selected because it represented a site that is open to all preschool-age children without an economic requirement. An additional site was added after only four parents of students from the Rockville preschool class were willing to take part in the study. The second site with 20 students was the preschool class of Achievement Primary School which is also under the administration of the county's Title I director.

\section{Permission to Study}

Approval to participate in the study was required on four different levels: from the Title I Director, from the principal of the school, from the teacher at the site, and from the parents of the children involved. Signed permission letters from the Title I Director, the principals of the schools, the teachers of the classes and the parents of the children participating are on file in order to maintain their anonymity Parental consent and willingness to participate were also required. I met with the Rockville parents at a previously-scheduled parent meeting to discuss the purpose of the study, the need for participants, and to recruit parents. Those parents who weren't able to attend the meeting received a letter explaining the program and inviting their participation. After only four parents committed to attending the training sessions, I 
included another site in the study. Letters explaining the program were sent to parents of the Achievement preschool class, and interested parents were invited to call me for more information. In addition, the teacher recommended the program to parents who were likely to follow through on a consistent basis. Six parents expressed an interest in being involved.

\section{Subjects}

Subject selection was managed according to convenience, parent interest, parent permission, and age level. The focus group consisted of the children of parents who were willing to participate in evening training sessions and spend about ten minutes nightly to work with their children. I recruited parents by attending a previouslyscheduled parent meeting at Rockville Elementary School. I explained the program to parents, and three parents agreed to participate. Knowing I would be interested in working with additional families, I sent letters to parents of the other children in the preschool class, and one other parent responded. In order to have more participants, I decided to offer the same program to parents of preschoolers at the Achievement Elementary School site sending interest letters home with all of the students. Six parents expressed an interest.

The parents offered a variety of backgrounds for the study. It was clear that at the rural Rockville location, childcare was a prohibiting factor for parent participation. In an effort to include all families who wanted to enroll, parents were invited to bring other children with them. One mother was a foster mother who brought with her two older sons, ages six and seven, and a younger daughter, age three in addition to her 
four-year-old preschool daughter. One mother was a volunteer at the school's afterschool program. Her older sons joined the group when the after-school program ended. This mother told me that she had been "home schooling" her daughter since she was about two years old. Another mother brought her two-year-old son with her to each session, and another mother brought a three-year-old to the sessions and left two older daughters in the car. Most of the siblings who were near in age to the preschool children participated in the planned activities. At this site, all four participants were girls who often sat on their mothers' laps as stories were read and depended on their mothers to help with various activities. Although fathers were invited to come, none did.

The participants at the Achievement site which is located in town provided a different socio-economic and educational complexion. Parents came alone with their children and watched attentively as children participated. Although one mother brought a baby for the last two sessions, the baby didn't interact with the preschool children. A father attended one of the sessions, and mothers talked about how their husbands helped work on the packet activities at home. This group, consisting of three boys and three girls, was well behaved and closely monitored. The teacher attended the sessions at this site in order to monitor the facility use for liability purposes, and his presence had an impact on expectations for behavior and following rules that were already in place.

After the first session, only three children and mothers continued with the program at each site. Table 1 provides a description of participants and their family life. 
Table 1 Participant Information

\begin{tabular}{|c|c|c|c|c|c|c|}
\hline \multirow[t]{8}{*}{ Name } & \multirow[t]{8}{*}{ Site } & Mom & \multirow[t]{8}{*}{ Siblings } & Time to & Attendance & Effect of \\
\hline & & works & & work with & at all & program on \\
\hline & & outside & & child in & sessions & literacy \\
\hline & & the home & & evening & & activities \\
\hline & & & & & & All spent \\
\hline & & & & & & more time as \\
\hline & & & & & & a result of the \\
\hline & & & & & & program. \\
\hline \multirow[t]{12}{*}{ Cindy } & \multirow[t]{12}{*}{ Rockville } & \multirow[t]{12}{*}{ No } & Two & Has been & \multirow[t]{12}{*}{ All } & Mom had \\
\hline & & & older & home- & & never \\
\hline & & & foster & schooled & & thought of \\
\hline & & & brothers & by Mom & & focusing on \\
\hline & & & (ages 9 & since age & & sound \\
\hline & & & \& 11) & 2 (at least & & classification \\
\hline & & & & 3 hrs. per & & drawing or \\
\hline & & & & day) & & writing. \\
\hline & & & & & & Now requests \\
\hline & & & & & & to do same \\
\hline & & & & & & activities as \\
\hline & & & & & & program. \\
\hline Julie & Rockville & No & Younger & Reads & All & Much more \\
\hline
\end{tabular}


brother stories

(age 2)

Sue Rockville Yes

Tommy Achieve- Yes

ment

Two
older
sisters
(ages 12

and 14)

and one

younger

sister

(age 3

years) interest on

words and

word

identification

Not very Missed 2 More

interested

interested in

hearing and

reading

stories.

\begin{tabular}{|c|c|c|}
\hline Older & Not much $\quad$ Missed 1 & Mom has \\
\hline brother & time. & more ideas \\
\hline (age 16), & Brother & for activities \\
\hline younger & spends & to do, but \\
\hline brother & more time & isn't \\
\hline (age 10 & than & successful in \\
\hline mo.) & Mom. & convincing \\
\hline
\end{tabular}


Tommy to

work with

her.

Bradley Achieve- No

Older

At least an Missed 1

Much more

ment

sister hour a day

interest in

(age 7)

letter and

word

identification

Linda Achieve- No

\begin{tabular}{|c|c|c|}
\hline Only & Missed 1 & Is excited \\
\hline child & stories, & about being \\
\hline until & but Mom & able to \\
\hline Mom & is & identify \\
\hline had a & concerned & words and \\
\hline baby & about her & read stories. \\
\hline during & being & Mother more \\
\hline program & ready for & comfortable \\
\hline & kindergarten & about her \\
\hline & & kindergarten \\
\hline & & preparation. \\
\hline
\end{tabular}




\section{Instrumentation and Materials}

According to Marie Clay (2000), children need to learn a number of different concepts about print including: directional movement, one-to-one matching of spoken words to printed words, and book conventions. As a result of a research project describing what a sample of five-year-old children did as they tried to read, she constructed the Concepts About Print test. This test has twenty-four components that reveal early progress in literacy learning. Clay says, "The test's greatest value is the guidance that it gives to teachers. Items uncover concepts yet to be learned or confusions to be untangled. Young children get low scores early in their schooling, and their scores should increase as their reading and writing improves. Teachers should see a control over these concepts gradually emerging, and retests at spaced intervals will show that change is occurring." (p.10)

In addition, the Dynamic Indicators of Basic Early Literacy Skills $6^{\text {th }}$ ed. (Good \& Kaminski, 2002) Benchmark 1 provided the basis of the initial sound fluency and letter naming fluency on the pretest and the posttest. (Appendix A) Because this is a kindergarten assessment, only the first benchmark that is to be given at the beginning of the year was used.

Content of the weekly training sessions included a read aloud model of dialogic reading, students responding to the story by drawing in journals, and a follow-up activity related to the story. Journal entries were analyzed to detect progress in the area of written literacy as well as the child's disposition to read and write. At the end of each session, children received a new book to read at home. Parents were given a 
prompt and asked to have their child respond to the prompt after hearing the story by drawing a picture.

The focus was on the three major constructs of literacy acquisition: concepts about print, concepts about words, concepts about letters and sounds. Parents were given weekly packets and asked to work with their child five times for ten minutes each time. The packets contained the following six resources to help parents support skill development in the three constructs of literacy acquisition:

1. Concepts About Print and Words Book-The book had repeating sentences and phrases with picture clues for new words. Cards with key words were included. Students were to listen to the story until they recognized the repetitions. Then they were to match the words on the cards with the words in the text, and finally they were to identify the word cards isolated from the text. Parents kept a daily tally of the number of words that the child could correctly identify.

2. Picture Cards-Parents were asked to identify the pictures on eight of the cards and then to ask their child to choose the picture that begins with the sound of a specific letter. The focus was on the sound that the letter makes, not on the name of the letter. Parents recorded how many of these sounds their child identified correctly. 3. Alphabet Book - This book had the upper-case letters, the lower-case letters, and a picture beginning with that letter. The child was to read the book "A a apple." The focus here is letter recognition and connecting the letter with a picture.

4. Alphabet Game-A variety of games were included, all focusing on letter identification. After reading the alphabet book and playing the game with their child, 
parents were asked to time their child and see how many letters the child could identify correctly in a minute and record that number.

5. Consonant Book-Each of these books focused on a different consonant sound, and most of the text of the story consisted of words beginning with the sound.

Students were to identify the words beginning with the specific sound.

6. Vowel Book-These books focused on a specific vowel sound, and students were asked to listen to determine which words contained that sound.

\section{Data Collection}

Patton (2002) explains that qualitative data may consist of direct quotations from people about their experiences, opinions, feelings, and knowledge obtained through interviews, and excerpts, quotations, or entire passages extracted from a variety of documents. Merriam (2001, p.69) contends that qualitative data gathering involves “asking, watching, and reviewing." And, it is the researcher's responsibility to determine whether or not a particular piece of information develops into data in the research study. According to Patton (2002):

We interview people to find out from them those things we cannot directly observe. The issue is not whether observational data are more desirable, valid, or meaningful than self-report data. The fact is that we cannot observe everything. We cannot observe feelings, thoughts, and intentions. We cannot observe behaviors that took place at some previous point in time. We cannot observe situations that preclude the presence of an observer. We cannot observe how 
people have organized the world and the meanings they attach to what goes on in the world. We have to ask people questions about those things.

The purpose of interviewing, then, is to allow us to enter into the other person's perspective. Qualitative interviewing begins with the assumption that the perspective of others is meaningful, knowable, and able to be made explicit. We interview to find out what is in and on someone else's mind, to gather their stories. (p. 341)

The informal conversational interview was used with parents and teachers as a part of ongoing participant fieldwork. Patton (2002) reveals that the conversational interview offers maximum flexibility to pursue information in whatever direction appears to be appropriate, depending on what emerges from observing a particular setting or from talking with one or more individuals in that setting. Some of the conversational questions were the result of the immediate context; however, I tried to concentrate on the prepared questions for parents, teachers, and children that are included in the Appendix B. Interviews took place individually with parents and the teachers at the beginning and end of the study. Focus group interviews with parents at the end of each session provided the most enriching information of the study. Interviews with children took take place during each session as they explained their journal entries.

Observations targeted the activity of students in terms of specific criteria on the checklist that appears in Appendix C. Students whose parents agreed to participate in the study were the focus of the observations. I watched the students as they 
participated in the dialogic reading experiences in terms of their behaviors in these areas: their attentiveness, the number of times that they respond to questions being asked by the reader, the amount of engagement in literacy activities, and their disposition for learning. These data were collected during each of the weekly sessions, providing a synopsis of the students' literacy behavior from the beginning of the parent partnership to the end.

Journals provided the resources for the data analysis as children responded to prompts about the story they heard during the dialogic reading. Students were asked to write about their pictures. Analysis was based on the work of Ana Teberosky (1990) who says that 4-year-olds involved in writing with pictures will "attempt either an attestation of the objects represented in the picture or a clarification of the information they hold regarding these objects." (p. 54 ) She categorizes their responses according to three different structures: constructions without verbs (usually just a noun:--cookies), verbal-nominal constructions (noun with a relative clause introduced by that — cookies that are hot), and verbal constructions (complete sentence-Cookies burn my tongue.) As the students drew a picture in their journals, I had a conversational interview with them regarding the picture and their writing about the picture using guiding questions (Appendix B) to prompt their thinking. As students responded to the interview questions, I also asked questions about their journal entries. I have included a copy of the check sheet I used to record their responses and a rubric for evaluating the recorded responses. (Appendix C) 
Table 2 Data Collection Process

\begin{tabular}{|c|c|c|c|}
\hline Week & Students & Parents & Teachers \\
\hline \multirow[t]{5}{*}{1} & Preprogram interview & Preprogram interview & Preprogram \\
\hline & Dialogic Reading & Observe Dialogic Reading & interview \\
\hline & observation & Training on the weekly packet & \\
\hline & Journal analysis & activities & \\
\hline & Conversational interview & & \\
\hline \multirow[t]{3}{*}{2} & Packet activities & Working with the packet & \\
\hline & Journal analysis & activities & \\
\hline & & Reflecting on child's response & \\
\hline \multirow[t]{5}{*}{3} & Packet activities & Focus group interview & \\
\hline & Dialogic Reading & Observe Dialogic Reading & \\
\hline & observation & Working with the packet & \\
\hline & Journal analysis & activities & \\
\hline & Conversational interview & Reflecting on child's response & \\
\hline \multirow[t]{3}{*}{4} & Packet activities & Working with the packet & \\
\hline & Journal analysis & activities & \\
\hline & & Reflecting on child's response & \\
\hline \multirow[t]{4}{*}{5} & Packet activities & Focus group interview & \\
\hline & Dialogic Reading & Observe Dialogic Reading & \\
\hline & observation & Working with the packet & \\
\hline & Journal analysis & activities & \\
\hline
\end{tabular}


Conversational interview Reflecting on child's response

6 Packet activities Working with the packet

Journal analysis activities

Reflecting on child's response

$7 \quad$ Packet activities $\quad$ Focus group interview

Dialogic Reading Observe Dialogic Reading

observation Working with the packet

Journal analysis activities

Conversational interview Reflecting on child's response

8 Packet activities Working with the packet

Journal analysis activities

Reflecting on child's response

9 Packet activities $\quad$ Focus group interview

Dialogic Reading Observe Dialogic Reading

observation Working with the packet

Journal analysis activities

Post-program interview Reflecting on child's response

10 Packet activities $\quad$ Working with the packet Post program

$\begin{array}{ll}\text { Journal analysis } & \text { activities }\end{array}$

Reflecting on child's response

Post program interview 


\section{Data Management and Analysis}

Qualitative findings describe academic growth in the following skills required for early literacy acquisition: concepts of print and words, letter identification, and sound classification. Outcomes also assess the impact of parental support (after training) on the child's disposition and progress toward early literacy. According to Creswell (1994, p. 154), "The process of qualitative analysis is based on data reduction and interpretation. The researcher takes a voluminous amount of information and reduces it to certain patterns, categories, or themes and then interprets this information by using some schema." The constant comparison method of data analysis was utilized throughout this study. Merriam (2001, p.179) defines this approach as "the continuous comparison of incidents, respondents' remarks, and so on, with each other. Units of data ... are literally sorted into groupings that have something in common." Interviews were transcribed and documents analyzed with responses and content displayed in appropriate matrices. I have interpreted the data, selectively categorizing findings, systematically developing themes, and utilizing quotes to demonstrate key points. A chart showing how the data was analyzed according to each research question appears in Appendix C. In addition, the pretest and posttest raw scores have been compared and reported along with total growth in skills exhibited through the weekly activity sheets.

\section{Validity and Reliability}

Both of the test instruments were designed to monitor the development of prereading and early reading skills rather than to measure achievement. The reliability 
of the tests was documented by the authors. Marie Clay (2000) provides a number of research studies to document the reliability and validity of her test instrument, but Stallman and Pearson (1990) also provide their support as a result of their review of formal measures of early literacy. The authors write:

We are convinced, based at least in part on our dissatisfaction with what is currently available, that the most productive methods of assessing early literacy lie in individual assessment of children while they are engaged in a literacy activity. . Only those in Marie Clay's battery come close to meeting such a standard. . . we need more work in this area so that we can develop approaches that are even more situated than Clay's. (pp. 41-42)

The DIBELS Home Page (2004) documents the validity and reliability of the instrument:

The measures were developed upon the essential early literacy domains discussed in both the National Reading Panel (2000) and National Research Council (1998) reports to assess student development of phonological awareness, alphabetic understanding, and automaticity and fluency with the code. Each measure has been thoroughly researched and demonstrated to be reliable and valid indicators of early literacy development and predictive of later reading proficiency to aid in the early identification of students who are not progressing as expected. When used as recommended, the results can be used to evaluate individual student development as well as provide grade-level feedback toward validated instructional objectives. 
Merriam (2001) asserts that the researcher assesses a qualitative study by examining its component parts, just as is done in other types of research. This includes addressing issues such as the reliable and valid construction of interviews, proper analysis of documents, and the development of conclusions based upon the data. Creswell (1994) supports this opinion saying, "Determining the accuracy of the account, discussing the generalizability of it, and advancing possibilities of replicating a study have long been considered scientific evidence of a scholarly study." (p. 157) Several strategies suggested by Creswell were utilized to enhance the validity of this study: triangulation, long-term observation, member checks, peer examination, and clarification of the researcher's biases. Triangulation has been utilized in this study to find convergence among qualitative information provided from interviews, observation, and document analysis and quantitative results of testing. The researcher was involved in observations for a ten-week period. I did member checks by asking interviewees and document authors to review and comment on data, interpretation, and results. I also employed peer examination by asking the teachers to comment on emerging findings.

Finally, my assumptions and philosophical orientation, or "the researcher's biases," were identified prior to initiating the study. In particular, I documented these four central assumptions that are the conceptual framework of this study:

1. Quality public preschools should be available to all children.

2. Preschool programs should adopt a curriculum that focuses on providing skills for early literacy. 
3. Partnership with parents is critical in preschool settings.

4. Parental support will have a strong positive impact on early literacy.

Creswell (1994) suggests that statements about the researcher's positions- - the central assumptions, the selection of informants, the biases and values of the researcher - enhance the study's chances of being replicated in another setting. According to Merriam (2001), "the question is not whether findings will be found again but whether the results are consistent with the data collected." (p. 206) She suggests three techniques to ensure that results are dependable:

1. The investigator's position —explains the assumptions and theory behind the study and her position

2. Triangulation - especially in terms of using multiple methods of data collection and analysis

3. Audit Trail—the investigator must describe in detail how data were collected, how categories were derived, and how decisions were made throughout the study.

Within the research design and method sections, I have clarified the assumptions and theory behind the study, identified my biases, and described the basis for selecting site and participants, and explained the methods of data collection.

\section{Limitations}

Limitations of this experimental design may be in the age and experience of the participants. Testing situations are often foreign to four-year-olds, which might skew the results and limit the ability to provide a standard testing environment for each individual. According to the National Institute for Early Education Research (NIEER) 
Early Childhood educators have strong concerns regarding the risks associated with assessing what and how much young children learn. Early education practitioners grapple with the reality that preschoolers are so capable of learning and yet are relatively unreliable — in comparison to older children-in demonstrating how much they learn, especially when given one-size fits all tests. (Barnett, 2004, p.2)

The National Educational Goals Panel (1989) concurs, and recommends both direct and indirect measures to evaluate pre-kindergarten programs. Even using both measures, results are "not accurate enough to make high-stakes decisions about individual children" (p.20). Even though the scores were used as a benchmark rather than a basis for high-stakes decisions, results of the pre and post assessments were not accurate.

Another limitation is evident in the fact that subjects were not randomly assigned. Choosing participants was dependent on willingness of parents to participate in the study. One might deduce that those parents who were willing to participate in a study of this nature are those who were already concerned about providing optimal opportunities for their children to learn to read. Another limitation was the consistency with which parents attended the training sessions and applied the skills and strategies that they learned as they worked with their children (the treatment group) to complete the packet activities and promote early literacy.

Limitations of observations included the possibility that the observer may affect the situation being observed in unknown ways, program staff and participants may 
behave in some atypical fashion when they know they are being observed, and the perception of the observer may distort the data. Observations are also limited in focusing only on external behaviors - the observer cannot see what is happening inside people. In addition, observational data might have been constrained by the limited sample of activities actually observed.

A weakness of the informal conversational interview that was used in this study may have been in the interviewer. Because this approach depends on the conversational skills of the interviewer to a greater extent than do more formal, standardized formats, Patton (2002) says that this style of interviewing may be susceptible to leading questions and biases, especially with novices. The interviewer must be able to interact easily with people in a variety of settings, generate rapid insights, formulate questions quickly and smoothly, and guard against asking questions that impose interpretations on the situation by the structure of the questions. Data obtained from this type of interview can be difficult to pull together and analyze.

The student journals were difficult to analyze because of their personal nature and the bias of the researcher. When considering document analysis, R. Murray Thomas (2003) advises, "The accuracy and comprehensiveness of the results of an analysis are dependent on how well the analyzed documents represent the researcher's field of interest." (p. 60) Conclusions drawn from analyzing preschoolers' journal entries are likely to be highly subjective and must be tied to specific criteria to allow for maximum validity. Finally, the researcher's bias stated in the validity section were likely to have had an effect on the results. 


\section{The Researcher's Role}

Creswell (1994) suggests that the researcher include statements about past experiences that provide familiarity with the topic, the setting, or the informants. I hold a BA degree in Elementary Education and a MA degree in Early Childhood Education, and am currently a doctoral student in Curriculum and Instruction at West Virginia University. I have taught for 28 years in kindergarten, first, and second grades, and for the past five years I have taught in the Education Department at West Virginia Wesleyan College, also serving as Director of Clinical Experiences.

While teaching in the public schools, my bus-time experiences with young children led me to be concerned about the plight of working parents and the hours between the end of the school day and the end of the parents' work day. I became frustrated that very little effort had been made by the school system to respond to the need of these working parents for childcare. Exploring funding opportunities, I wrote a grant to fund an after-school program and initiated the program after receiving grant approval. The positive response to the program was highly consistent, but so was the amount of work to maintain the after-school program in addition to a full-time teaching job. Therefore, I determined that I wouldn't seek additional funding to offer the program another year.

Now that I'm a grandmother of a very precocious little girl who turned five in November, I've become aware of another area in which our government has not responded to societal changes brought about by the increase in the number of working mothers. Most preschools limit their enrollment to children of low-economic status, 
or who have special needs or exhibit other at-risk characteristics. In addition, some private preschools only operate for a few hours a day making it impossible for working parents to transport their children to the program sites. It has been my experience that most parents are eager to give their children a jump-start in their education, but often do not know what strategies or techniques to use to help their children. I wanted to learn how much impact parents who are trained to foster concepts for literacy can have on their preschooler's early literacy acquisition. 


\section{CHAPTER 4: PRESENTATION OF FINDINGS}

The purpose of this study was to describe the impact of parental support on emergent literacy skills in preschoolers. The study examined the development of literacy skills of ten preschoolers from two sites as they worked with their parents for a ten-week period. The parents were asked to attend five training sessions with their children and to spend ten minutes a day for five days a week working on literacy activities in the packets provided at the training. In addition, children were observed as they listened to story books, responded in journals, and worked on related activities at the training sessions. This chapter will review the data for these four research questions:

1. How will participating preschoolers' concepts of print and words change during the course of the family support literacy program?

2. How will the participating preschoolers' ability to identify sound-letter relationships change during the course of the family support literacy program?

3. How will participating preschoolers' acquisition of letter names change during the course of the family support literacy program?

4. In what ways do family literacy training sessions impact the ability of parents to support their preschooler's emergent literacy skills?

\section{Results}

Student achievement throughout the program was examined in terms of progress in the three constructs of early literacy_concepts of words, sound classification, and 
letter identification. Performance in these three areas was recorded five times a week by parents as they did the activities in the take-home packets. Students also took a pretest and a post test which described progress in the three constructs of early literacy. (See Table 3)

Table 3: Pre and Post test results

\begin{tabular}{|c|c|c|c|c|c|c|}
\hline \multirow[t]{2}{*}{ Name } & \multicolumn{2}{|c|}{ Concepts of Print } & \multicolumn{2}{|c|}{ Sound Classification } & \multicolumn{2}{|c|}{ Letter Identification } \\
\hline & Pretest & Posttest & Pretest & Posttest & Pretest & Posttest \\
\hline Cindy & $42 \%$ & $67 \%$ & $31 \%$ & $56 \%$ & $18 \%$ & $15 \%$ \\
\hline Julie & $46 \%$ & $38 \%$ & $19 \%$ & $94 \%$ & $43 \%$ & $50 \%$ \\
\hline Sue & $17 \%$ & $21 \%$ & $25 \%$ & $38 \%$ & $5 \%$ & $4 \%$ \\
\hline Tommy & $38 \%$ & $54 \%$ & $19 \%$ & $44 \%$ & $22 \%$ & $15 \%$ \\
\hline Bradley & $33 \%$ & $58 \%$ & $50 \%$ & $31 \%$ & $0 \%$ & $27 \%$ \\
\hline Linda & $17 \%$ & $58 \%$ & $6 \%$ & $19 \%$ & $16 \%$ & $32 \%$ \\
\hline
\end{tabular}

Additional notes on the pre and post test:

Cindy's mother was present during both the pretest and the post test. Cindy looked to her for evidence of approval as she responded. Her mother indicated that Cindy didn't like the format of the letter identification portion of the weekly activity sheets (which was the same as the format on the tests), so she made flash cards for practice instead. My assumption is that the format affected the way she performed on the post test in this area.

Julie had difficulty maneuvering the index cards to indicate one word, two words, and specific letters in the concepts of print book on the posttest. She was confident in 
her ability to identify the letters and classify the beginning sounds. Sue and Tommy had difficulty paying attention during the posttest. Both were distracted by other things going on around them.

On the pretest, Bradley's score in the area of sound classification was far superior to the others in the program. She indicated that Bradley had been working with a speech therapist for two years and that he was accustomed to working with sounds. She felt as though this emphasis on thinking about sounds had given him a head start on this skill area. Bradley was asleep at naptime when I was scheduled to do the post test. His mother brought him to my office at a later time so that I could do the post test. She was disappointed in his performance on the posttest, but felt that the different environment probably provided distractions that weren't evident in the preschool classroom.

Linda's mom expressed her surprise at the difficulty she had with the initial sound classification portion of the test saying, "The picture cards were her favorite part of the packets; I don't understand why she had so much trouble with this section of the posttest." I responded by indicating that when they worked on the picture cards in the packet, Linda was allowed to name the picture first (for example, one picture could have been either a rat or a mouse) and then to give the beginning sound. The test had a very specific response expected for each picture. One of the pictures was of a bear “cub." Even after I identified the picture as a "cub," Linda gave the beginning sound /b/ for "bear." 
Overall progress on the weekly packets gained from activity sheet information for the 8 weeks between the pretest and post test is charted below for each child.

Following each tables is a summary of information gained through parent interviews before and after the sessions as well as weekly focus group interviews.

Table 4 Cindy

\begin{tabular}{|c|c|c|c|c|c|c|c|c|c|c|c|c|c|c|c|}
\hline \multirow{3}{*}{$\begin{array}{c}\text { Week } \\
1\end{array}$} & \multirow{2}{*}{\multicolumn{5}{|c|}{$\begin{array}{l}\text { Concepts of print /words } \\
\text { Number found /out of }\end{array}$}} & \multirow{2}{*}{\multicolumn{5}{|c|}{$\begin{array}{l}\text { Beginning Consonants } \\
\text { Number found/out of }\end{array}$}} & \multicolumn{5}{|c|}{ Letter Naming } \\
\hline & & & & & & & & & & & & orrec & per & $\min$ & \\
\hline & $3 / 5$ & $4 / 5$ & $5 / 5$ & $5 / 5$ & $5 / 5$ & $8 / 8$ & $8 / 8$ & $8 / 8$ & $8 / 8$ & $8 / 8$ & 25 & 28 & 30 & 35 & 37 \\
\hline 2 & $4 / 5$ & $5 / 5$ & $5 / 5$ & $5 / 5$ & $5 / 5$ & $8 / 8$ & $8 / 8$ & $8 / 8$ & $8 / 8$ & $8 / 8$ & 33 & 33 & 33 & 34 & 35 \\
\hline 3 & $5 / 5$ & $5 / 5$ & $5 / 5$ & $5 / 5$ & $5 / 5$ & $8 / 8$ & $8 / 8$ & $8 / 8$ & $8 / 8$ & $8 / 8$ & 32 & 35 & 37 & 36 & 40 \\
\hline 4 & $5 / 5$ & $5 / 5$ & $5 / 5$ & $5 / 5$ & $5 / 5$ & $8 / 8$ & $8 / 8$ & $8 / 8$ & $8 / 8$ & $8 / 8$ & 32 & 35 & 33 & 35 & 39 \\
\hline 5 & $4 / 5$ & $5 / 5$ & $5 / 5$ & $5 / 5$ & $5 / 5$ & $8 / 8$ & $8 / 8$ & $8 / 8$ & $8 / 8$ & $8 / 8$ & 37 & 40 & 38 & 37 & 40 \\
\hline 6 & $6 / 8$ & $7 / 8$ & $8 / 8$ & $8 / 8$ & $8 / 8$ & $8 / 8$ & $8 / 8$ & $8 / 8$ & $8 / 8$ & $8 / 8$ & 38 & 40 & 40 & 41 & 40 \\
\hline 7 & $5 / 6$ & $6 / 6$ & $6 / 6$ & $6 / 6$ & $6 / 6$ & $8 / 8$ & $8 / 8$ & $8 / 8$ & $8 / 8$ & $8 / 8$ & 36 & 42 & 40 & 41 & 40 \\
\hline 8 & $10 / 1$ & 11 & 13 & 14 & 14 & $8 / 8$ & $8 / 8$ & $8 / 8$ & $8 / 8$ & $8 / 8$ & 35 & 37 & 41 & 40 & 40 \\
\hline
\end{tabular}

Cindy's mom told me that she had been "home-schooling" Cindy since she was two years old. She said that they work about three hours a day and that Cindy had been using a computer for two years. During the pre-session interview, she indicated that most of their work involved reading books (chosen by Cindy) and writing words of her choice as well as doing computer work. After the first week, she said that as a result of the program, "The amount of time and the way I do literacy activities have 
both changed. We spend more time doing the activities. Now I know different ways to teach the sounds of the letters and matching sounds to pictures. I never really worked much with the sounds before-just the letters. I was really surprised at the amount of sounds my child knew." Throughout the program, Cindy preferred to read the books that were in color and to do the literacy games, and she didn't like doing the letter recognition activity. By the end of the program, Cindy's mom said that they had increased the amount of time that they worked on literacy activities and had broadened the types of activities they did. She said that they now make up literacy games and play them often when they work together.

Table 5 Julie

\begin{tabular}{|c|c|c|c|c|c|c|c|c|c|c|c|c|c|c|c|}
\hline \multirow{3}{*}{$\begin{array}{c}\text { Week } \\
1\end{array}$} & \multirow{2}{*}{\multicolumn{5}{|c|}{$\begin{array}{l}\text { Concepts of print /words } \\
\text { Number found /out of }\end{array}$}} & \multirow{2}{*}{\multicolumn{5}{|c|}{$\begin{array}{l}\text { Beginning Consonants } \\
\text { Number found/out of }\end{array}$}} & \multicolumn{5}{|c|}{ Letter Naming } \\
\hline & & & & & & & & & & & & orrec & per & $\min$ & \\
\hline & $2 / 5$ & $2 / 5$ & $2 / 5$ & $3 / 5$ & $3 / 5$ & $8 / 8$ & $8 / 8$ & $7 / 8$ & $8 / 8$ & $8 / 8$ & 28 & 42 & 34 & 42 & 40 \\
\hline 2 & $2 / 5$ & $3 / 5$ & $3 / 5$ & $2 / 5$ & $5 / 5$ & $8 / 8$ & $8 / 8$ & $8 / 8$ & $8 / 8$ & $8 / 8$ & 42 & 41 & 41 & 44 & \\
\hline 3 & $6 / 6$ & $6 / 6$ & $6 / 6$ & $6 / 6$ & $6 / 6$ & $8 / 8$ & $8 / 8$ & $8 / 8$ & & & 40 & 38 & 44 & 42 & \\
\hline 4 & $2 / 10$ & 2 & 4 & 6 & 8 & $7 / 8$ & $8 / 8$ & & $8 / 8$ & $8 / 8$ & 24 & & & & \\
\hline 5 & $4 / 6$ & $4 / 6$ & $5 / 6$ & $6 / 6$ & $6 / 6$ & $8 / 8$ & $8 / 8$ & & & $8 / 8$ & 20 & 49 & 41 & & \\
\hline 6 & $12 / 14$ & 12 & 14 & 14 & 13 & $8 / 8$ & & & $8 / 8$ & & 30 & 35 & & & 38 \\
\hline 7 & $3 / 5$ & $5 / 5$ & $5 / 5$ & $4 / 5$ & $5 / 5$ & $8 / 8$ & & $8 / 8$ & & $8 / 8$ & & 40 & & & \\
\hline 8 & $5 / 5$ & $5 / 5$ & $5 / 5$ & $5 / 5$ & $5 / 5$ & $8 / 8$ & $8 / 8$ & $8 / 8$ & & & & 30 & 33 & & \\
\hline
\end{tabular}

During the pre-program interview, Julie's mom indicated that most of the time they spent on literacy activities was devoted to reading story books of Julie's choice. 
During the program, she indicated that Julie preferred to play the letter recognition games, but didn't like the timed letter recognition sessions because she didn't want to read them from the activity sheet. She was bored with the sound classification activity because, according to her mom, she knew her sounds. Then she started laying out all of the beginning sound picture cards and sorting the ones that start with the same sound. According to her mom, "Julie was more willing to do the activities when she knew I was writing down her 'score.' She talked about key words several times during the day because she didn't want me to put any in the 'wrong' pile." By the last session, she had started finding the key words when they appeared in other books. During the post session interview, Julie's mom told me that they played "key word" games while waiting or when they had free time and didn't have the packets available. 
Table 6 Sue

\begin{tabular}{|c|c|c|c|c|c|c|c|c|c|c|c|c|c|c|c|}
\hline \multirow{3}{*}{$\frac{\text { Week }}{1}$} & \multirow{2}{*}{\multicolumn{5}{|c|}{$\begin{array}{l}\text { Concepts of print /words } \\
\text { Number found /out of }\end{array}$}} & \multirow{2}{*}{\multicolumn{5}{|c|}{$\begin{array}{l}\text { Beginning Consonants } \\
\text { Number found/out of }\end{array}$}} & \multicolumn{5}{|c|}{ Letter Naming } \\
\hline & & & & & & & & & & & & orrec & tper & $\min$ & \\
\hline & $0 / 6$ & $1 / 6$ & $3 / 6$ & $4 / 6$ & $5 / 6$ & $0 / 8$ & $2 / 8$ & $4 / 8$ & $7 / 8$ & $8 / 8$ & 1 & 3 & 4 & 6 & 6 \\
\hline 2 & $2 / 8$ & $3 / 8$ & $5 / 8$ & $7 / 8$ & $8 / 8$ & $4 / 8$ & $5 / 8$ & $6 / 8$ & $8 / 8$ & $8 / 8$ & 2 & 5 & 6 & 7 & 8 \\
\hline 3 & $5 / 5$ & $5 / 5$ & $5 / 5$ & $5 / 5$ & $5 / 5$ & $4 / 8$ & $4 / 8$ & $6 / 8$ & $6 / 8$ & $6 / 8$ & 5 & 5 & 6 & 8 & 10 \\
\hline 4 & $5 / 5$ & $5 / 5$ & $5 / 5$ & $5 / 5$ & $5 / 5$ & $6 / 8$ & $6 / 8$ & $8 / 8$ & $8 / 8$ & $8 / 8$ & 10 & 10 & 11 & 11 & 12 \\
\hline 5 & $3 / 6$ & $3 / 6$ & $4 / 6$ & $5 / 6$ & $6 / 6$ & $6 / 8$ & $6 / 8$ & $8 / 8$ & $8 / 8$ & $8 / 8$ & 10 & 10 & 11 & 12 & 12 \\
\hline 6 & $4 / 6$ & $5 / 6$ & $6 / 6$ & $6 / 6$ & $6 / 6$ & $8 / 8$ & $8 / 8$ & $8 / 8$ & $8 / 8$ & $8 / 8$ & 8 & 9 & 9 & 10 & 11 \\
\hline 7 & $4 / 5$ & $5 / 5$ & $5 / 5$ & $5 / 5$ & $5 / 5$ & $6 / 8$ & $7 / 8$ & $8 / 8$ & $8 / 8$ & $8 / 8$ & 10 & 10 & 12 & 12 & 13 \\
\hline 8 & $5 / 5$ & $5 / 5$ & $5 / 5$ & $5 / 5$ & $5 / 5$ & $6 / 8$ & $7 / 8$ & $8 / 8$ & $8 / 8$ & $8 / 8$ & 13 & 14 & 14 & 15 & 15 \\
\hline
\end{tabular}

Sue was the most immature child in the program. Her younger sister accompanied her to most of the sessions, and she appeared to rely on her for support. During the first session, she spent most of the time on her mother's lap, and even though her mother encouraged her to join the other children, Sue was often reluctant. When I interviewed her before the program began, Sue's mother spoke about her concerns about Sue's maturing level. Her hope was that by participating in the program, Sue would become a more independent worker and more self confident. Sue's mom said that prior to the program, their literacy time was spent reading the books that Sue chose. During the program, Sue enjoyed the packet games the most and always wanted to spend more than the suggested 10 minutes a day. According to her mom, 
Sue liked the books and "seems to be recognizing whole words better than single letters." By the end of the program, Sara's mom was pleased with her progress and was glad to have a variety of activities to use as they worked in the evenings.

Table 7 Tommy

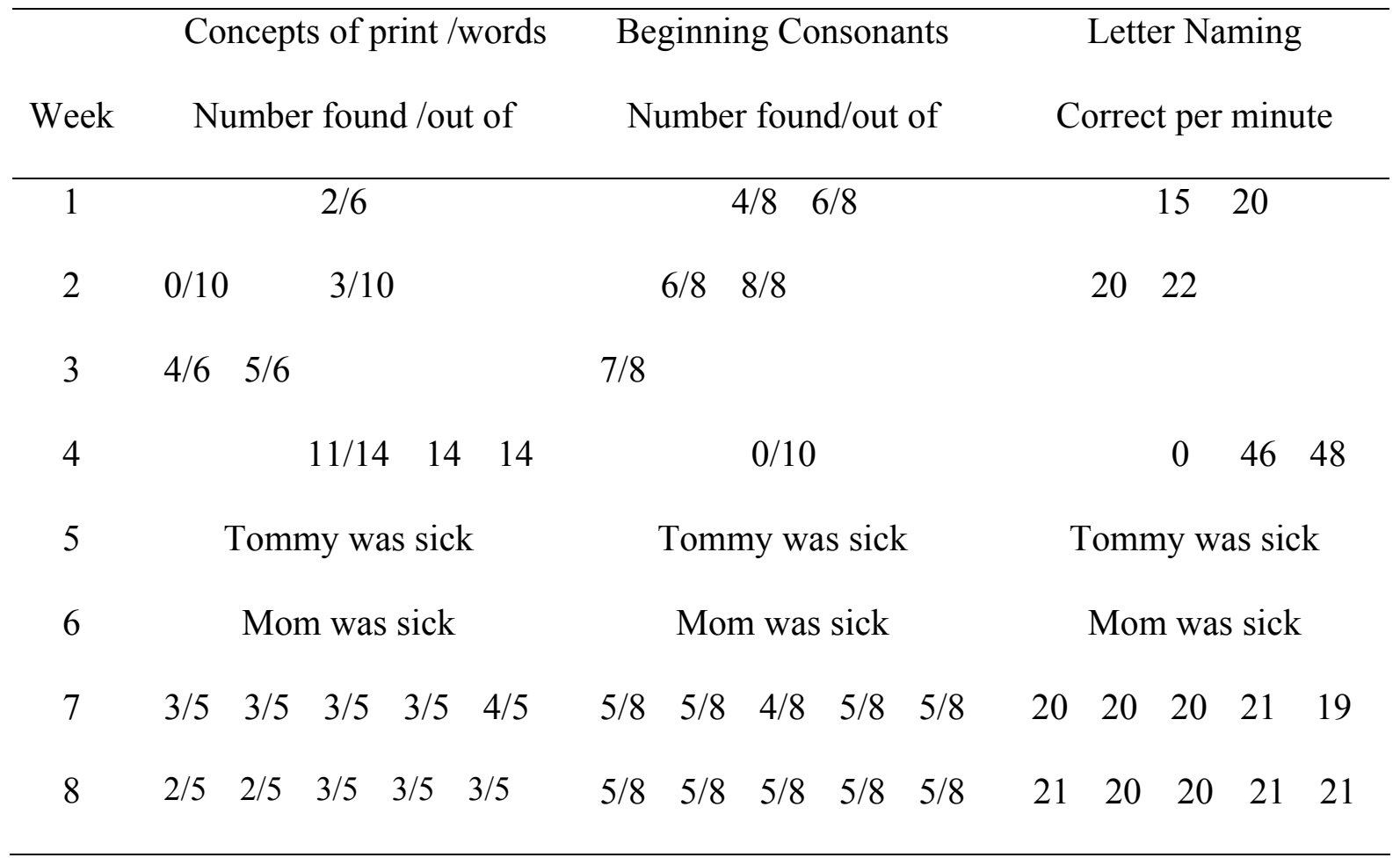

Tommy's mom confided in me at the beginning of the program that she had very little time to devote to helping Tommy with literacy activities in the evenings at home. She has a full-time job and cares for her two deaf parents in addition to her three sons. She said that Tommy was usually reluctant to work with her and was not cooperative when they did work together. During the sessions, she was amazed at the things that Tommy would do while journaling that he wouldn't do for her at home. As a result, his weekly activity sheets revealed more of what he would do than what he could do. In addition, some of the journal entries that he did at home contained 
pictures that were obviously drawn by someone else. During the program, Tommy got glasses, and his mother hoped that his attention to the weekly activities would improve, but she indicated that she didn't see a change. At the end of the program, Tommy's mom said that he was showing more interest in reading, but that he did more for his older brother than he would do for her.

Table 8 Bradley

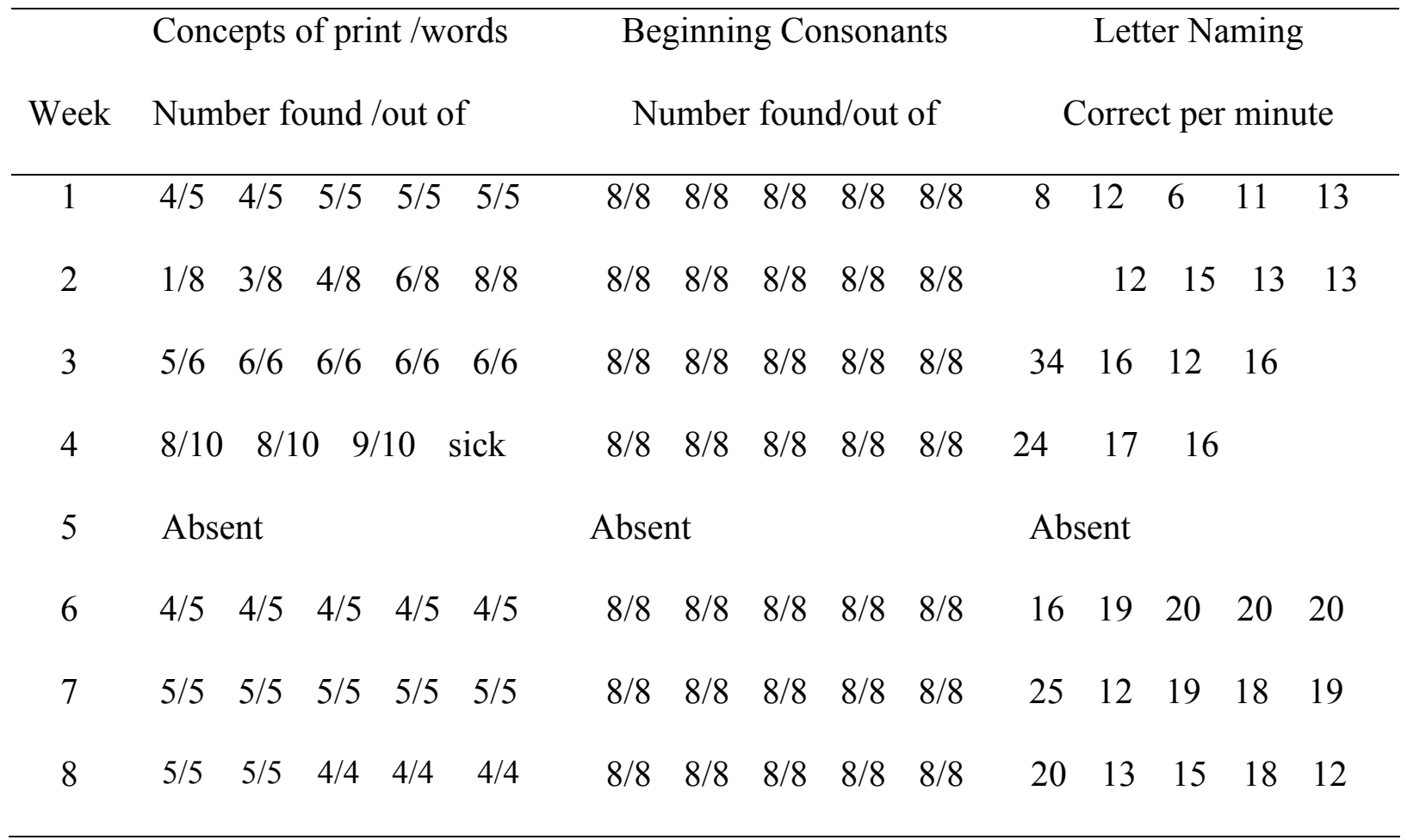

Bradley exhibited an enthusiasm that was unmatched by any other child that was participating in the program. He was the most eager participant in the dialogic reading, and often had to be reminded to move back so that others could see the book. At the beginning of the program, Bradley's mom told me that she already had a "homework" time with her children in the evenings. When Bradley's sister worked 
on some her first grade homework, Mom was anxious to have some activities to offer Bradley. She mentioned that Bradley was more willing to work for others than for family members, but that they had found ways to get him involved using the packet activities. She said that originally he didn't like naming the letters that were listed in rows of twenty, but that they turned it into a competition (complete with ready, set, go) as they timed him for a minute, and he really got excited. She thought that since he worked with a speech therapist already, he had some prior knowledge of sound classification that made the packet activities easy for him. During the program, she appeared to be anxious to compare his progress with that of the other students, asking the parents how their children were doing on some of the activities. At the end of the program, she thought he had made more progress than was indicated by the test.

Table 9 Linda

\begin{tabular}{|c|c|c|c|c|c|c|c|c|c|c|c|c|c|c|c|}
\hline \multirow{3}{*}{$\begin{array}{c}\text { Week } \\
1\end{array}$} & \multirow{2}{*}{\multicolumn{5}{|c|}{$\begin{array}{l}\text { Concepts of print /words } \\
\text { Number found /out of }\end{array}$}} & \multirow{2}{*}{\multicolumn{5}{|c|}{$\begin{array}{l}\text { Beginning Consonants } \\
\text { Number found/out of }\end{array}$}} & \multicolumn{5}{|c|}{ Letter Naming } \\
\hline & & & & & & & & & & & \multicolumn{5}{|c|}{ Correct per minute } \\
\hline & $3 / 6$ & $4 / 6$ & $5 / 6$ & $5 / 6$ & $6 / 6$ & $7 / 8$ & 78 & $8 / 8$ & $8 / 8$ & $8 / 8$ & 21 & 26 & 28 & 27 & 30 \\
\hline 2 & $9 / 14$ & 10 & 11 & 10 & 13 & $8 / 8$ & $8 / 8$ & $8 / 8$ & $8 / 8$ & $8 / 8$ & 32 & 36 & 28 & 35 & 30 \\
\hline 3 & $4 / 5$ & $5 / 5$ & $5 / 5$ & $5 / 5$ & $5 / 5$ & $8 / 8$ & $8 / 8$ & $8 / 8$ & $8 / 8$ & $8 / 8$ & 29 & 33 & 37 & 38 & 34 \\
\hline 4 & $6 / 8$ & $6 / 8$ & $6 / 8$ & $6 / 8$ & $6 / 8$ & $8 / 8$ & $8 / 8$ & $8 / 8$ & $8 / 8$ & $8 / 8$ & 30 & 32 & 34 & 28 & 35 \\
\hline 5 & \multicolumn{5}{|c|}{ absent } & \multicolumn{5}{|c|}{ absent } & \multicolumn{5}{|c|}{ absent } \\
\hline 6 & \multicolumn{5}{|c|}{ Mom had a baby } & \multicolumn{5}{|c|}{ Mom had a baby } & \multicolumn{5}{|c|}{ Mom had a baby } \\
\hline 7 & $4 / 5$ & $4 / 5$ & $4 / 5$ & $5 / 5$ & $5 / 5$ & $8 / 8$ & $8 / 8$ & $8 / 8$ & $8 / 8$ & $8 / 8$ & 27 & 30 & 28 & 31 & 32 \\
\hline 8 & $5 / 5$ & $5 / 5$ & $5 / 5$ & $5 / 5$ & $5 / 5$ & $8 / 8$ & $8 / 8$ & $8 / 8$ & $8 / 8$ & $8 / 8$ & 25 & 24 & 26 & 30 & 32 \\
\hline
\end{tabular}


During the pre-program interview, Linda's mom shared with me that she was concerned that Linda might not have the skills that she needed in order to be successful in kindergarten the next year. She indicated that she had heard stories about requirements that the children should be able to read a certain number of words. During the program, she shared stories about how much Linda was learning, especially in the area of reading and identifying the key words. She said that she now "recognizes words in story books, at the store, and at home." Making the real-life connection with the words in the packet books and activities is a real bonus. Linda's mom had a baby during the fifth week of the program, so Linda missed having the activity results recorded for weeks five and six. At the post-program interview, Linda's mom indicated that she plans to continue working with the packet activities and other books that I provided.

Qualitative information was triangulated through observations, interviews, and analysis of the students' journal entries. Observations took place at the weekly training sessions with a more specific focus on the children's reading behaviors during dialogic reading. Interviews took place with students as they reacted to the story by drawing in their journals, with the teachers at the beginning and end of the program, and with parents. Perhaps the richest information came from the parents. They were interviewed at the beginning and end of the program as well as in a focus group at each training session. In addition, they responded to questions about their child's progress using the daily packet activities on the weekly assessment sheet. 
Journal analysis was done at each session as the students responded to the story that was read. These findings will be explored as they relate to each research question.

Research question 1. How will participating preschoolers' concepts of print and words change during the course of the family support literacy program?

\section{Observations}

After observing students during the five training sessions, a definite improvement in their reading behaviors was noted. During dialogic reading sessions, student performance was evaluated in the following areas: attentiveness, responsiveness, response indicates comprehension, response indicates skill development, enthusiasm. These behaviors were assessed on the basis of 3 being "competent," 2 being "developing," and 1 being "not yet exhibited."(Appendix C) The average score of the students from the first session was 1.9, and from the last session was 2.8. Linda was attentive, but didn't respond in any way during the first session. By the last session, she was volunteering responses that indicated that she comprehended the story. Bradley was responsive from the beginning of the program, and was often so involved that he had to be reminded to back away from the book so that others could have a chance to see the pictures and the words. Some of the students preferred to sit on their mothers' laps as the story was being read while others appeared to be comfortable sitting on the floor with the reader. During one session we had as many siblings listening to the story as we did preschoolers, and the children in the program were more involved when they had a brother or sister beside them. At the Achievement site, the teacher was present during most of the sessions. It was clear 
that if students didn't follow the classroom rules and routines, they'd be corrected by the teacher. This may have eliminated some of the off-task behaviors that might have surfaced otherwise.

\section{Interviews}

\section{Students}

As they were drawing their journal responses, students were interviewed. I asked questions that would lead the children to express their attitudes toward reading. The first question I asked was "How do you feel about reading?" In the beginning, one boy told me that he didn't know how to read, but at the end of the program he responded, "I like to read big books." In response to the second question, "What do you have to do to be a good reader?" a little girl said, "You have to look at the words." Two other students said, "You have to practice." These responses indicate that these students had an awareness of the concepts of print and words. When asked if it is important to be a good reader, most children said "Yes," but Bradley showed a little more insight when he responded, 'I know how to read stop on a stop sign. It's important so cars stop." One comment that showed the most positive development in relation to reading came in answer to the question "What do you like to do when it's a quiet time? At the beginning of the program, Bradley said, "Football with Daddy is fun." At the end of the program, he responded, "Read a hard book."

\section{Teachers}

The teachers of both groups were interviewed both at the beginning and at the end of the program. Mr. Lockney noted that his students were more interested in words at 
the conclusion of the program. He said, "At free time, I find that Bradley and Tommy will be sitting together copying words, writing names, and looking at books." He also noticed that Tommy became more attentive after participating in the program. At the beginning of the program, Sue's teacher told me that Sue showed no interest on her own to initiate reading when there were other things to do, but by the end of the program she was more willing to write her name and tell stories and was more interested in books. Julie's teacher shared that her writing ability blossomed during the program as she became more interested in sounds and sight words and used them in her writing.

Parents

During the focus group interviews, the parents indicated that as a result of the program, children were beginning to make connections between the words in their books and words that appear elsewhere. Linda's mom explained, "We'll be reading and she'll say, 'Look, Mommy, there's the word is, there's the. Let me see how many words I can read."' She said that the program has helped Linda to recognize words in storybooks, at the store, and at home. Julie's mom offered another way to practice the words. "We write words on scrap paper, and I try to remember the words that were on the word cards with the concepts of print book to see if she could remember them and make a connection with the words she knew." In addition to reading and finding isolated words, Cindy's mom reported that Cindy was able to read the books that were in the packets. "Now Cindy wants to read the books to everyone. She calls Grandma on the phone and reads her book of the week. She 
learned to read the Sorry Sam! book the first night. My husband said she just memorized it, so I wrote all the words on paper and took them out of order, and she could still read it. He was amazed. . . Thank you for giving us the materials to teach our children."

The connections that the students made were valuable as they began to make meaning of the words they read. In fact, Julie's mom reported that as they did their daily packet work, Julie began to prefer to work on words rather than letters. Susie's mom replicated this finding on week four when she reported that Susie "seems to be recognizing whole words better than single letters." It's clear that the meaning that's attached to the words made them more relevant to the children than the isolated letters.

\section{Journal Analysis}

Students reacted to the story that they heard by drawing pictures in a journal in response to a prompt. These responses were evaluated on a scale of 3 (competent), 2 (developing), and 1 (not yet exhibited) and included the following behaviors: connection between picture and child's explanation, connection between explanation and "writing," picture/explanation indicates story comprehension, picture includes detail, child elaborates verbally, and response structure (noun, noun + clause, or sentence). An example of the analysis chart and a rubric for assessing responses appears in Appendix C. At each session, students were given a new book to take home with a journaling prompt and were asked to do this journal entry during the week that we weren't in session. Two of the behaviors were evaluated on the entry 
that was drawn at home-picture includes detail and picture indicates story comprehension - but the behaviors requiring a response or verbal explanation were not applicable.

Data analyses of the journal entries were more difficult to tie with change in behavior over the course of the program, but several trends did surface. By the end of the program, all of the students were able to indicate that they comprehended the story through their pictures. In the beginning, some of the students changed their explanation of the pictures they drew each time they talked to a different person. They appeared to think about their pictures and then rethink when they noticed something different about what they had drawn. By the end of the program, students freely explained their pictures as they drew them.

During each journal session, I asked the children to label their pictures. The most striking response was that at the beginning of the program only one of the students was comfortable with "writing" about her pictures or labeling parts of the pictures independently. The others wouldn't write the label without adult assistance or a model of the word to copy. Tommy even took the book after it was read and asked where the word snake was. When shown the word snake, he copied the word down to label his picture of a snake. Sue, the one child who was willing to "write" about her picture independently, drew the most immature pictures of any in the program. Often they were scribbles and squiggles, and she had to explain everything she drew, but she could identify the "words" she had written to name the pictures. This child exhibited immature tendencies throughout the program and was really tied to her 
mother at every session. The teacher and mother had discussed whether retention in preschool might be to her advantage, giving her an opportunity to mature. By the end of the program Cindy and Julie were willing to label the items in their pictures, but wanted help with spelling the words correctly.

As I examined the journal responses over the period of time that the children worked with the program, it was clear that the entries depended on the child's mood at the time. Julie was sometimes not willing to draw a picture, but when she was in the mood, could draw and label detailed pictures. Linda was a quiet little girl and not always responsive during the story reading, but expressed her thoughts well through her pictures. Tommy reluctantly drew his journal entries at the session, but the entries that were done at home had pictures that were drawn by someone else. Bradley's pictures always related to the story, and he could verbally explain what everything was. Sue's pictures were very immature, but she could identify which ones were words. Cindy's pictures contained correctly spelled labels (even a phrase - "getting my hair washed"-with the picture for the prompt "What makes you grouchy?"). She went to her mother to be sure her words were correctly spelled except once when she wrote horse HRCE.

Research question 2. How will the participating preschoolers' ability to identify sound-letter relationships change during the course of the family support literacy program? 


\section{Observations}

During dialogic reading sessions, student observations focused on specific reading behaviors. Although these behaviors weren't directly tied to the student's ability to classify sounds, some of the responses pointed to skill development in this area. For instance, one of the books was a rhyming book. The reader paused when she came to a rhyming word and encouraged students to offer the correct word to complete the sentence. Five of the students were able to do this correctly, indicating skill development in the areas of sound classification and concepts of words.

When Julie and Cindy began to try to label some of their journal drawings, they would look to their mothers for help. It was common for them to ask questions such as this, "What makes the /h/ sound that starts horse?" Sound classification skills were strong in this case, but identifying the alphabet letter that made the sound posed a problem for them.

\section{Interviews}

\section{Students}

Most of the conversation with students about sound classification came as a result of their attempts to label their drawings. It was clear that students were more concerned about accuracy in their writing than they were about getting their point across through identifying what their pictures were about. Cindy drew a picture of a house that had about five faces stuck on the sides. She told me that these were family members looking out of the windows. I asked her to tell me the name of each person in the picture, and then I asked her to write the names beside the faces. I thought that 
since she had written Barbie on some of her other drawings that these shorter names like Bob and Jim might be easier for her to write. She turned to her mother who began to assist her in "sounding out" the names and identifying how to spell them correctly. As the program continued, Cindy became more willing to try to write independently.

\section{Teachers}

Both teachers indicated at the beginning of the program that they spent a large portion of their day working with sound/letter relationships, and both said that students were more interested in sounds as a result of the program. When I asked if students whose parents were involved with the program were more advanced skillwise than the others in the class, both teachers said "No." One of the teachers responded, "The students who are in the program are on about the same skill level as the rest of the class, but I have others in class who are at a higher level than those students in the program.

\section{Parents}

The weekly activity packet contained a set of about 60 cards with a single picture on each. One of the daily activities was for the parents to choose eight of the cards and ask their child to match the picture with a beginning sound voiced by the parent. Parents were asked to record the number of sounds their child matched correctly each time they practiced. When I trained the parents on using the beginning sound picture cards, I cautioned them to make the sound rather than saying the letter when they asked their children to choose the picture that began with a specific sound. After the 
first week of the program, Cindy's mom wrote, "Now I know different ways to teach the sounds of the letters and matching sounds to pictures. I never really worked much with the sounds before- - just the letters." At the next session she said, "It really helps to know what to do at this level. I had always asked Cindy questions like, 'Which picture starts with a B?' but by making the /b/ sound, she really began to pick that up. I've learned how important it is to ask the question the right way. Cindy goes all over the house looking for something that starts with a /b/. We'll be watching TV and she'll say, 'Mommy, let's play a game. Let's see which ones on the screen start with a /b/." She mentioned that Cindy had noticed that Cindy starts with a $c$ but it says /s/ and cat starts with a $c$, but it says $/ \mathrm{k} /$. "She's starting to notice that $c$ makes two different sounds," Mom reported, You can see it light up on her little face when she says, "That starts with the sound of . .."

According to his mother, Bradley learned to do this type of activity with his speech teacher last year when he began his speech sessions. This exposure allowed him to feel experienced when doing the sound classification activity. Julie's mother reported that she has to lay out all 60 of the cards instead of just eight. "Then she finds all the ones that start the same and groups them together."

Julie's mother shared this story, "Julie was having trouble with the word the. I must say it $d u h$ because she kept asking why it didn't start with a $d$. It took me a long time to figure out that I was saying it wrong." These parents were excited about the progress of their daughters, and pleased to know that they could continue to work with them as they explored reading through sound-letter relationships. Trends in the 
quantitative data also suggested that students became more aware of sound classification throughout the time they worked with the program.

\section{Journal Analysis}

As students drew their journal entries, I asked them to describe their pictures as they related to the story that was read. After hearing about the pictures, I asked the students to write the name of several pictures. At the beginning of the program, they were usually unwilling to try, but as they became more familiar with me, they began to make an attempt. However, they often looked to their parents for help with the correct spelling as they labeled their pictures. Journal analyses didn't give a true picture of the students' ability to identify sound-letter relationships.

Research question 3. How will the participating preschoolers' acquisition of letter names change during the course of the family support literacy program?

\section{Observations}

During dialogic reading sessions, student observations focused on specific reading behaviors. These behaviors weren't tied to the student's ability to identify letter names, so no observations were made in this area.

\section{Interviews}

\section{Students}

Most of the interviews took place as the students were drawing. The only time that letter identification took place was when they were labeling their pictures. Often they looked to their parents for support in spelling the words, but as parents gave the correct spelling, the students were able to write the letters that the parents named. 


\section{Teachers}

Both teachers indicated that the students involved in the program were much more interested in identifying and writing letters at the end of the program than they were at the beginning.

\section{Parents}

The weekly packets contained letter identification games and an alphabet book that focused on naming a picture and identifying the beginning letter of the name. Parents were asked to read the book nightly with their children and to play a game if time. After practicing letter identification, parents were instructed to time their children for one minute and see how many letters in a row they could identify. This assessment was in the same format as the pre and post test with the purpose being to familiarize the students with the format and the time constraint.

Parents reported that the children enjoyed playing the letter identification games, but when it was time to see how many letters the children could identify in a minute from the list of letters, the children lost their enthusiasm. This was the least favorite activity overall, and parents began to try different methods of enticing their children to participate. Cindy's mom and Linda's mom made flash cards of the letters and reported that the girls liked that better. Cindy's mom thought it was because the letters were isolated and larger on the cards; however, she also reported, "Cindy would practice her letters on the paper for her daddy and let him time her, but not for me. She likes to use flash cards, but she tells me that she doesn't know them on the paper, and they're the same as the ones on the cards, only smaller. 
For some of the children, the problem with the daily letter identification assessment was the requirement that it must be timed for a minute. Julie's mom said that she would only do it if she wasn't timed. Linda's mom said that she had to hide the fact that she was timing Linda because it made her nervous. However, Bradley's mom said that he loved the competition with the clock. She said, "My husband will have the watch in his hand and say, 'Ready, set, go.' We make a big game of it with cheering and high-fives when we're finished. Bradley is at the point now where he won't do it without being timed and hearing the 'Ready, set, go.'”

Julie's mom shared a story about how Julie's two-year-old brother loved the ABC book. She said that every time she and Julie worked on the packet activities, he'd get the $\mathrm{ABC}$ book out and read. Although he was only saying a few words at this point, he would read some of the pictures aloud and say the letter name like he heard Julie do. She pulled the alphabet book out of the packet and said, "That's why the ABC book is always messy—because he's trying to grab it while we're trying to read it."

According to his mother, Bradley preferred to identify letters in his reading (“There's a B, and it's in my name.”). As he made connections that added relevance to the activity, he began to enjoy it more and to do it more often. He walked into his sister's classroom and said, "Look, Mom, there’s an upper-case R.” "If he sees a letter or a word that he has learned before, he'll point it out to me," commented his mother.

When writing words, Julie has to ask her mom the letters. According to her mom, Julie can usually get the first one right but has to ask for help on the others. Cindy's 
mom described the same behavior in Cindy, but went on to talk about her independent writing. "She wrote a letter to the doctor, 'I (heart) you.' She always makes her $y$ 's backward, but she doesn't want to do it wrong. She also gets the $p$ and $g$ backward. She's afraid to tell you because she doesn't want to get them wrong. I've made the q with a tail on her flash cards, so she can tell the difference then." Both of these children depended on their mothers to help them write correctly and both were reluctant to take a risk and write words to go along with their journal pictures.

Tommy's mom reported that he got glasses during the program and she hoped it would make letter recognition easier for him. She later reported that she didn't see much change because he just refused to try for her. The power of motivation was evident again.

\section{Journal Analysis}

As the children began to label the pictures in their journals, they became more interested in the sound-letter correspondences. They would ask, "What letter makes

the /b/ that starts book?" When told, the students could usually make the letter. They displayed a good grasp of letter recognition skills.

Research question 4. In what ways do family literacy training sessions impact the ability of parents to support their preschooler's emergent literacy skills?

\section{Observations}

Parents watched the dialogic reading at each session, and most acknowledged that although they read to their children every evening, it was often the adult reading and 
the child looking at the pictures. Seeing this approach modeled at each session reminded them of ways that they could encourage their children to interact with the story. Bradley's mom reported that she regularly used this participatory approach, and Bradley was the child who responded without hesitation to the reader at the first session. As stated in the question one data analysis, by the end of the program, on a three-point scale assessing the observed reading behaviors of the students, the average score from the first session was 1.9, and from the last session was 2.8. Students were more responsive, more attentive, and more eager to participate at the end of the program.

\section{Interviews}

\section{Students}

By the end of the program, students brought in things they had made at home with their parents as they were working on their literacy activities. It was clear that parents were extending their literacy activities beyond those in the weekly packet. Cindy was especially proud of pictures she had made by gluing little puffy cut-outs to background pictures she had drawn. She was eager to tell the story that went along with the picture.

\section{Teachers}

According to the teachers, an overwhelming result of the program was that students displayed more interest in words, copying words, writing names, and taking the initiative to engage in literacy activities like reading, drawing, and story telling. 


\section{Parents}

At the beginning of the program, most of the parents were in agreement that they took part in the program in order to find ways to work with their children. One parent responded, "I'm here so that you can learn me how to teach Cassie to read." That parent brought her child to the program for the first session and then didn't come back.

When I asked the parents how they decided what to do when they read or drew with their child, all of them said that they allowed the child to choose the books to read. Most of the parents said that they were comfortable with their knowledge of what their child should be able to do at this age, but Julie's mom wanted ideas for other ways to work with her. Linda's mother was concerned that Linda might not be ready for kindergarten next fall. She said that she'd heard scary stories about how many words children needed to be able to read in kindergarten, and she wanted to do all she could to help her child learn all she needs to know in order to start kindergarten.

Initially, I asked parents how they decided what to do when they worked with their children on literacy activities. The unanimous response was that they read to their children, and they allowed their children to choose the books that they read. One parent responded, "I usually do what I did with my older children—mostly read. I didn't think about working on the sounds. We used to only read with the children." 
Parents reported at the last session that they now had more ideas about how to work with their children. They now do a variety of activities.

According to her mom, for a long time, Cindy didn't like anything but the games and the books that were in color, but she liked to do them over and over again. She didn't like the books with the word cards, but by the end of the program she began to connect the words with the story, and she really liked that. In addition to the packet activities, Cindy's mom talked about how they read together now. She continued, "We read in more detail now. We read the pictures. We guess what's going to happen next. Before, we pretty much read the words and nothing else. Now, she likes to draw picture stories like she did in her journal. I didn't realize how important drawing was."

Parents reported that each time they did an activity, the children became more capable. As they became more capable, they were more motivated to learn. At the end of the program, Bradley's mom reported that he had become more interested in trying to find words that he has learned from the books they read. She said, "Initially, he could read the little packet books, but if I showed him a word card, he couldn't read it. Then I'd match it with a word in the book and he'd know it." Cindy's mom reported that now they make up literacy games and play together. They even went on-line to Starfall.com and did literacy activities. (The website was given on the back of the vowel book in the packet.) Julie's mom shared that Julie wanted to work longer, and her younger brother who was 2 years old wanted to work too. The mom 
was pleased that her little boy could name some of the letters and pictures in the alphabet book and asked him to read them to me.

\section{Journal Analysis}

Over the ten-week period that the program was in session, journal entries became more descriptive and full of detail. The children were more willing to attempt to write the names of the pictures, and although they continued to look to their mothers for spelling support, some were willing to try invented spelling as they responded. For example, Cindy wrote HRCE for horse in one of her last responses. The number of words the children wrote increased as well. In the beginning of the program, Julie would only write one-word responses about her pictures, but at the end, she wrote a complete sentence: "Getting my hair washed makes me grumpy." It was evidenced in the complexity of the drawings and in the descriptions of the students that they experienced a deeper level of story comprehension as they progressed through the program. Students were more focused on representing their comprehension of the story as they drew. They even began to retell the story as they described their journal entries and how they related to the story. Cindy's mom said that as a result of the program, they can no longer just read a book. She explained further, "Now after we've read a book at home, Cindy asks me 'tell me what to draw a picture of like we do at night school.'. . I'm just amazed at the things she's learned." 


\section{Summary of Findings}

This chapter presents the results of the study of a family support emergent literacy program. Data sets include descriptive findings from pretest and post test scores and weekly reports of parents as well as qualitative findings from observations, interviews, and journal analysis. The children in both preschool classes appeared to have equal skill levels on concepts of print and words, on letter identification, and on sound classification. Trends appeared in terms of the number of training sessions that the parents and children attended and the number of days the parents worked with their children on the literacy activities. Data analysis indicated that both of these areas had a positive impact on the children's performance in the skill areas of concepts of print and words, sound classification, and letter identification.

Descriptive data included observations, interviews, and journal analyses. Observations revealed that students were more responsive in discussions about stories being read, and that their responses indicated comprehension of the stories. Students began to use writing more readily as they were asked to label the pictures in their journals, and the pictures they drew were more accurate indications that they understood the main idea of the story. Children's enthusiasm increased as they became familiar with me and comfortable with the routine of the sessions.

Journal analyses revealed that by the end of the program, children were able to draw pictures that demonstrated an understanding of the story that was read. Pictures drawn at the beginning of the program contained less detail and often demonstrated 
lack of focus and no transition with the plot of the story while journal entries later in the program displayed greater comprehension. Children were asked to label their pictures, and their skill progress in the areas of sound-letter relationship and letter identification was evident in their labeling. Journal entries were also evaluated according to the response structure in place (noun, noun + clause, sentence). Oral responses to questions about journal entries progressed from single-word answers to long explanations, often involving a story. Written responses progressed from oneword labels to sentences.

Students, teachers, and parents were interviewed. Teachers noticed increased interest among the children in letter identification and word recognition as well as story reading and writing. Students spoke with pride about their work, and their answers to specific questions revealed an increase in their self confidence and motivation to read. Interviews with parents provided the largest amount of data as they described their evening literacy sessions with their children as well as how their progress impacted their every-day activities. The overwhelming response was that parents thought the literacy sessions and the take-home activities had provided them information and ideas about how to enhance their children's literacy development. One of the parents summarized the impact of the program saying, "It isn't the amount of time, but the way we spend time that has changed since the program started. The activities are more purposeful." 


\section{CHAPTER 5: CONCLUSIONS, IMPLICATIONS AND RECOMMENDATIONS}

"I came so you could learn me how to teach Cassie to read," replied a mother

when I asked what prompted her to take part in the family support literacy program. I had told the parents that we'd work on activities centered around reading and writing, but I hadn't told them that the children would learn to read in the ten-week period.

The program was initiated to answer the following research questions:

1. How will participating preschoolers' concepts of print and words change during the course of the family support literacy program?

2. How will the participating preschoolers' ability to identify sound-letter relationships change during the course of the family support literacy program?

3. How will participating preschoolers' acquisition of letter names change during the course of the family support literacy program?

4. In what ways do family literacy training sessions impact the ability of parents to support their preschooler's emergent literacy skills?

Although none of the literacy skills addressed in these questions will magically allow a child to read, these are all critical skill areas in fostering emergent literacy. The purpose of this study was to describe the impact of parental support on emergent literacy in preschoolers as a result of the training sessions rather than to "learn" the parents to teach their children to read. Results will be interpreted according to each of the research questions.

How will participating preschoolers' concepts of print and words change during the course of the family support literacy program? Parents found that students 
became more familiar with words and more interested in discovering where words appear in printed text. They were able to connect this new knowledge with real life and make it practical. Students enjoyed finding the words they knew in other texts. This skill transferred to the area of writing as well. When asked to label the pictures in their journals, most of the students were willing to write the word only when they were assured that it was written and spelled correctly. Research has demonstrated that children's writing and print awareness develop before formal schooling, much earlier than previously thought. On the basis of their extensive study of preschool children's writing, Harste, Burke, and Woodward (1982) made the following conclusions: written language is learned naturally, children in literate societies are involved at an early age in understanding and controlling print, and children's perceptions of print are organized, systematic, and identifiable.

This perception of an organized, systematic method of writing might explain the reluctance of children to try to write independently. When children focus on the "correctness" of what they write and ask for adult help rather than trying on their own, they eliminate the opportunity for one to determine their stage of developmental spelling and writing. I have found in my experience teaching young children and working with this literacy program that they are reluctant to write a word without being sure of the correct spelling. In their effort to support their children's emergent literacy, parents usually help their children to spell and write words correctly. However, analyzing the child's independent spelling provides insight into the child's knowledge of letter-sound relationships. If a further study of this type were done, 
modeling ways that parents could encourage their children to write on their own would provide more insight into the development of this skill.

I had hoped to use the findings of Ferreiro who studied the development of written representation and found that "3- and 4-year-old children think that the name of the image is written in the letters accompanying a picture. Ferreiro affirms that children at this age even use the term name to refer to the written text. The name would be both the written text and the content that can be attributed to it" (Teberosky, 1990). I encouraged the children to "write about" their pictures or to "name" them, but initially was unsuccessful. Students immediately turned to their parents to ask how to write a word or for help "sounding out" the words that they wanted to write. They were unwilling to take a risk on their own and "write" a word that might not be correctly written. In the beginning, some wouldn't even attempt to write so that I could see if they were able to connect the image with letters accompanying the picture as Ferreiro suggested. I assume that one of two things might have happened. Sometime prior to this experience, the students had determined that there was a right way and a wrong way to write, and they were unwilling to try on their own and risk being wrong. Another possibility might have been that I was a stranger and the children weren't comfortable with me in the teacher role yet and so were reluctant to share any work that might be incorrect.

Sue was the only child who was willing to name her pictures during the first journal activity. According to her teacher, she was the most immature child in the program. Her "writing" was circles and squiggles and was hard to distinguish from 
the pictures; however, Sue could point out each "word" and tell what it said. It is possible that she was still in the stage that Ferreiro was referring to in her study while the others' perceptions had matured to the point that they recognized the difference between pretend writing and the real thing.

How will the participating preschoolers' ability to identify sound-letter relationships change during the course of the family support literacy program? Parents who attended the training became more aware of the importance of emphasizing beginning sounds of words rather than the letter that began the word. Often, parents try to teach their children using the methods and strategies that were used with them when they learned to read, and many did not learn using phonics. Parents indicated that they hadn't thought of focusing on sounds, but that when they used the techniques they learned, they were pleased with the results. Once children learned this skill, they were able to transfer this knowledge to apply it to identifying words according to the phonetic clues.

The National Reading Panel (NRP) (2000) identified phonemic awareness and letter knowledge as the two best school-entry predictors of how well children will learn to read during the first two years of instruction. According to the NRP, there is currently much interest in phonemic awareness training programs because of claims about their value in improving children's ability to learn to read. The NRP findings do not support the conventional wisdom that has suggested that preschool students might not be ready for phonics instruction. Clare Wood (2004) agrees, saying that "there is evidence to support the view that implicit phonemic awareness does occur 
naturally" and that phonemic awareness is observed in pre-school, pre-literate children. (Wood, p. 4) However, Santi, Menchetti, and Edwards (2004) contend that "One of the skills necessary for learning to decode print involves being able to identify the individual sounds, or phonemes, in words. They quote research showing that readers who are considered at risk or instructionally naïve have difficulty in distinguishing sounds on their own and require explicit instruction in these skills." ( p. 190)

The sound classification game that was done as a part of the packet was a basic phonics activity asking students to identify beginning sounds of items on picture cards. Parents were instructed to focus on the sounds that the letters made at the beginning of the word pictures rather than the letter name. Although this is phonemic awareness in the formative stage, it is still an indication of whether the child is conscious of the part that sounds play in word formation. In addition, parents are trained in ways to scaffold their child's progress in learning phonics and provided materials to use as they work with their child.

How will participating preschoolers' acquisition of letter names change during the course of the family support literacy program? Although a little improvement was evident in letter name acquisition, this was the area of the least amount of change. Parents indicated that they had already practiced letter identification skills with their children prior to the program. Educational shows on television and commercial products such as flash cards provide the materials that the parents used to enhance this skill prior to being involved with the program. Parents revealed that when doing 
the packet activities, students read the alphabet book and enjoyed playing the games, but often the skill didn't transfer to the format that was used in the timed test. Gunning (2003) suggests that direct instruction should take place when teaching the alphabet, and that using names is a good way to introduce the alphabet. He shares results of study that revealed that a majority of entering kindergartners (66 percent) can recognize letters of the alphabet by name. According to Wood (2004), "The fact that many children know the names of letters before they go to school would suggest that some tuition in reading skills does take place. The question is, then, can tuition in the alphabetic principle account for the relationship that is observed between phonological awareness and reading ability?" (p. 5) Her findings show no connection between alphabetic knowledge and phonological awareness or literacy attainment.

My assumption is that since letter recognition was a part of the daily curriculum in the preschool classes and because children were exposed to letters through educational television and learning to write their names, children had a basis in this skill before the program started. For this reason, the amount of progress that was noted in letter recognition was not to the extent that was evident in the other areas. However, some of the parents said that their child was more interested in identifying words than letters as a result of the program. This outcome is a sign that students were beginning to attach meaning to their reading, and words transmit meaning better than letters.

In what ways will family literacy training sessions impact the ability of parents to support their preschooler's emergent literacy skills? The most telling results were 
confirmed in this area. I find it interesting that a greater connection existed between the number of days the parents worked with the students and the scores in the areas of concepts of print and sound classification than scores on the letter identification. Information shared by the parents indicated that prior to the program they knew how to foster letter identification through the use of flash cards and identifying letters in names and words before the training sessions began. However, they hadn't thought to focus on the sounds that the letters make or the idea that isolated words can be connected to the print in a story (as was the intent of the concepts of print books in the packet). When parents received the training and the materials to support their preschoolers' literacy skills and then took the time to work with their children, they were able to have a positive effect on their children's performance. Parents who continued with the training sessions and worked with their children on the packet activities during the week saw the most growth. Expressing appreciation for the ideas and activities to use to support their children's literacy skills, parents indicated that they felt more confident in the types of activities that they could now use to support the literacy growth of their children.

After analyzing the data collected through observations, journal entries, and interviews, it was clear that the students developed more confidence in their abilities to perform literary activities over the course of the program. While the behaviors that were observed weren't exactly tied to the development of concepts of print, letter recognition, or sound classification, children's positive attitudes toward reading directly affected each one's performance in all three of the constructs of early 
literacy. According to Don Holdaway (1999), the creator of big books, "If children could work on literature tasks most of the time at a level of success, we would have solved the biggest problem in learning to read and write." Children who feel successful will be far more willing to read and write than those who think they can't read.

In 1998 the National Research Council made a similar statement when they listed these three main reading difficulties in young children:

1. Difficulty with the alphabetic principle

2. Failure to transfer comprehension skills of the spoken language to reading 3. Absence or loss of initial motivation to read They specified that in kindergarten it's more important to build self confidence and motivation than skills. (Snow, Burns, \& Griffin, 1998) I think that the same dynamics worked with the parents that worked with the children. The success that they had doing the literacy activities at home motivated them to continue to spend the time required to do more to foster their children's literacy development. A recent study of eight kindergarten phonemic awareness programs found that supplementary and home enrichment materials were not routinely provided (Santi et al., 2004). Having the materials available and training parents to use them fostered skill development in the area of phonemic awareness among the program participants.

The mother who said "I came so you could learn me how to teach Cassie to read" spoke volumes to me about today's culture and expectations. Parents were told that this would be a ten-week training program with five sessions to be held every other 
week. Weekly packets were given to the parents with ideas and activities with which they could support the literacy of their children. It became apparent that some of the parents were looking for a "quick fix" that would immediately transform their preschoolers into readers. Isn't that symbolic of today's culture? We live in an age of fast food, express lanes, and automation. We want things done now and with as little effort as possible.

\section{Recommendations for Research}

Allington and Wamsley (1995) address this concern in their book (aptly titled) No Quick Fix saying:

An estimated one in four children fail to complete school with adequate literacy abilities. To correct this, we need to come to grips with a number of issues. The first is that we need to take a perspective on literacy difficulties that start well before school and is sensitive to what happens beyond school. For example, we know that children's literacy experiences in the first few years of life play an important part in their eventual literacy success yet few schools are willing to invest time and effort in preschool literacy programs or actively target preschool children whose early literacy experiences are seriously impoverished. There is a legitimate question as to whether schools should be involved in preschool literacy. Our concern is not so much who should be responsible, but rather that all children receive adequate preschool literacy experiences. One of the America 2000 goals is that all children shall come to school ready to learn. ... We need to seize this opportunity and start thinking about what literacy experiences are needed prior to 
formal schooling, and how we are to have children experience them. Second, we need to expand these early literacy programs to target parents and parents-to-be so that at least they know what literacy experiences their children need and have the appropriate materials at hand. We will need many different approaches, but they will all have one thing in common, namely, to ensure that the children themselves are exposed to appropriate literacy experiences before they come to school. Some of these experiences we will try to ensure take place at home; if that does not work, we will have to see that they take place in day care, nursery school, or Head Start settings. (p. 255)

The federal government has started the Early Reading First program which is part of the President's "Good Start, Grow Smart" initiative to address this need. This program was created on January 8, 2002, as a component of the No Child Left behind Act of 2001 to "prepare young children to enter kindergarten with the necessary language, cognitive, and early reading skills for learning success.” (U. S. Department of Education) Program goals include language and literacy activities that support the age-appropriate development of oral language, phonological awareness, print awareness, and alphabetic knowledge. These skills are the same ones that were the focus of the early literacy parental support program. The drawback is that the Early Reading First program was designed to serve only children from low-income families. 
Implications for Practice

This leads to my first recommendation, that family literacy training sessions be offered as a part of the preschool program within the public schools and be available to everyone regardless of income level. Often, parents will view training sessions as a priority if they're connected with the school system rather than being offered as a voluntary program through another person or agency. However, as indicated earlier, a majority of families of preschool-age children have both parents working outside the home. If training were offered during the school day, a number of parents would be prohibited from participating because of work obligations. At the same time, parents who work during the day need the evening hours to maintain the household and complete chores that can't be done during the day, making evening hours valuable. If the packet activities were a requirement of the preschool program, ten minutes of time each night would allow parents to reinforce the literacy skills that are taught during the school day; parents might be more intentional about doing them with their children.

Parents who worked with the family support literacy program were disappointed when it ended. Several of them asked if a summer program would be available or if we could continue the sessions in the fall. All of the parents asked to keep the activity packets so that they could continue to work with their children. In fact, as the fall school term began, one of the parents referred to me a mother who was new to the community. This mother called to see if I could offer any suggestions for an affordable preschool class for her child. She indicated that she had worked prior to 
moving into the area, but now was unable to work because of child care issues. She pointed out the fact that her brother's family was receiving government-financed child care and preschool opportunities even though his family was in a higher economic bracket than hers. She said that he and his wife had learned how to "take advantage of the system" by establishing an at-home buying and selling business using the Internet and not reporting their income. This mother felt that she was being penalized for working outside the home and being honest about their income because no affordable preschool programs were available to her. As I mentioned earlier, I think that our school systems need to respond to societal changes and offer universal preschool programs. I would suggest that this study be replicated, but in some way be more tied to the school curriculum so that it might be available to everyone, and not just those families that qualify for the government programs.

Research has shown that the depth of children's attitudes and beliefs about themselves determines how they will make sense of and employ literacy. The most common way that children are impacted is through peers and families (Neuman \& Dickinson, 2001). Barbara Wasik and her colleagues studied family literacy programs and the complex issues that surround such programs. They found that providing an intense program, offering direct child services, and coaching parents to create interventions are consistently important aspects of family literacy programs (Wasik, Dobbins, \& Herrmann, 2001). These services were all offered as a part of the family support literacy program; however, I would recommend a longer duration for the program in a new study in order to strengthen its intensity and impact. 
Holly Kreider (2002), a researcher for the Harvard Family Research Project, presents "evidence that family involvement in young children's education may contribute not only to a smooth transition to elementary school for children, but also for parents, by helping to prepare them for later involvement in their children's learning." (p.1) She lists research studies that suggest that family involvement in preschool education can boost young children's academic success and might promote parent involvement throughout children's schooling. Findings suggest that early childhood programs may help set the stage for strong partnerships across families and between families and schools. She suggests that an implication for practice would be to continue early childhood parent involvement programs in order to replicate these positive results.

The National Research Council released its own report on Preventing Reading Difficulties in Young Children emphasizing the critical importance of diverse forms of support for children's early literacy, including not only phonemic awareness but also meaningful literacy events (Snow, Burns, \& Griffin, 1998). The family support literacy program offered meaningful literacy events as children participated in dialogic reading of storybooks, journaling, and related activities. Parents were trained to foster phonemic awareness, concepts of print and words, and letter recognition skills and were provided materials to use as they worked with their children. Research has shown that four major weaknesses were found in phonemic awareness instructional materials. Two of those weaknesses are: first, that all of the materials needed for instruction were not routinely provided and second that supplementary and 
home enrichment materials were not routinely provided. (Santi et al, 2004) The weekly packets that were used at home during the early literacy program met these needs allowing parents to provide instruction to their children in the three constructs of early literacy. An additional recommendation for practice is that parental involvement programs provide these necessary resources.

Parents attending the sessions with their children were able to observe effective read-aloud techniques. According to Leseman and deJong (1998), parents' ways of interacting with their children are determined by cultural factors. For example, some parents may read in an authoritative style and fail to interact with their child. The modeling done at the training sessions gave parents strategies to use and examples to follow as they guided their children through literacy activities.

\section{Recommendations for Research}

Throughout most of the $20^{\text {th }}$ century, the how of literacy entailed formal reading instruction beginning at age six. This practice was associated with the age of compulsory schooling and based on the belief - supported by the 1930's child study and testing movements - that a mental age of 6.5 years is associated with better reading progress than what occurs when instruction begins at younger ages. Challenges to this notion were first initiated when researchers began to suspect that the onset of reading is more a function of instructional strategy than child age. Research on early readers - young children learning to read without any type of formal instruction — eventually shifted the discussion from identification of the precise instructional strategy or time when children are "ready' to read to an interest 
in the processes by which children's literacy skills emerge. (New, 2001) In other words, "literacy begins at birth, is ongoing, and is influenced and interpreted by the surrounding sociocultural context” (Neuman \& Roskos, 1998). A family support literacy program would help families understand the literacy process and provide techniques that can be used to scaffold children through the process. Since I wasn't able to use statistical methods, I would recommend replicating this study with a larger population so that a treatment group could be compared with a control group to see if scaffolding by parents led to development of skills.

Allington and Wamsley (1995) agree that we "cannot continue to simply fine-tune existing programs and practices in order to address the literacy learning difficulties many children now experience in our schools" (p. 259). They suggest that we "expand our horizons and think about restructuring beyond the normal school day. These so-called extended -time efforts might involve before- or after-school activities, Saturday school, or summer school." I suggest that they might also involve training sessions for parents because of the stability that is obtainable through using the same approach at home and at school. The Harvard Family Research Project has also recommended further research of family involvement programs to see if results confirm their initial findings which suggest that early childhood programs may help set the stage for strong partnerships across families and between families and schools.

If we're "leaving no child behind," and if all students are to reach the proficient level in reading/language arts by the 2013-2014 school year as the No Child Left Behind legislation specifies, then schools need to take the initiative to meet this goal. 
I recommend that public preschools be available to everyone who desires to have their four-year-olds involved. According to a NIEER Policy Brief (2004), providing free public preschool to all children could be the smartest and most cost-effective way to reach children who need early enrichment programs the most. Some research suggests that disadvantaged children may make bigger gains in socio-economically mixed programs than they do in classrooms filled with children who are at risk of school failure. Further research should be done comparing the benefits of universal preschools with that of targeted programs.

Head Start is now mandated to three performance standards that require that children develop print and numeracy awareness (more specifically, that they can recognize a word as a unit of print, identify at least ten letters of the alphabet, and associate sounds with written words), understand and use an increasingly complex vocabulary, and develop and demonstrate an appreciation of books (Gunning, 2005). I recommend that these three goals should be expected of all children entering kindergarten and that all children deserve a "head start" toward these standards. I also suggest that training parents in how to support the literacy efforts of their preschool children will pay dividends in the long term success of the children. 


\section{References}

Adams, M. (1990). Beginning to read: Thinking and learning about print. Cambridge, MA: MIT Press.

Allington, R. \& Walmsley, S. (Eds.). (1995). No Quick Fix Rethinking Literacy Programs in America's Elementary Schools. New York: Teachers College Press.

American Federation of Teachers. (2002, Dec.). At the starting line: Early childhood education programs in the 50 states. Retrieved July 28, 2003, from http://www.aft.org/edissues/downloads?EarlyChildhoodreport.pdf.

Association for Childhood Education International. (2000-2002). Global guidelines for early childhood education and care in the 21 st century. Retrieved June 28 , 2003, from http://www.acei.org/wguides.htm.

Banks, R. (2001). The early childhood education curriculum debate: Direct instruction vs. child-initiated learning. Frequently Requested Information. ERIC Digest. Champaign, IL: ERIC Clearinghouse on Elementary and Early Childhood Education. Retrieved July 28, 2003, from http://ericeece.org/faq/preshcoolcurr.html.

Barnett, S. (2004, June/July). Testing and protesting preschool test taking. Preschool matters. 2(3) 2. A Publication of the National Institute for Early Education Research.

Bass, E. (1998, winter). Early childhood education: Part of the NCA family? NCA Quarterly. 72(3) 411-16. 
Begley, S. (1995). Your child's brain. Newsweek. 127, 56-62.

Bredekamp, S. \& Copple, C. (Eds.). (1997). Developmentally appropriate practice in early childhood programs. Washington, DC: National Association for the Education of Young Children.

Bruner, J. (1960). The process of education. Cambridge, MA: Harvard University Press.

Bruner, J. (1985). Vgotsky: A historical and conceptual perspective. In J. Wertsch (Ed.), Culture, communication, and cognition: Vygotskian perspectives (pp. 21-34). New York: Cambridge University Press.

Bush, G. (2002, Jan.). Good start, grow smart: The Bush administration's early childhood initiative. Retrieved July 25, 2003, from http://www.whitehouse.gov/infocus/earlychidlhood/sect 1.html.

Cambourne, B. \& Turbill, J. (1987). Coping with chaos. Maryborough, Vic: Australian Print Group.

Chugani, H. (1998). A critical period of brain development: Studies of cerebral glucose utilization with PET. Preventive Medicine. 27, 184-88.

Clay, M. (2000). Concepts about print. Auckland, New Zealand: Heinemann. Clay, M. (1979). Reading: The patterning of complex behavior. Portsmouth, NH: Heinemann.

Committee for Economic Development. (2002). Early education project: Preschool for all: Investing in a productive and just society. A statement on national policy by the Research and Policy Committee of the Committee for Economic 
Development. Retrieved August 8, 2003, from

http://www.ced.org/projects/prek.shtml.

Creswell, J. (1994). Research design: Qualitative and quantitative approaches.

Thousand Oaks, CA: Sage Publications.

DIBELS Home Page. (2004). Retrieved November 23, 2004 from

http://dibels.uoregon.edu.

Edwards, P. (1999). A path to follow: Learning to listen to parents. Portsmouth, NH: Heinemann.

Edwards, P. (1989). Supporting lower SES mothers attempts to provide scaffolding for book reading. In J.B. Allen \& J. M. Mason (Eds.), Risk makers, risk takers, risk breakers: reducing the risks for young literacy learners. pp. 222250. Portsmouth, NH: Heinemann.

Elkind, D. (1981). Children and adolescents. Oxford: Oxford University Press.

Fears, L. (1999). A cozy spot of their own [Special issue]. Parenting, p. 11-19.

Ferreiro, E. (1990). Literacy development: Psychogenesis. In. Y. Goodman (Ed.) How children construct literacy. (pp. 12-25). Newark: International Reading Association.

Gesell, A. (1940). The first five years of life: A guide to the study of the preschool child. New York: Harper.

Glasser, W. (1969). Schools without failure. New York: Harper \& Row. 
Goffin, S. (2003). NAEYC Commission seeks comments on early childhood program standards. Young Children. Retrieved July 28, 2003, from http://www.naeyc.org/resources/journal.

Good, R. \& Kaminski, R. (Eds.). (2002). Dynamic Indicators of Basic Early Literacy Skills $\left(6^{\text {th }}\right.$ ed.). Eugene, OR: Institute for the Development of Educational Achievement. Retrieved August 26, 2003, from http://dibels.uoregon.edu.

Gottfried, A., Fleming, J. \& Gottfried, A. (1998). Role of cognitively stimulating home environment in children's academic intrinsic motivation: A longitudinal study. Child Development. 69(5) 1448-60.

Gronlund, G. (2001). Rigorous academics in preschool and kindergarten?: Yes! Let me tell you how. Young Children. 56(2) 42-43.

Gunning, T. (2005). Creating Literacy Instruction for All Students. $5^{\text {th }}$ ed. New York: Pearson Education, Inc.

Hancock, L. (1995). Why do schools flunk biology? Newsweek. 127(7), 58-59.

Harste, J., Burke, C. \& Woodward, V. (1982). Children's language and world: Initial encounters with print. In J. Langer \& M. Smith-Burke (Eds.), Reader meets author: Bridging the gap. (pp. 105-131). Newark DE: International Reading Association.

Heath, S. (1982). What no bedtime story means: Narrative skills at home and school. In C.A Ferguson and S.B. Heath (Ed.) Language in the USA.. Cambridge: Cambridge University Press.

Holdaway, D. (1999). Northeast Reading Recovery Fall Conference, Boston, Mass. 
Johnson, T. \& Louis, D. (1987). Literacy through literature. Portsmouth, NH: Heinemann.

Jordan, G., Snow, C., \& Porche, M. (2000). Project EASE: The effect of a family literacy project on kindergarten students' early literacy skills. Reading Research Quarterly. 35(4), 524+.

Katz, L. (1999). Curriculum disputes in early childhood education. ERIC Digest. Champaign, IL: ERIC Clearinghouse on Elementary and Early Childhood. Education. (ERIC Document No. ED430735).

Katz, L. (1995).Talks with teachers of young children: A collection. Norwood, NJ: Ablex Publishing Corporation.

Klein, L. (2002, October). Positive social-emotional development creates strong foundation for school achievement. National Center for Children in Poverty Newsletter. Retrieved September 12, 2002, from http://www.nccp.org/pub fal02h.html.

Kotulak, R. (1996). Inside the brain: Revolutionary discoveries of how the mind works. Kansas City, MO: Andrews McMeel.

Kreider, H. (2002, April).Getting parents "ready" for kindergarten: The role of early childhood education. Harvard Family Research Project. Retrieved November 22,2004 from http://www.gse.harvard.edu/hfrp/content/proects/fine/resources/research/kreider.doc. Learning to read and write: Developmentally appropriate practices for young children. A joint position statement of the International Reading Association 
and the National Association for the Education of Young Children, adopted 1998. (1998, October) The Reading Teacher. 52(2).193-216.

Leseman, P. \& deJong, P. (1998). Home literacy: Opportunity, instruction, cooperation and social-emotional quality predicting early reading achievement. Reading Research Quarterly, 33, 294-318.

Leslie, L., \& Allen, L. (1999). Factors that predict success in an early literacy intervention program. Reading Research Quarterly, 34, 404-424.

Lofland, J. (1971). Analyzing Social Settings. Belmont, CA: Wadsworth.

Lonigan, C. \& Whitehurse, G. (1998).Relative efficacy of a parent and teacher involvement in a shared-reading intervention for preschool children from lowincome backgrounds. Early Childhood Research Quarterly, 13, 262-290.

Mason, J. \& Shobha, S. (1993). Emerging literacy in the early childhood years: Applying a Vygotskan model of learning and development. In Bernard Spodek (Ed.), Handbook of research on the education of young children. (pp. 137-150). New York: Macmillan.

McCarthy, D. (1930). The language development of the pre-school child. Minneapolis, MN: University of Minnesota Press.

Merrow, J. (2002, Oct. 6). The promise of preschool a documentary which aired on PBS's Frontline. Text retrieved July 28, 2003, from http://www.pbs.org/merrow/tv/transcript.

Merriam, S. (2001). Qualitative research and case study applications in education. San Francisco: Jossey-Bass Publishers. 
Moore, E. (1960). Increasing parental involvement as a means for improving our nation's schools. (Report No. PSO19174). Washington, DC: National Black Child Development Institute. (ERIC Document Reproduction Service No. ED $32232)$.

National Education Association. (1990). Early childhood education and the public schools. Washington, DC: National Education Association.

National Educational Goals Panel. (1989). Principles and recommendations for early childhood assessment. Washington, DC: Author.

National Reading Panel (2000, April). Findings and determinations of the National Reading Panel by topic areas. In Report of the National Reading Panel: Teaching children to read (Alphabetics). Retrieved September 22, 2002, from http://www.nichd.nih.gov/publications/nrp/findings.htm.

Nash, M. (1997, February 3). Fertile Minds. [Special Report] Time, 149, 1-8.

Neuman, S. and Dickinson, D. (2001). Handbook of Early Literacy Research. New York: The Guilford Press.

Neuman, S. \& Roskos, K. (Eds.). (1998). Children achieving; Best practices in early Literacy. Newark, DE: International Reading Association.

New, R. (2001). Early Literacy and Developmentally Appropriate Practice: Rethinking the Paradigm. In Susan Neuman \& David Dickinson (Eds.) Handbook of Early Literacy Research. (pp. 245-262). New York: The Guilford Press. 
Nieer Policy Brief. (2004, June/July). Should the U.S. have preschool for all?

Potential win-win for kids, taxpayers. Preschool matters. 2(3) 4-7.

Nunnally, J. \& Bernstein, I. (1994). Psychometric Theory, $3^{\text {rd }}$ Ed. New York: Mc-Graw-Hill.

Office of Educational Research and Improvement, (1996). Building knowledge for a nation of learners. Washington, D.C: U.S. Department of Education.

Office of Educational Research and Improvement. (1996). Years of promise: A comprehensive learning strategy for America's children. Washington, D.C.: U.S. Department of Education.

Patton, M. (2002). Qualitative research \& evaluation methods, $3^{\text {rd }}$ Edition. Thousand Oaks, CA: Sage.

Phillips, W. (1997). The smartest thing you can do for your baby. Parenting. 107-08. Purcell-Gates, V. (1995). Other people's words: The cycle of low literacy. Cambridge, MA: Harvard University Press.

Ramey, C. (1999). Abecedarian preschool treatment effects. Presentation retrieved on July 28, 2003, from http://che.georgetown.edu/presentations/csrameyb.pdf

Renkl, M. (1999). Read all about it! [ Special Issue] Parenting. 48-50.

Roberts, J. \& Burchinal, M. (2001). The complex interplay between biology and environment: Otitis Media and mediating effects on early literacy development. In S. B. Neuman and D. K. Dickinson (Eds.), Handbook of Early Literacy Research. New York: The Guilford Press. 
Santi, K., Minchetti, B. \& Edwards, B. (May/June 2004). A comparison of eight kindergarten phonemic awareness programs based on empirically validated instructional principles. Remedial and Special Education. 25(3), 189-96.

Senechal, M. \& Lefevre, J. (2002). Parental involvement in the development of children's reading skill: A five-year longitudinal study. Child Development. 73(2), 445-461.

Snow, C., Burns, M., Griffin, P. (Eds.). (1998). Preventing Reading Difficulties in Young Children. Committee on the Prevention of Reading Difficulties in Young Children, National Research Council.

Sousa, D. (1998, December 16). "Is the fuss about brain research justified?" Education Week. p. 35.

Stahl, S. \& Murray, B. (1997). Defining phonological awareness and its relationship to early reading. Journal of Educational Psychology 86(2):221-34.

Stallman, A. \& Pearson, D. (1990). Formal measures of early literacy. In L. Morrow and J. Smith (Eds.), Assessment for Instruction in Early Literacy. Englewood Cliffs, NJ: Prentice-Hall.

Stanovich, K. (1994). Romance and Reality. The Reading Teacher. 47:280-91.

Stevens, J., Hough, R. \& Nurss, J. (1993). The influence of parents on children's development and education. . In Bernard Spodek (Ed.), Handbook of research on the education of young children. (pp. 137-150). New York: Macmillan.

Teberosky, A. (1990). The language young children write: Reflections on a learning situation. In. Y. Goodman (Ed.) How children construct literacy. (pp. 45-58). 
Newark: International Reading Association.

Tolchinsky, L. (1990). Literacy Development and pedagogical implications:

Evidence from the Hebrew system of writing. In. Y. Goodman (Ed.) How

children construct literacy. (pp. 26-44). Newark: International Reading Association.

Thomas, R. (2003). Blending qualitative \& quantitative research methods in theses and dissertations. Thousand Oaks, CA: Corwin Press.

Turner, P. \& Hamner, T. (1994). Child development and early education: Infancy through preschool. Needham Heights, MA: Allyn and Bacon.

U.S. Census Bureau. (2001). Statistical abstract of the United States: $2001\left(121^{\text {st }}\right.$ ed.). Washington, DC: Author.

U.S. Department of Education. (n.d.). Student Achievement and School Accountability Programs: Early Reading First. Retrieved September 21, 2004 from http://www.ed.gov/print/programs/earlyreading/index.html.

Venezky, R. (1975). The curious role of letter names in reading instruction. Visible Language. 9(1): 7-23.

Vygotsky, L. (1983). School instruction and mental development. In M. Donaldson, R. Grieve, \& C. Pratt (Eds.), Early childhood development and education: Readings in psychology (pp 263-269). New York: Guilford Press.

Vygotsky, L. (1978). Mind in Society. Cambridge, MA: Harvard University Press. Vygotsky, L. (1929). The problem of the cultural development of the child. Journal of Genetic Psychology, 26, 415-434. 
Walsh, D., Price, G. \& Gillingam, M. (1988). The critical but transitory importance of letter naming. Reading Research Quarterly 23: 108-22.

Wasik, B. (2001, January). Teaching the alphabet to young children. Young Children. 56(1) 34-40.

Wasik, B., Dobbins, D. \& Herrmann, S. (2001). Intergenerational family literacy: Concepts, research, and practice. In S. B. Neuman and D. K. Dickinson (Eds.) Handbook of Early Literacy Research. New York: The Guilford Press.

Whitehurst, G. (1992). How to read to your preschooler. Hartford Courant. Retrieved at http://www.whitehurst.sbs.sunvsb.edu/pubs/ctread.htm.

Winter, M., \& Roluse, J. (1990). Fostering intergenerational literacy: The Missouri parents as teachers program. Reading Teacher, 43(8), 382-387.

Wood, C. (Feb. 2004). Do levels of preschool alphabetic tuition affect the development of phonological awareness and early literacy? Educational Psychology. 24(1). 1-11.

Wright, K. (1997, October). Babies, bonds, and brains. Discover. 18: 75-78. 


\section{Appendix A}

\section{Concepts About Print Score Sheet}

Figure A1

Concepts About Print Score Sheet

Name:

Age:

Site:

\begin{tabular}{|c|c|c|c|}
\hline Pretest & Posttest & Item/page number & Comment \\
\hline & & 1. Front of book/cover & \\
\hline & & 2. Print contains message/2-3 & \\
\hline & & $\begin{array}{l}\text { 3. Where to start } / 4 /-5 \\
\text { 4. Which way to } g \circ / 4-5 \\
\text { 5. Return sweep to left/4-5 } \\
\text { 6. Word-by-word matching/4-5 }\end{array}$ & \\
\hline & & 7. First and last concept/6 & \\
\hline & & 8. Bottom of picture/7 & \\
\hline & & $\begin{array}{l}\text { 9. Begins bottom line, top OR turns } \\
\text { book/8-9 }\end{array}$ & \\
\hline & & 10. Line order altered/10-11 & \\
\hline & & $\begin{array}{l}\text { 11. Left page before right/ } 12-13 \\
12 . \text { One change in word order } / 12-13 \\
13 . \text { One change in letter order/12-13 }\end{array}$ & \\
\hline & & $\begin{array}{l}\text { 14. One change in letter order } / 14-15 \\
15 . \text { Meaning of a question mark/14-15 }\end{array}$ & \\
\hline & & $\begin{array}{l}\text { 16. Meaning of full stop (period)/16-17 } \\
\text { 17. Meaning of comma/16-17 } \\
\text { 18. Meaning of quotation marks/16-17 } \\
\text { 19. Locates specified letter/16-17 }\end{array}$ & \\
\hline & & 20. Reversible words was, no/18-19 & \\
\hline & & $\begin{array}{l}\text { 21. One letter: two letters/ } 20 \\
\text { 22. One work: two words/ } 20 \\
\text { 23. First and last letter of word/20 } \\
\text { 24. Capital letter } / 20\end{array}$ & \\
\hline & & Total score out of 24 & \\
\hline
\end{tabular}

Dynamic Indicators of Basic Early Literacy Skills $6^{\text {th }}$ Ed. Benchmark 1

\begin{tabular}{|r|c|l|l|}
\hline Pretest & Posttest & \multicolumn{1}{|c|}{ Item/per minute } & Comment \\
\hline$/ 16$ & $/ 16$ & Initial Sound Fluency (sounds per min.) & \\
\hline$/ 100$ & $/ 100$ & Letter Naming Fluency & \\
\hline
\end{tabular}

This score sheet was adapted to include the items on Marie Clay's Concepts About Print test and the sections of the DIBELS test that indicated student skills in sound classification and letter identification. Permission to use the tests and the related score sheets as well as a copy of a score sheet from which this sheet was modeled follows. 
Figure A2

\section{Concepts About Print Score Sheet Copyright Permission}

Published by Heinemann Education, a division of Reed Publishing (NZ) Ltd, 39 Rawene Road, Birkenhead, Auckland, New Zealand. Associated companies, branches and representatives throughout the world.

In the United States: Heinemann, a division of Reed Publishing (USA) Inc. 361 Hanover Street, Portsmouth, NI 03801-3912.

This book is copyright. Except for the purpose of fair reviewing, no part of this publication may be reproduced or transmitted in any form or by any means, electronic or mechanical, including photocopying, recording, or any information storage and retrieval system, without permission in writing from the publisher. Infringers of copyright render themselves liable for prosecution.

ISBN 0868632988 (NZ)

Library of Congress Cataloging-in-Publication Data

CIP data is on file with the Library of Congress.

ISBN 0325002371 (USA)

(1) 2000, Marie M. Clay

First Published 2000

Reprinted 2000 (twice)

Printed in China

\section{Cover : Brenda Cantell}

The pronouns she and he have often been used in this text to refer to the teacher and the child respectively. Despite a possible charge of sexist bias it makes for clearer, easier reading if such references are consistent.

The author and publishers permit the following observation record sheets to be copied by teachers for use with children. The commercial use of any of these observation record sheets is strictly prohibited.

- Concepts About Print Score Sheet - Foliowo Me, Moon/No Shoes page 14

- Concepts About Print Score Sheet - Sand/Stones page 30 
Figure A3

Concepts About Print Score Sheet

\section{CONCEPTS ABOUT PRINT SCORE SHEET}

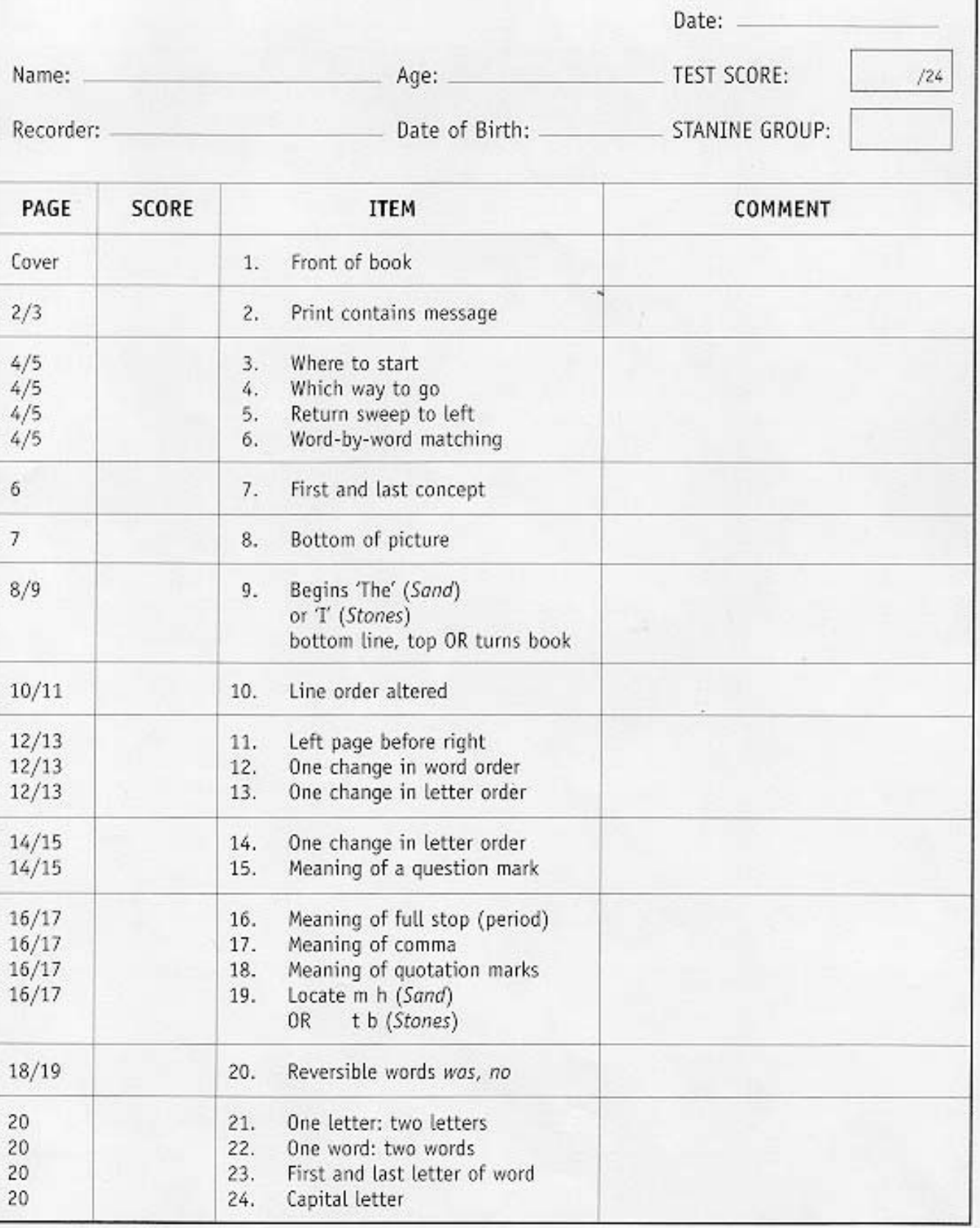


Figure A4

DIBELS Copyright Permission

Ofticial DIBELS Home Page

Page 1 of 1

Introduction - Data System

Download DIBELS Materials

DBBS

Introduction

Data System

Description

Sample

Reports

Manual

Measures

Download

Benchmarks

Kindergarten

First Grade

Second Grade

Third Grade

Pricing

Information

Technical Reports

For Younger

Children

Logistics

Sponsors

Trainers

Frequently Asked Questions

Contact

Information

Links of Interest
The Dynamic Indicators of Basic Early Literacy Skills (DIBELS) are a set of standardized, individually administered measures of early literacy development. They are designed to be short (one minute) fluency measures used to regularly monitor the development of pre-reading and early reading skills.

The measures were developed upon the essential early literacy domains discussed in both the National Reading Panel (2000) and National Research Council (1998) reports to assess student development of phonological awareness, alphabetic understanding, and automaticity and fluency with the code. Fach measure has been thoroughly researched and demonstrated to be reliable and valid indicators of early literacy development and predictive of later reading proficiency to aid in the early identification of students who are not progressing as expected. When used as recommended, the results can be used to evaluate individual student development as well as provide grade-level feedback toward validated instructional objectives.

The DIBELS measures are FREE to download and use. Just go here to login, or to sign up for a materials download account if you do not already have one. Benchmark and Progress Monitoring booklets are available for Kindergarten through Sixth Grade. Benchmark booklets are available for Kindergarten through Third Grade for the Spanish version of DIBELS, Indicadores dinámicos del éxito en la lectura 6 ta Edición (IDEL).

We also offer an optional additional service, the DIBELS Data System, which allows you to enter your students' DIBELS data online and generate automated reports, for $\$ 1$ per student, per year. For the 2004-2005 school year, 6292 schools are actively using the DIBELS Data System, across 1940 districts in 49 states and Canada, totaling over 1.35 million students $(K-3)$.

BILLING UPDATE: For the 2004-2005 school year, the DIBELS Data System will continue to offer FREE services for 4 th-6th grades, and for IDEL (Spanish DIBELS) accounts. Bllling will not start for those services until the 2005-2006 school year.

NOTE FOR OREGON SCHOOLS: The DIBELS Data System will provide free service for all Oregon schools, public and private, for the duration of Oregon Reading First.

\section{Using the Dynamic Indicators of Basic Early Literacy (DIBELS)}

1. What are the Dynamic Indicators of Basic Early Literacy Skills or DIBELS?

2. Why uSE DIBELS?

3. How do I use DIBELS in my school?

Links of Interest

\section{(c) 2000-2004}




\section{Figure A5}

\section{DIBELS Initial Sound and Letter Naming Fluency Measure}

\section{Benchmark K-1
DIBELS ${ }^{\text {MM }}$ Initial Sound Fluency}

This is tomato, cub, plate, doughnut (point to pictures).

1. Which picture begins with $/ \mathrm{d} /$ ?

2. Which picture begins with/t/?

3. Which picture begins with $/ \mathrm{k} /$ ?

4. What sound does "plate" begin with?

This is bump, insect, refrigerator, skate (point to pictures)

5. Which picture begins with $/ \mathrm{sk} /$ ?

6. Which picture begins with $/ r /$ ?

7. Which picture begins with $/ \mathrm{b} /$ ?

8. What sound does "insect" begin with?

This is rooster, mule, fly, soap (point to pictures).

9. Which picture begins with $/ \mathrm{r} /$ ?

10. Which picture begins with /fl/?

11. Which picture begins with $/ \mathrm{s} /$ ?

12. What sound does "mule" begin with?

This is pliers, doctor, quilt, beetle (point to pictures).

13. Which picture begins with $/ \mathrm{b} /$ ?

14. Which picture begins with $/ \mathrm{pl} /$ ?

15. Which picture begins with $/ \mathrm{d} /$ ?

16. What sound does "quilt" begin with?

Time:

$60 \times$ Total Correct

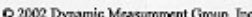
Seconds

Total Correct: Correct Initial Sounds per Minute

\section{Seconds}

$\begin{array}{lll}0 & 1\end{array}$

$0 \quad 1$

$\begin{array}{ll}0 & 1\end{array}$

$\begin{array}{ll}0 & 1\end{array}$

$\begin{array}{ll}0 & 1\end{array}$

$\begin{array}{ll}0 & 1\end{array}$

$\begin{array}{ll}0 & 1\end{array}$

$0 \quad 1$

$\begin{array}{ll}0 & 1\end{array}$

$\begin{array}{ll}0 & 1\end{array}$

$\begin{array}{ll}0 & 1\end{array}$

$\begin{array}{ll}0 & 1\end{array}$
Make sure you have reviewed the long form of the directions and have them available. Say these specific directions to the student

Here are some letters (point to the stadent probe). Tell me the names of as many letters as you can. When I say "begin", start here (point to first letter), and go across the page (point). Poin to each letter and tell me the name of that letter. If you come to a letter you don't know I'll tell it to you. Put your finger on the first letter. Ready, begin.

$$
\text { }
$$

\begin{tabular}{llllllllll} 
g & N & E & Y & R & l & V & d & H & Z \\
\hline N & d & X & S & C & n & j & H & s & S
\end{tabular}

\begin{tabular}{llllllllll}
\hline E & n & G & h & c & i & h & B & b & O \\
\hline
\end{tabular}

\begin{tabular}{lllllllllll}
$\mathrm{Y}$ & $\mathrm{F}$ & $\mathrm{p}$ & $\mathrm{D}$ & $\mathrm{L}$ & $\mathrm{i}$ & $\mathrm{q}$ & $\mathrm{c}$ & $\mathrm{D}$ & $\mathrm{Q}$ \\
\hline
\end{tabular}

\begin{tabular}{lllllllllll}
$\mathrm{R}$ & $\mathrm{v}$ & $\mathrm{F}^{\prime}$ & $\mathrm{J}$ & $\mathrm{Z}$ & $\mathrm{M}$ & $\mathrm{P}$ & $\mathrm{o}$ & $\mathrm{p}$ & $\mathrm{u}$ \\
\hline
\end{tabular}

\begin{tabular}{lllllllllll}
1 & $G$ & $A$ & $f$ & $V$ & $B$ & $P$ & $k$ & $m$ & $I$ \\
\hline
\end{tabular}

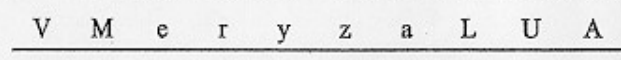

\begin{tabular}{lllllllllll} 
d & $y$ & $q$ & $v$ & $w$ & $u$ & $T$ & $w$ & $N$ & $U$ \\
\hline
\end{tabular}

\begin{tabular}{cccccccccc}
$H$ & $\mathrm{j}$ & $\mathrm{K}$ & $\mathrm{e}$ & $\mathrm{r}$ & $\mathrm{X}$ & $\mathrm{T}$ & $\mathrm{Z}$ & $\mathrm{Y}$ & $\mathrm{X}$ \\
\hline $\mathrm{Z}$ & $\mathrm{x}$ & $\mathrm{f}$ & $\mathrm{m}$ & $\mathrm{W}$ & $\mathrm{W}$ & $\mathrm{s}$ & $\mathrm{J}$ & $\mathrm{I}$ & $\mathrm{k}$ \\
\hline $\mathrm{I}$ & $\mathrm{E}$ & $\mathrm{R}$ & $\mathrm{K}$ & $\mathrm{g}$ & $\mathrm{N}$ & $\mathrm{E}$ & $\mathrm{Y}$ & $\mathrm{R}$ & 1 \\
\hline
\end{tabular}

Total: 
Figure A5, cont.

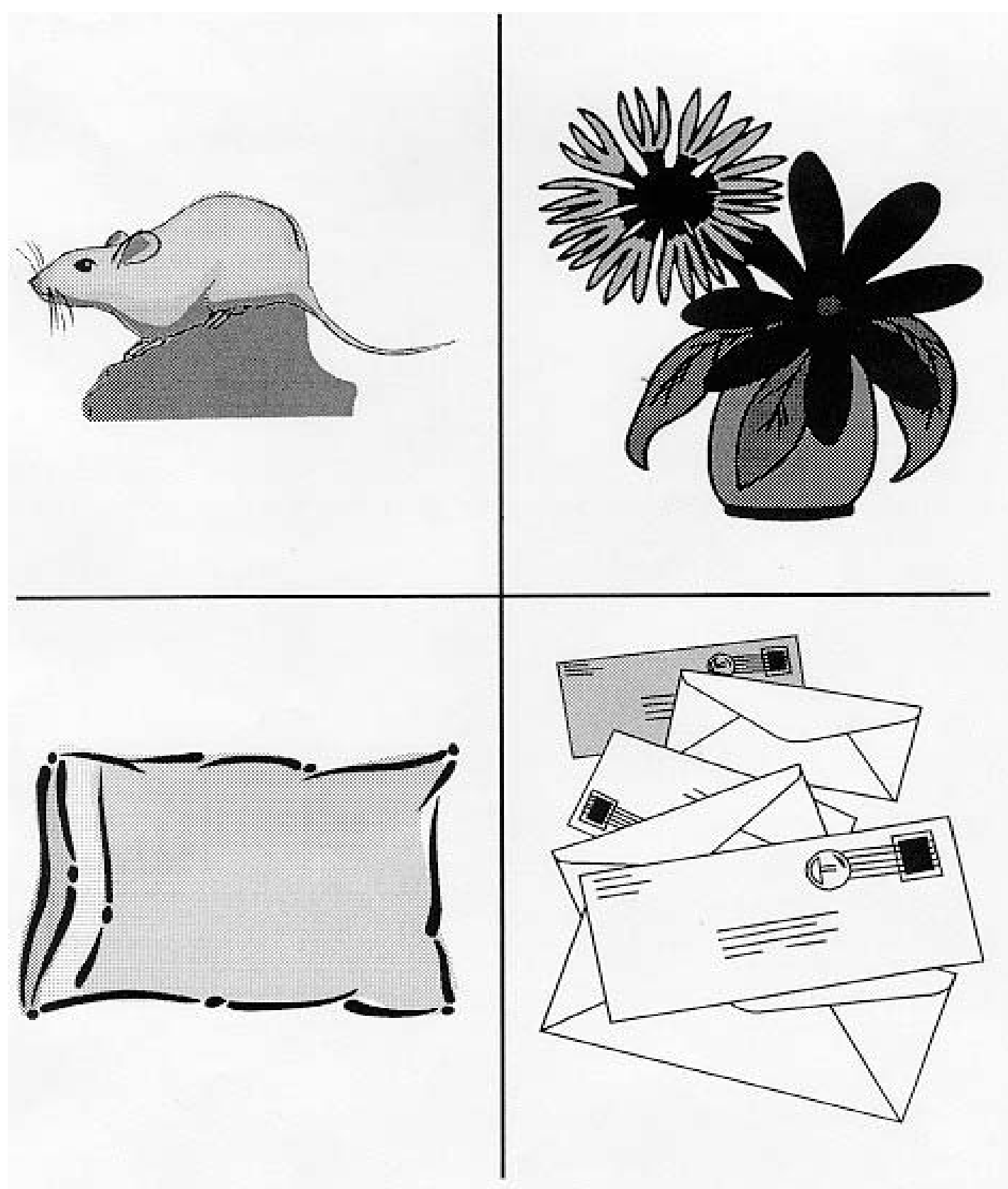


Figure A5, cont.

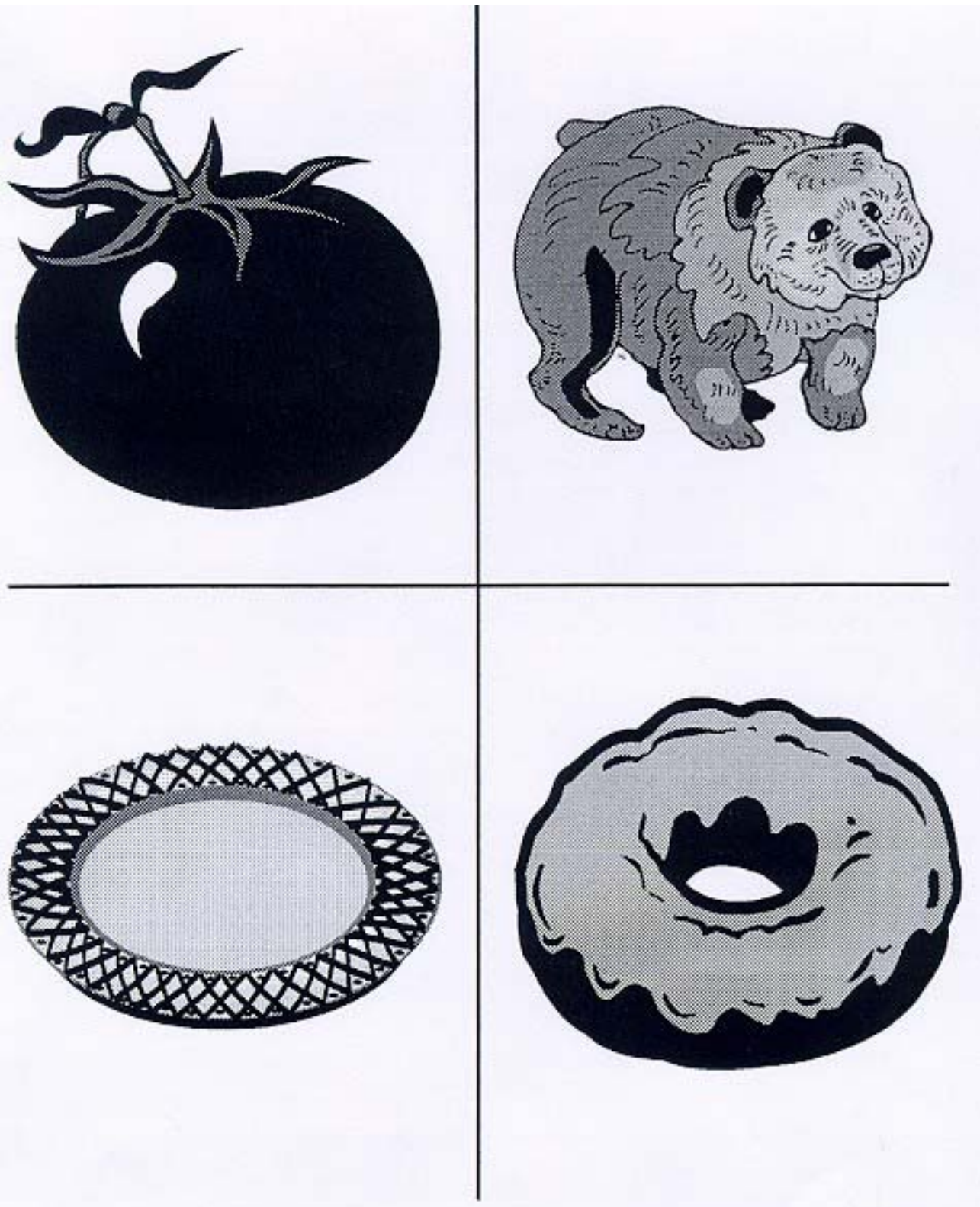


Figure A5, cont.

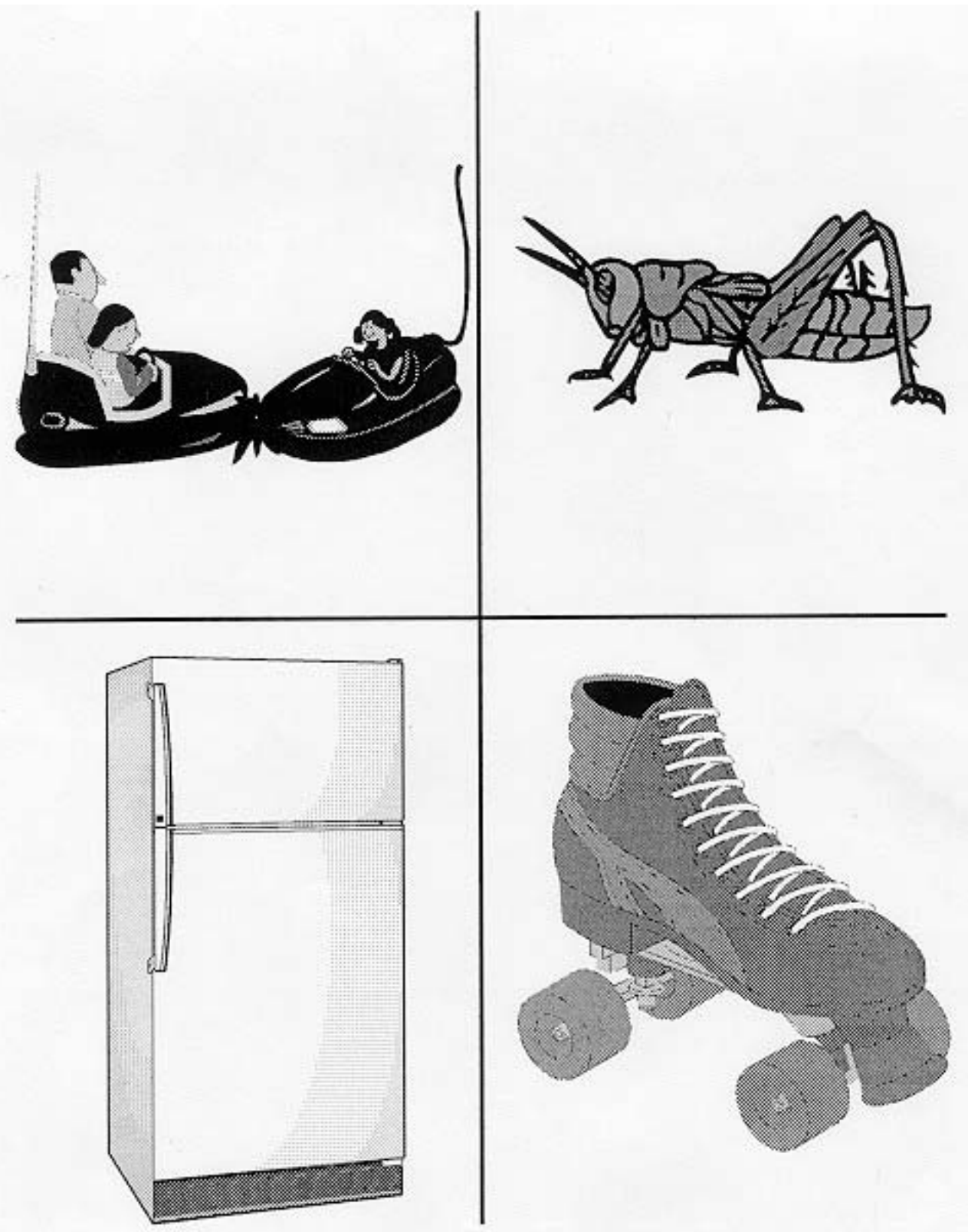


Figure A5, cont.

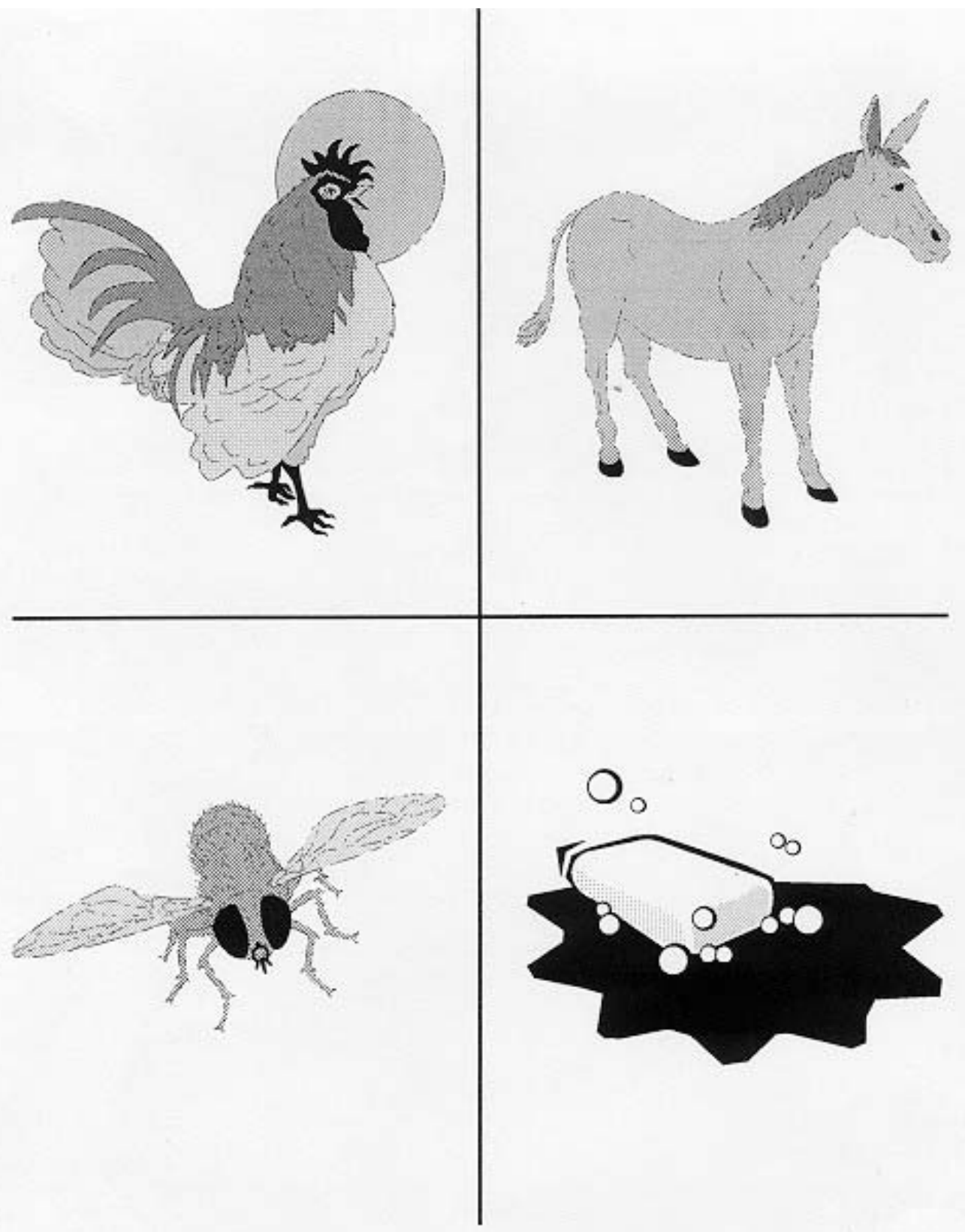


Figure A5, cont.

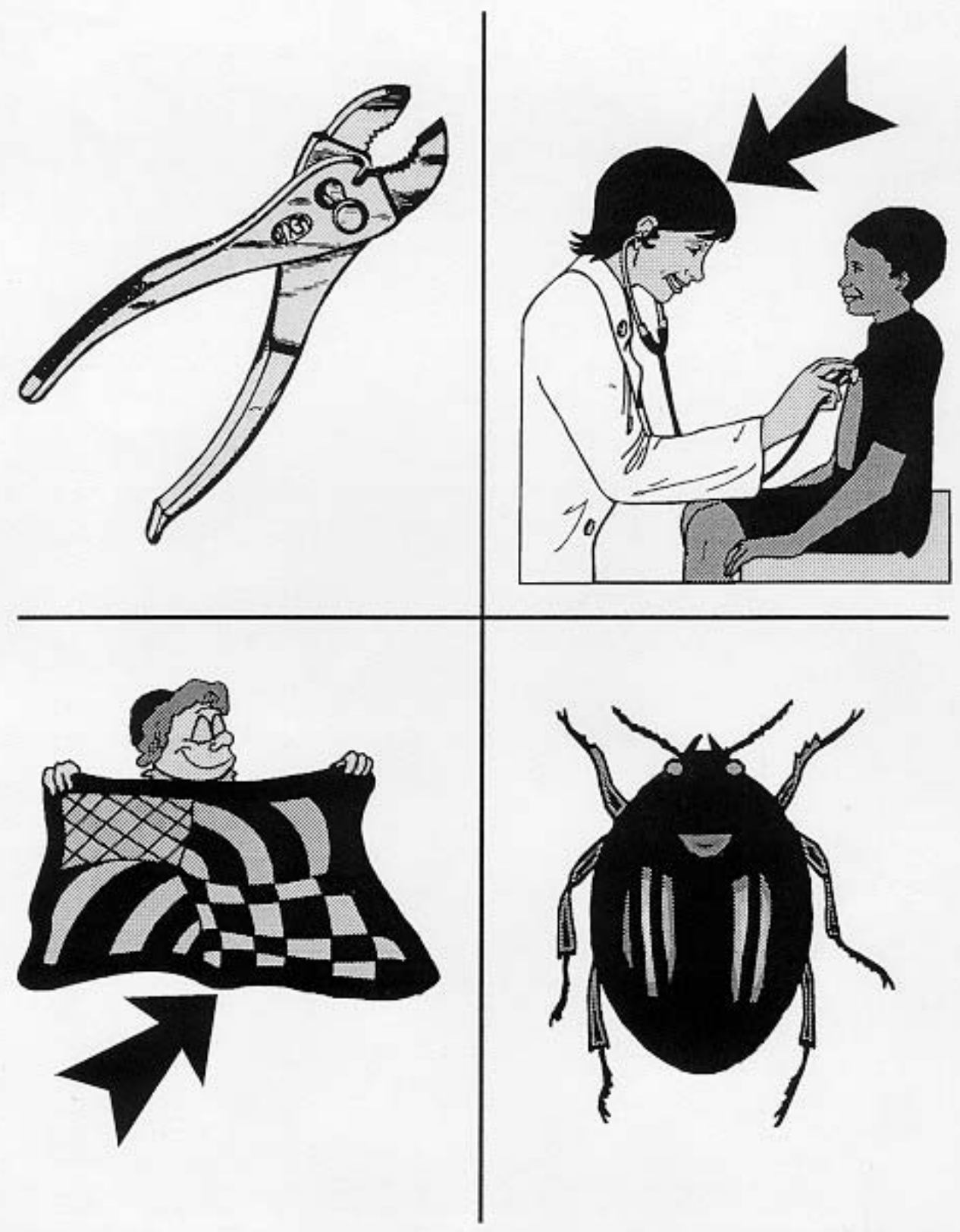


Figure A5, cont.

\begin{tabular}{llllllllll} 
g & N & E & Y & R & 1 & V & d & H & Z \\
\hline
\end{tabular}

\begin{tabular}{llllllllll}
$N$ & $d$ & $x$ & $S$ & $C$ & $n$ & $j$ & $H$ & $s$ & $S$ \\
\hline
\end{tabular}

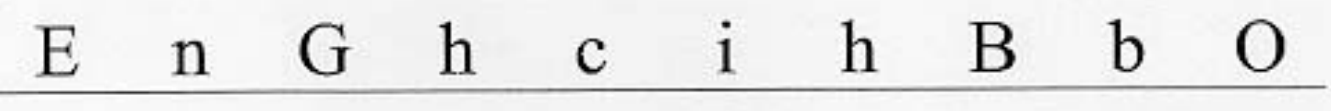

\begin{tabular}{llllllllll}
$Y$ & $F$ & $p$ & $D$ & $L$ & $i$ & $q$ & $c$ & $D$ & $Q$ \\
\hline
\end{tabular}

\begin{tabular}{llllllllll}
$R$ & $v$ & $F$ & $J$ & $Z$ & $M$ & $P$ & $o$ & $p$ & $u$ \\
\hline
\end{tabular}

\begin{tabular}{llllllllll}
1 & $G$ & $A$ & $f$ & $V$ & $B$ & $P$ & $k$ & $m$ & $I$ \\
\hline
\end{tabular}

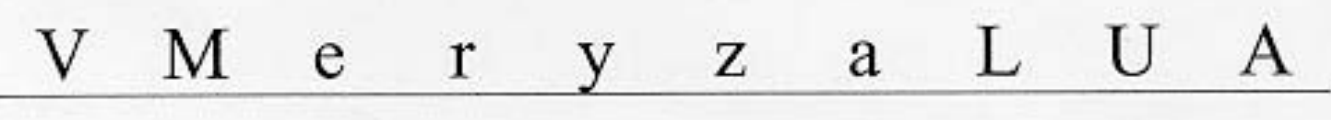

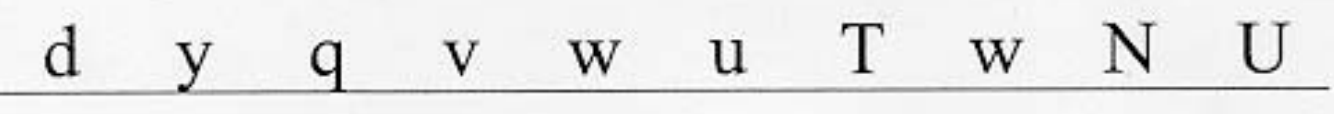

\begin{tabular}{llllllllll}
$H$ & $j$ & $K$ & $e$ & $r$ & $X$ & $T$ & $z$ & $Y$ & $X$ \\
\hline
\end{tabular}

\begin{tabular}{llllllllll}
$Z$ & $x$ & $f$ & $m$ & $W$ & $W$ & $s$ & $J$ & $I$ & $k$ \\
\hline
\end{tabular}

\begin{tabular}{llllllllll}
1 & $E$ & $R$ & $K$ & $g$ & $N$ & $E$ & $Y$ & $R$ & 1 \\
\hline
\end{tabular} 


\section{Appendix B \\ Interview Questions}

Figure B1

Script for Study - Students

Hello. I have some questions I'd like to ask you. Would you be willing to talk to me? If you decide you don't want to answer one on the questions, that's fine, just let me know. When you get tired of talking to me, tell me, and we'll be finished.

Interview questions for the student

During document analysis of the picture in the journal.

1. Tell me about the story we read.

2. What does your picture show?

3. What do these words say?

4. What part of the story does your picture go with?

When assessing dispositions about reading:

1. How do you feel about reading?

2. What do you have to do to be a good reader?

3. Is it important to be a good reader? Why/Why not?

3. Are you a good reader? Why/Why not?

4. What do you like to do when it's a quiet time? Why?

5. Can you read without a book? 
Figure B2

$$
\text { Script for Study - Teachers }
$$

Good afternoon. Thank you for agreeing to participate in my study. The goal of my research is to measure the impact of parental support on early literacy. The information gathered will be used as data in research for my dissertation. I want to point out several things to you before we start:

1. Your participation is entirely voluntary and you do not have to respond to every item or question.

2. Your responses will remain anonymous and confidentiality will be maintained.

3. You are free to withdraw from this study at any time.

Thank you for agreeing to participate.

\section{Interview Questions for Teacher}

1. Describe the child's disposition toward reading.

2. What are the child's choices to do during unstructured time? Does he ever choose reading over other activities? How often?

3. Tell me about how attentive the child is when reading or being read to.

4. Describe the child's behaviors with books. (Prompts might be: Does he ever pretend to read independently? Does he read to toys, stuffed animals, siblings? Does he prefer to look at books alone or with an older person?)

5. How does the child respond to reading? (Prompts might be: Does he ask/answer questions during the reading? Does he connect the text with the pictures? Does he make pictures of the story? Does he retell the story?)

6. Does the child respond to environmental print?

7. In what ways (if any) has the child's performance on literacy tasks changed during the course of this study? 
Figure B3

\section{Script for Study - Parents}

Good afternoon. Thank you for agreeing to participate in my study. The goal of my research is to measure the impact of parental support on early literacy. The information gathered will be used as data in research for my dissertation. I want to point out several things to you before we start:

1. Your participation is entirely voluntary and you do not have to respond to every item or question.

2. Your responses will remain anonymous and confidentiality will be maintained.

3. You are free to withdraw from this study at any time.

Thank you for agreeing to participate.

\section{Interview Questions for Parents}

1. Talk to me about why you agreed to take part in this project.

2. How much time (on average) do you spend nightly reading or drawing with your child?

3. How do you decide what to do when you read or draw with your child?

4. Are you comfortable with your knowledge of what your child should know or be able to do at this age? Why or why not?

Describe your child's reading behaviors with the following criteria in mind:

5. How often does he/she request to read with you?

6. Tell me about how attentive your child is when reading or being read to.

7. Describe your child's behaviors with books. (Prompts might be: Does he ever pretend to read independently? Does he read to toys, stuffed animals, siblings? Does he prefer to look at books alone or with an older person?)

8. What does your child do before reading a book? During? After?

9. Does your child respond to environmental print? (Prompts might be: Can he tell you what the Golden Arches mean? Can he find his favorite cereal box and read the title of the cereal on the box?)

Focus group questions to be asked at the end of each session:

1. Describe how you carried out the activities this week. Would you change things in way if you did them again?

2. Has the amount of time you spend with your child changed in any way?

3. In what ways have the activities impacted your child's ability to do the assigned task? 
Appendix C

Observation of Dialogic Reading Checklist

Figure $\mathrm{C} 1$

Student name:

$3=$ competent $\quad 2=$ developing $\quad 1=$ not yet exhibited

\begin{tabular}{|l|l|l|l|l|l|}
\hline Observed behaviors Week: & 1 & 2 & 3 & 4 & 5 \\
\hline Attentive & & & & & \\
\hline Responsive & & & & & \\
\hline Response indicates comprehension & & & & & \\
\hline Response indicates skill development & & & & & \\
\hline Enthusiasm & & & & & \\
\hline
\end{tabular}

Rubric for evaluating observed behaviors

\begin{tabular}{|l|l|l|l|}
\hline Behaviors & 3 competent & 2 developing & 1 not yet exhibited \\
\hline Attentive & $\begin{array}{l}\text { Sits still and looks } \\
\text { at the pictures for } \\
\text { the entire story }\end{array}$ & $\begin{array}{l}\text { Sits still and looks at } \\
\text { the pictures for most } \\
\text { of the story }\end{array}$ & $\begin{array}{l}\text { Doesn't pay } \\
\text { attention to the } \\
\text { story }\end{array}$ \\
\hline Responsive & $\begin{array}{l}\text { Responds to } \\
\text { questions either } \\
\text { verbally or with } \\
\text { body language }\end{array}$ & $\begin{array}{l}\text { Sometimes answers } \\
\text { questions }\end{array}$ & $\begin{array}{l}\text { Withdrawn from } \\
\text { the group and } \\
\text { doesn't respond }\end{array}$ \\
\hline $\begin{array}{l}\text { Response } \\
\text { indicates } \\
\text { comprehension }\end{array}$ & $\begin{array}{l}\text { Provides expected } \\
\text { responses to } \\
\text { indicate } \\
\text { understanding }\end{array}$ & $\begin{array}{l}\text { Sometimes provides } \\
\text { an answer to } \\
\text { indicate } \\
\text { understanding }\end{array}$ & $\begin{array}{l}\text { Tells stories that } \\
\text { don't apply to the } \\
\text { topic }\end{array}$ \\
\hline $\begin{array}{l}\text { Response } \\
\text { indicates skill } \\
\text { development }\end{array}$ & $\begin{array}{l}\text { Exhibits application } \\
\text { of a skill } \\
\text { (predicting, } \\
\text { rhyming), }\end{array}$ & $\begin{array}{l}\text { Sometimes can } \\
\text { apply a learned skill } \\
\text { to guide response }\end{array}$ & $\begin{array}{l}\text { Response doesn't } \\
\text { indicate that child } \\
\text { has mastered a skill }\end{array}$ \\
\hline Enthusiasm & Eager to participate & $\begin{array}{l}\text { Participates } \\
\text { reluctantly }\end{array}$ & $\begin{array}{l}\text { Doesn't willingly } \\
\text { participate }\end{array}$ \\
\hline
\end{tabular}




\section{Figure $\mathrm{C} 2$}

\section{Document Analysis (Journals)}

Student name:

\section{$3=$ competent $\quad 2=$ developing $\quad 1=$ not yet exhibited}

\begin{tabular}{|l|l|l|l|l|l|l|l|l|l|l|}
\hline Observed behaviors Week: & 1 & 2 & 3 & 4 & 5 & 6 & 7 & 8 & 9 & 10 \\
\hline Connection between picture and child's explanation & & & & & & & & & & \\
\hline Connection between explanation and "writing" & & & & & & & & & & \\
\hline Response structure: noun & & & & & & & & & & \\
\hline Response structure: noun + clause & & & & & & & & & & \\
\hline Response structure: sentence & & & & & & & & & \\
\hline Picture/explanation indicates story comprehension & & & & & & & & & & \\
\hline Picture includes detail & & & & & & & & & & \\
\hline Child elaborates verbally & & & & & & & & & & \\
\hline
\end{tabular}

Rubric for assessing observed behaviors

\begin{tabular}{|l|l|l|l|}
\hline Observed behaviors & 3 competent & 2 developing & 1 not exhibited \\
\hline $\begin{array}{l}\text { Connection between } \\
\text { picture and child's } \\
\text { explanation }\end{array}$ & $\begin{array}{l}\text { Child can explain } \\
\text { what is drawn and } \\
\text { why }\end{array}$ & $\begin{array}{l}\text { Child can explain } \\
\text { most of the pictures } \\
\text { drawn }\end{array}$ & $\begin{array}{l}\text { Child doesn't explain } \\
\text { what is drawn }\end{array}$ \\
\hline $\begin{array}{l}\text { Connection between } \\
\text { explanation and "writing” }\end{array}$ & $\begin{array}{l}\text { Child's label of the } \\
\text { picture relates to what } \\
\text { was drawn }\end{array}$ & $\begin{array}{l}\text { Some connection } \\
\text { between the label and } \\
\text { the picture }\end{array}$ & $\begin{array}{l}\text { Won't label the } \\
\text { pictures }\end{array}$ \\
\hline Response structure: noun & $\begin{array}{l}\text { When asked to } \\
\text { explain, provides a } \\
\text { one-word (noun) } \\
\text { response }\end{array}$ & $\begin{array}{l}\text { When asked to } \\
\text { explain, the response } \\
\text { doesn't match the } \\
\text { picture }\end{array}$ & Won't respond \\
\hline $\begin{array}{l}\text { Response structure: noun } \\
+ \text { clause }\end{array}$ & $\begin{array}{l}\text { Responds with a noun } \\
\text { and a clause }\end{array}$ & $\begin{array}{l}\text { Doesn't respond with } \\
\text { a noun and a clause }\end{array}$ & Won't respond \\
\hline $\begin{array}{l}\text { Response structure: } \\
\text { sentence }\end{array}$ & $\begin{array}{l}\text { Responds with a } \\
\text { sentence }\end{array}$ & $\begin{array}{l}\text { Doesn't respond with } \\
\text { a sentence }\end{array}$ & Won't respond \\
\hline $\begin{array}{l}\text { Picture/explanation } \\
\text { indicates story } \\
\text { comprehension }\end{array}$ & $\begin{array}{l}\text { Child's explanation of } \\
\text { the picture connects } \\
\text { with story }\end{array}$ & $\begin{array}{l}\text { Some of child's } \\
\text { explanation connects } \\
\text { with story }\end{array}$ & $\begin{array}{l}\text { Response doesn't } \\
\text { indicate } \\
\text { comprehension }\end{array}$ \\
\hline Picture includes detail & $\begin{array}{l}\text { Picture has enough } \\
\text { detail for the viewer to } \\
\text { understand what is } \\
\text { being portrayed }\end{array}$ & $\begin{array}{l}\text { Picture includes some } \\
\text { detail }\end{array}$ & $\begin{array}{l}\text { Picture doesn't } \\
\text { include detail }\end{array}$ \\
\hline Child elaborates verbally & $\begin{array}{l}\text { Child will talk about } \\
\text { the picture and the } \\
\text { story }\end{array}$ & $\begin{array}{l}\text { Child will only } \\
\text { respond to specific } \\
\text { questions }\end{array}$ & Child won't respond \\
\hline
\end{tabular}




\section{Figure C3}

Report of Data Sources According to Research Questions

\section{Research Question 1}

How will participating preschoolers' concepts of print and words change during the course of the family support literacy program?

\section{Interviews}

\section{Student:}

1. What does your picture show?

2. What do these words say?

3. What part of the story does your picture go with?

4. Can you read without a book?

\section{Parent focus group:}

1. Describe how you carried out the activities this week. Would you change things in some way if you did them again?

2. Has the amount of time you spend or the literacy activities you do with your child changed in any way?

3. In what ways have the activities impacted your child's ability to do the related literacy activity?

\section{Parent:}

1. What types of literacy activities do you and your child do together? Prompts might be: read together, sing together, write stories, draw and talk about drawings, tell stories, listen to your child read, read food labels, make shopping lists, read recipes, etc. Extensions: How often do you do these things? When and where do you do these things?

2. How much time (on average) do you spend daily reading, writing, talking, or drawing with your child? What do you normally do during this time?

3. How do you decide what to do when you read, write, talk or draw with your child?

\section{Parent and Teacher:}

1. Describe the child's behaviors with books.

2. What does the child do before, during, and after reading a book?

3. How does the child respond to reading?

4. Does the child respond to environmental print?

5. In what ways has the child's performance on literacy tasks changed during the course of this study? 


\section{Teacher:}

1. What are the child's choices to do during unstructured time?

2. Tell me about how attentive the child is when reading or being read to.

\section{Student Observation Checklist Items}

attentive, responsive, response indicates comprehension, time spent reading/listening, time spent writing/drawing, pictures drawn relate to story read, connection between picture and "writing"

\section{Document Analysis}

Connection between picture and child's explanation, Connection between explanation and "writing", Response structure, Picture/explanation indicates story comprehension, Picture includes detail, Child elaborates verbally.

\section{Pre/Post Test}

Marie M. Clay's Concepts About Print.

\section{Research question 2}

How will participating preschoolers' acquisition of letter names change during the course of the family support literacy program?

\section{Interviews}

\section{Student:}

1. Are you a good reader? Why?

\section{Parent focus group:}

1. Describe how you carried out the activities this week. Would you change things in some way if you did them again?

2. Has the amount of time you spend or the literacy activities you do with your child changed in any way?

3. In what ways have the activities impacted your child's ability to do the related literacy activity?

\section{Parent:}

1. What types of literacy activities do you and your child do together? Prompts might be: read together, sing together, write stories, draw and talk about drawings, tell stories, listen to your child read, read food labels, make shopping lists, read recipes, etc. Extensions: How often do you do these things? When and where do you do these things?

2. How much time (on average) do you spend daily reading, writing, talking, or drawing with your child? What do you normally do during this time?

3. How do you decide what to do when you read, write, talk or draw with your child? 
Figure C3, Cont

\section{Teacher:}

1. In what ways has the child's performance on letter recognition changed during the course of this study?

\section{Student Observation Checklist Items}

Response indicates skill development

\section{Document Analysis}

Connection between explanation and "writing"

\section{Pre/Post Test}

DIBELS: BenchmarkK-1 Letter Naming Fluency

Figure C3, cont.

\section{Research Question 3}

How will the participating preschoolers' ability to identify sound-letter relationships change during the course of the family support literacy program?

\section{Interviews}

\section{Student:}

1. Are you a good reader? Why?

\section{Parent focus group:}

1. Describe how you carried out the activities this week. Would you change things in some way if you did them again?

2. Has the amount of time you spend or the literacy activities you do with your child changed in any way?

3. In what ways have the activities impacted your child's ability to do the related literacy activity?

\section{Parent:}

1. What types of literacy activities do you and your child do together? Prompts might be: read together, sing together, write stories, draw and talk about drawings, tell stories, listen to your child read, read food labels, make shopping lists, read recipes, etc. Extensions: How often do you do these things? When and where do you do these things?

2. How much time (on average) do you spend daily reading, writing, talking, or drawing with your child? What do you normally do during this time?

3. How do you decide what to do when you read, write, talk or draw with your child? 
Figure C3, Cont

\section{Teacher:}

1. In what ways has the child's performance on sound-letter relationships changed during the course of this study?

Student Observation Checklist Items

Response indicates skill development

Document Analysis

Connection between explanation and "writing"

Pre/Post Test

DIBELS: Benchmark K-1 Initial Sound Fluency

\section{Research Question 4}

In what ways do family literacy training sessions impact the ability of parents to support their preschooler's emergent literacy skills?

\section{Interview}

\section{Student:}

1. Are you a good reader? Why/Why not?

\section{Parent:}

1. Talk to me about why you agreed to take part in this project.

2. What types of literacy activities do you and your child do together? Prompts might be: read together, sing together, write stories, draw and talk about drawings, tell stories, listen to your child read, read food labels, make shopping lists, read recipes, etc. Extensions: How often do you do these things? When and where do you do these things?

3. How much time (on average) do you spend daily reading, writing, talking, or drawing with your child? What do you normally do during this time?

4. How do you decide what to do when you read, write, talk or draw with your child?

5. Are you comfortable with your knowledge of what your child should know or be able to do related to literary skills at this age? Why or why not?

\section{Parent focus group:}

1. Describe how you carried out the activities this week. Would you change things in some way if you did them again?

2. Has the amount of time you spend or the literacy activities you do with your child changed in any way? 
Figure C3, cont.

3. In what ways have the activities impacted your child's ability to do the related literacy activity?

\section{Student Observation Checklist Items}

attentive, responsive, response indicates comprehension, time spent reading/listening, time spent writing/drawing, pictures drawn relate to story read, connection between picture and "writing", response indicates skill development

\section{Document Analysis}

Parental commitment to attend sessions regularly

Parental participation in weekly skill assessments of their child

Connection between picture and child's explanation

Connection between explanation and "writing", Picture/explanation indicates story

comprehension, Response structure Picture includes detail, Child elaborates verbally

\section{Pre/Post Test}

Marie M. Clay's Concepts About Print

DIBELS: Benchmark K-1 Letter Naming Fluency

DIBELS: Benchmark K-1 Initial Sound Fluency 


\section{Appendix D}

\section{Institutional Review Board Approval}

\section{Figure D1}

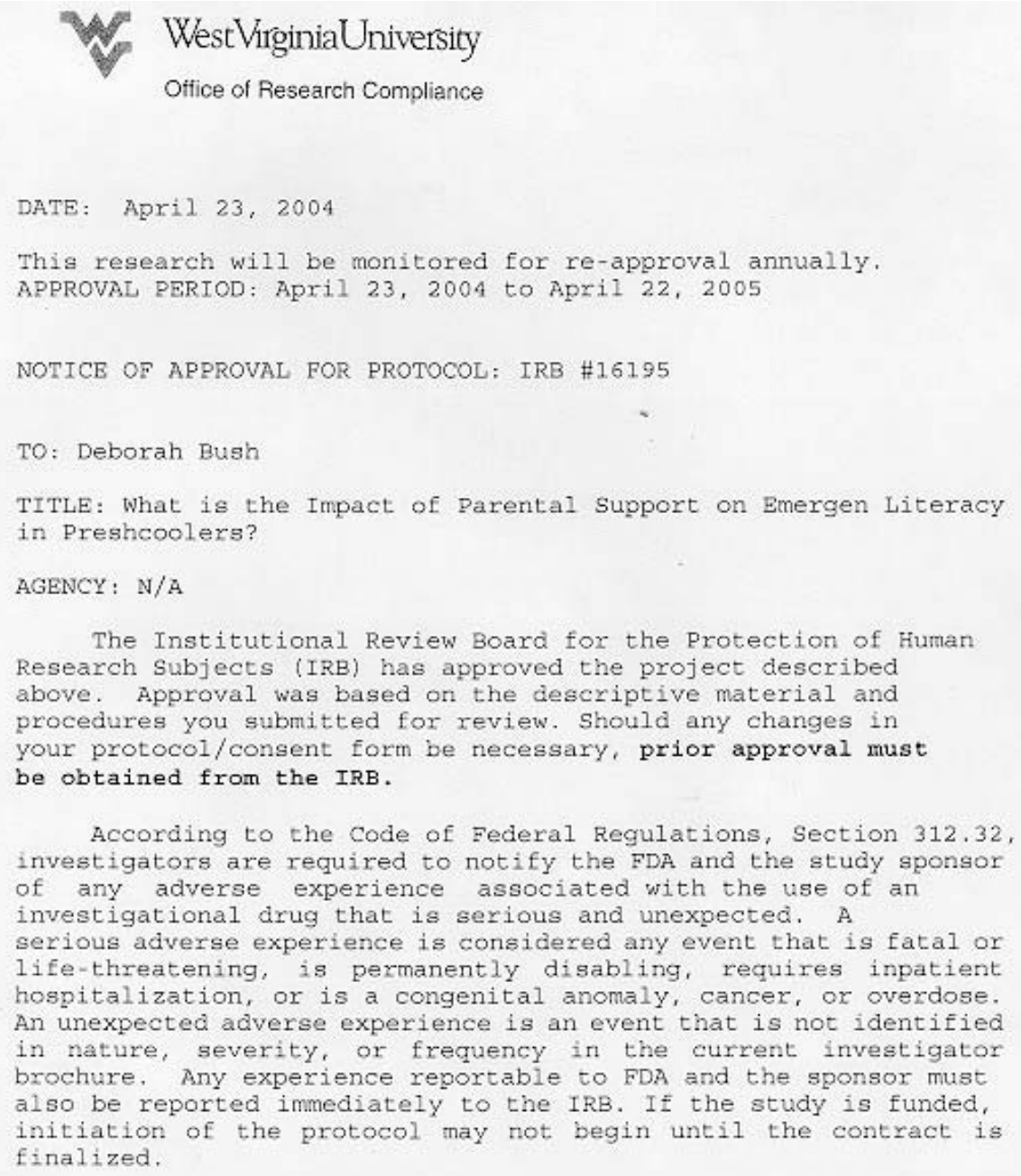

According to the Code of Federal Regulations, Section 312.32 , investigators are required to notify the FDA and the study sponsor of any adverse experience associated with the use of an investigational drug that is serious and unexpected. A serious adverse experience is considered any event that is fatal or life-threatening, is permanently disabling, requires inpatient hospitalization, or is a congenital anomaly, cancer, or overdose. An unexpected adverse experience is an event that is not identified in nature, severity, or frequency in the current investigator brochure. Any experience reportable to FDA and the sponsor must also be reported immediately to the IRB. If the study is funded, initiation of the protocol may not begin until the contract is finalized. 
Figure D1, cont.

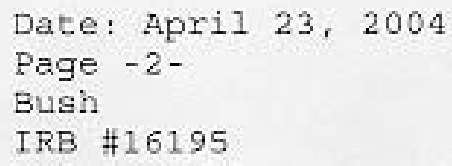

A consent form* $\mathrm{x}$ is__ is not required of each subject.

An assent form_ is $\mathrm{X}$ is not required of each subject.

A recruitment ad has__ has not $x$ been approved.

$A$ consent form waiver has__ has not $X$ been approved.

An authorization form to use PHI has__ has not $\mathrm{X}$ been approved.

A PHI waiver has has not $\mathrm{X}$ been approved.

Only copies of the consent and/or assent form with the IRB's approval stamp may be used with human subject research. It is the responsibility of the investigator to submit a revised consent form for the IRB's approval should funding be obtained. This stamped consent form must then be used for subjects enrolled. A copy of each subject's signed Consent/Assent Form must be retained by the investigator and accessible to federal regulatory authorities for at least three years after the study is completed.

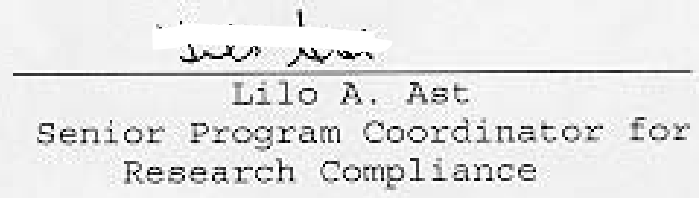

LAA / clg 


\section{Figure D2}

\section{Parental or Guardian Consent and Information Forms}

\section{We WestVirginiaUniversity \\ College of Human Resources and Education}

Dear Parents,

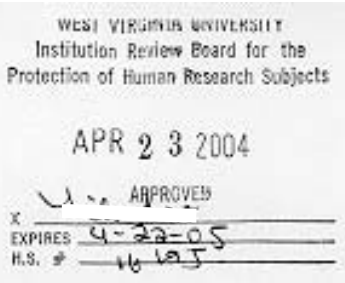

1 have an opportunity to offer you and your child. 1 ' $m$ in the process of learning how much gain preschool children experience in literacy skills (reading, writing, speaking) when they have parental support. I'd like to do a 10-week study with a preschool class in the county, but I need at least five parents who are committed to working with me. My plan is to have ten weekly sessions for an hour with parents and their preschoolers. At the sessions we'll do a read-aloud, some journaling, and an art project with the students, and parents will also participate in a group discussion. I will provide a packet for you to take home each week to work with your children on different literacy activities. My hope is that you'll be willing to spend 10 minutes for 5 evenings during the week to work on these packets. I'll try to choose a day or evening and a time when the most parents can come.

Why am I providing this opportunity? As a former kindergarten ( 7 years) first grade (14 years) and second grade (6 years) teacher, I thought that often parents wanted to help their children to succeed in school, but weren't always sure what to do. I teach at the college now and am still interested in seeing how much parental support impacts the progress of children, so I'm finishing my doctorate degree by engaging in this study. If you're interested in participating with me, please supply the information below and return it to $\mathrm{Mr}$. Lockhart tomorrow. If we have enough parents for me to do the study with this class, I'll call you with more information. Please know that you don't have to attend ALL ten sessions, but the more often you can come, the better the results should be.

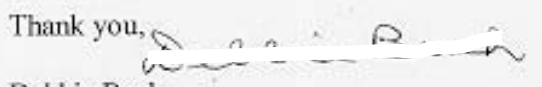

Debbie Bush

is interested in participating in

(your name)

the study. My phone number is The only days,

evenings, or times that I can't attend are:

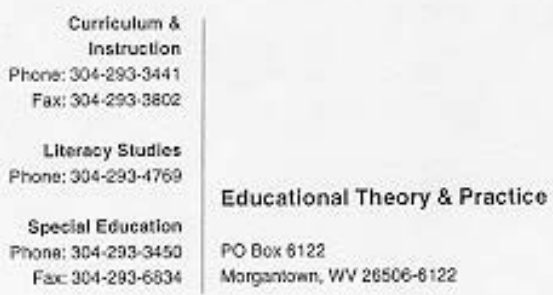

Sargantorn, WV 26506-6122 


\section{Figure D2, cont.}

\section{West VirginiaUniversity \\ College of Human Resources and Education}

WEST VIRGIMIR UNINERSITY Institution Review Bosird for the Protection of Human Resestch Subjacts

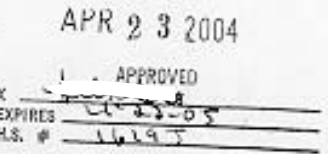

Dear Parent:

I am working on my doctoral dissertation in the Department of Curriculum and Instruction at West Virginia University, with the goal of studying the impact of parental support on the development of emergent literacy in preschool children. Emergent literacy refers to the gradual, ongoing process of learning language skills-listening, speaking, reading, and writing. I have been given permission to work with your child's class, but need the additional cooperation of several parents who are willing to be a part of this study with their children.

Those who choose to participatc will be asked to attend ten weekly sessions at the school for about an hour where we'll do reading, drawing, and other literacy activities. You will be given materials to use to work with your child at home to reinforce the skills and activities that are part of the instruction in your child's class. You and your child will be asked some questions regarding your child's interest in reading. Your child will respond to stories by drawing in a journal, and I will talk with him/her informally about the drawings. Your child will also participate in a pre- and post assessment during school as a part of the instructional day.

If you would like to participate, please designate your interest by completing the attached consent and information form and returning it to school. If you are chosen to participate, you'll receive further information regarding the date, time, and place of our meeting.

Sincerely,

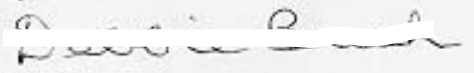

Debbie Bush

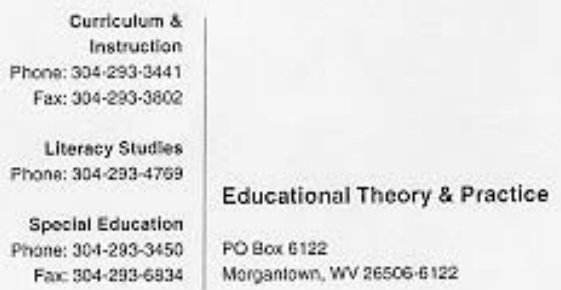

Equal Oppartunisy/Affimathe Action Institution 


\section{Figure D2, cont.}

\section{WestVirginiaUniversity}

College of Human Resources and Education
WEST VIRTHENA USIVEPSTY Institution Revlew Board for the Protection of Fuman Ressarch Subjects

$$
\text { APR } 232004
$$

1 . A APROVEO

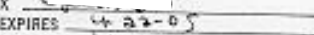
H.S. +16195

Parental or Guardian Consent and Information Form

Research Title: What is the impact of parental support on emergent literacy in preschoolers?

Introduction: I, have been asked to allow my child

to participate with me in this study. Debbie Bush, under the direction of Dr. Joy Faini Saab, is conducting this research to fulfill the requirements for a doctoral dissertation in the Department of Curriculum and Instruction at West Virginia University. Debbie Bush has explained the study to me.

Purpose of the Study: The purpose is to learn more about the effectiveness of parental support in developing children's emergent literacy skills.

Description of the Procedures: This study will be performed at school. My child and I will attend ten weekly sessions for about an hour where we'll do reading, drawing, and other literacy activities. I will also work with my child at home to reinforce the literacy skills introduced at school using materials that I will be given. I understand that I will participate in an interview concerning the kinds of reading, talking, writing, and drawing that I do with my child and that my child will participate in a similar interview as well as being asked questions about drawings that will be part of the weekly journal responses. In addition, I will share results of a daily assessment that I will do at home to measure my child's progress.

Risks and Discomforts: There are no known or expected risks from participating in this study,

Benefits: I understand that this study may not be of direct benefit to my child, but the knowledge gained may be of benefit to others.

Contact Person: For more information about this research, 1 can contact Debbie Bush at 473-8345 (work) or 472-6106 (home).

Confidentiality: I understand that any information obtained as a result of my child's participation in this research will be kept as confidential as legally possible. My name or that of my child or any information from which we might be identified may not be published without my consent.

Voluntary Participation: Participation in this study is voluntary, I understand that I may withdraw my child from this study at any time. Refusal to participate or withdraw will involve no penalty or loss of benefits for my child or me. I have been given the opportunity to ask questions about the research, and I have received answers concerning areas I did not understand. Upon signing this form, I will receive a copy. I willingly consent to participate and to allow my child to participate with me.

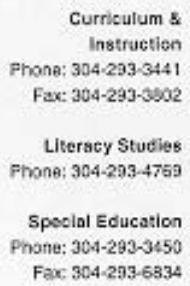

$$
\text { Signature of parent or guardian }
$$

$$
\text { Signature of investigator }
$$

\section{Educational Theory \& Practice}

PO $80 x 6122$

Morganlown, WN 26506-6122$$
\text { date }
$$

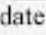

date 
Vita

\section{Deborah Bush}

West Virginia Wesleyan College

Department of Education

Buckhannon, WV 26201

Office (304) 473-8345 bush d@wvwc.edu
134 East Main Street

Buckhannon, WV 26201

Home phone: 304-472-6106

dbush@mountain.net

\section{PERSONAL INFORMATION}

Born: April 23, 1949

Marital Status: Married

\section{EDUCATION}

B.A. Elementary Education, 1971, WV Wesleyan College, Buckhannon, WV

M.A. Early Childhood Education, 1977, WV College of Graduate Studies

Currently pursuing Ed.D.Curriculum and Instruction, WV University, Morgantown, WV

Coursework and research study are completed, now waiting for a dissertation defense date.

\section{HONORS AND AWARDS}

Cum Laude, WV Wesleyan, 1971

Teacher of the Year, Upshur County, 1993

Faculty Senate Chair receiving National Blue Ribbon School of Excellence Award, 1997

All USA Teacher, Second team, 2000

\section{ASSOCIATION MEMBERSHIPS}

WV Professional Educators

Upshur County Reading Council

WV Reading Association

IRA

Delta Kappa Gamma Education Honorary

ACEI

WV Council of Teachers of Math

\section{PROFESSIONAL EXPERIENCE}

1971-72 First grade teacher, Peterson School, Weston, WV

1972-73 Kindergarten teacher, Ronceverte Elementary, Ronceverte, WV

1974-75 private kindergarten at Old Stone Church, Lewisburg, WV

1975-80 kindergarten teacher, Lewisburg Elementary, Lewisburg, WV

1980-93 first grade teacher, East Main Street School, Buckhannon, WV

1993-2001 second grade teacher, Academy Primary, Buckhannon, WV

1990-97 Governor's Summer Youth Enhancement Program, Reading teacher 
Spring 2001 funded, initiated, and supervised an after-school program at Academy 2001-2004 Educator in Residence, WV Wesleyan College, Buckhannon, WV 2001-present Member of the PT3 (technology) team

2002-2003 Co-authored the Elementary Education Program Review and Rejoinder for ACEI and NCATE accreditation of the Elementary Education program at WV Wesleyan 2002 Piloted a study of using Work Sample Methodology with student teachers during the fall semester 2003 Published an article in the Delta Kappa Gamma Bulletin regarding the work sample study 2003 Presented at the WV State Math Conference 2003 Presented at the ACEI International Conference Fall 2004 Assistant Professor and Director of Clinical Experiences at WV Wesleyan College

\section{HIGHER ED TEACHING EXPERIENCE}

I have taught the following courses at WV Wesleyan College:

EDU 210: The Teaching of Reading

EDU 211: Diagnostic Reading Tools and Strategies

EDU 260: Methods for Teaching Elementary Math

EDU 205: Clinical Experience I Elementary

EDU 206: Clinical Experience I Secondary

EDU 305: Clinical Experience II Elementary

EDU 310: Methods for Teaching Language Arts

In addition, I have taught INDS 115: Freshman Seminar, and serve as an academic advisor to over forty students yearly.

I have also been in charge of placements of students in the public schools, serving as the Director of Clinical Placements and the Director of Clinical Studies. My duties have included supervising clinical students and student teachers and being the Student Teacher Coordinator. I serve as the Department's liaison to the public schools, and I'm a member of a number of Departmental Committees including the Educational Advisory Committee (EAC) and the Teacher Education Committee (TEC). I also served as secretary of the 2003 WV Wesleyan General Studies Committee.

I have piloted the first International travel experience to meet the Department's new multicultural field experience requirement. Thirteen students and I traveled to Toronto with 28 other students from Wesleyan and while there we visited the schools and heard from a panel of education professionals. I will coordinate placements for other field experiences to meet the multicultural field experience requirement. 